Universidade de São Paulo

Faculdade de Economia, Administração e Contabilidade de Ribeirão Preto

Departamento de Economia

Programa de Pós-graduação em Economia - Área: Economia Aplicada

Régis Toshimitsu Kurokawa

\title{
Incentivos e tributos: promovendo veículos menos poluentes e a economia de combustível
}

Orientador: Prof. Dr. Cláudio Ribeiro de Lucinda

Ribeirão Preto

2018 


\author{
Prof. Dr. Vahan Agopyan \\ Reitor da Universidade de São Paulo \\ Prof. Dr. Dante Pinheiro Martinelli \\ Diretor da Faculdade de Economia, Administração e Contabilidade de \\ Ribeirão Preto \\ Prof. Dr. Renato Leite Marcondes \\ Chefe do Departamento de Economia \\ Prof. Dr. Sergio Naruhiko Sakurai \\ Coordenador do Programa de Pós-graduação em Economia - Área: Economia \\ Aplicada
}


Régis Toshimitsu Kurokawa

\title{
Incentivos e tributos: promovendo veículos menos poluentes e a economia de combustível
}

\section{Versão Corrigida}

(A original encontra-se disponível na FEA-RP/USP)

\begin{abstract}
Dissertação apresentada ao Programa de PósGraduação em Economia - Área de Concentração: Economia Aplicada, da Faculdade de Economia, Administração e Contabilidade de Ribeirão Preto da Universidade de São Paulo, para obtenção do título de Mestre em Ciências.
\end{abstract}

Universidade de São Paulo - USP

Faculdade de Economia, Administração e Contabilidade de Ribeirão Preto

Programa de Pós-Graduação em Economia Aplicada

Orientador: Prof. Dr. Cláudio Ribeiro de Lucinda

Ribeirão Preto

2018 
Autorizo a reprodução e divulgação total ou parcial deste trabalho, por qualquer meio convencional ou eletrônico, para fins de estudo e pesquisa, desde que citada a fonte.

Régis Toshimitsu Kurokawa

Incentivos e tributos: promovendo veículos menos poluentes e a economia de combustível/ Régis Toshimitsu Kurokawa. - Ribeirão Preto, 2018-

96 p. : il. (algumas color.) ; $30 \mathrm{~cm}$.

Orientador: Prof. Dr. Cláudio Ribeiro de Lucinda

Dissertação (Mestrado) - Universidade de São Paulo - USP

Faculdade de Economia, Administração e Contabilidade de Ribeirão Preto

Programa de Pós-Graduação em Economia Aplicada, 2018.

1. Simulação de políticas. 2. Análise de bem estar. 3. Emissões de $\mathrm{CO}_{2}$. I. Prof. Dr. Cláudio Ribeiro de Lucinda. II. Universidade de São Paulo. III. Faculdade de Economia, Administração e Contabilidade de Ribeirão Preto. IV. Dissertação (Mestrado) 


\section{Incentivos e tributos: promovendo veículos menos poluentes e a economia de combustível}

Dissertação apresentada ao Programa de PósGraduação em Economia - Área de Concentração: Economia Aplicada, da Faculdade de Economia, Administração e Contabilidade de Ribeirão Preto da Universidade de São Paulo, para obtenção do título de Mestre em Ciências.

Trabalho aprovado. Ribeirão Preto,

Prof. Dr. Cláudio Ribeiro de Lucinda (Orientador)

USP/FEA-RP

Prof. Dr. Sergio Naruhiko Sakurai

USP/FEA-RP

Prof. Dr. Leonardo Bandeira Rezende PUC-RJ

Prof. Dr. Rodrigo Menon Simões

Moita

Insper

Ribeirão Preto

2018 



\section{Agradecimentos}

Agradeço a minha família por seu apoio incondicional.

Ao professor Cláudio Lucinda, por toda sua paciência, apoio e empenho ao me orientar neste mestrado. E igualmente a todos os amigos do mestrado e doutorado, pela ajuda nos estudos, amizade e pelas críticas muito valiosas a este trabalho.

A Universidade de São Paulo que proveu minha formação profissional, e ao CNPQ pelo apoio financeiro. 



\section{Resumo}

KUROKAWA, R.T. Incentivos e tributos: promovendo veículos menos poluentes e a economia de combustível. 2018. 96 p. Dissertação (Mestrado) - Faculdade de Economia, Administração e Contabilidade de Ribeirão Preto, Universidade de São Paulo, Ribeirão Preto, 2018

O setor de transporte automotivo é um dos principais responsáveis pelas emissões de gases nocivos à saúde ou causadores do efeito estufa. Existem inúmeras propostas econômicas para a redução destas emissões, que se dividem basicamente entre regulamentação de emissões e impostos sobre combustível ou veículos. Apresentaremos neste trabalho um esquema de feebate, uma alternativa baseada num mercado de carbono em que um carro que tem emissões de poluentes abaixo de certo nível ganha um subsídio para sua compra, enquanto que outro que apresenta emissões acima paga um imposto. Este esquema é projetado para que no fim, contabilizados o imposto pago e o subsídio oferecido, faça com que o governo não tenha receita, nem despesas com este. Para mostrar sua eficácia, faremos simulações com base em estimações do mercado de automóveis brasileiro do período de 2008 a 2012 usando um modelo de escolhas discretas através de um logit multinomial aninhado, e faremos análises de bem estar.

Palavras-chave: Externalidades. Emissões de $\mathrm{CO}_{2}$. Tributos. Impostos. Feebate. Indústria automotiva. Regulamentação. 



\section{Abstract}

KUROKAWA, R.T. Incentives and taxes: promoting cleaner vehicles and fuel economy. 2018. 96 p. Dissertation (Master Degree) - Faculdade de Economia, Administração e Contabilidade de Ribeirão Preto, Universidade de São Paulo, Ribeirão Preto, 2018

The automotive transport sector is one of the main responsible for emissions of harmful gases and greenhouse gases. There are numerous economics proposals for reducing these emissions, which are basically divided between emission regulations and taxes on fuel or vehicles. We will present in this work a feebate scheme, an alternative based on a carbon market in which a car that has emissions of pollutants below a certain level gains a subsidy for its purchase, while another that presents emissions above a level pays a tax. This scheme is designed so that at the end, counting the tax paid and the subsidy offered, make the government have no revenue, nor expenses with it. To show its effectiveness, we will make simulations of this scheme based on estimates of the Brazilian auto market from 2008 to 2012 using a discrete choice model with a nested multinomial logit, and we will analise social welfare changes.

Keywords: Externalities. $\mathrm{CO}_{2}$ emissions. Taxes. Feebate. Automotive industry. Standards. JEL classification: Q51, H23, D61 



\section{Lista de tabelas}

Tabela 1 - Limites Máximos de Emissão de Poluentes para Veículos Automotores Veículos Leve de Passageiros . . . . . . . . . . . . . . . . . 18

Tabela 2 - Custos nos Estados Unidos da externalidade causada pelo uso de automóveis . . . . . . . . . . . . . . . . . . . . . . . 21

Tabela 3 - Incidencia de impostos sobre combustíveis no Brasil . . . . . . . . . . . 22

Tabela 4 - Variações na tabela de IPI de 2004 a 2013 . . . . . . . . . . . . . . . . 40

Tabela 5 - Custo do $\mathrm{CO}_{2}$ em US\$ de 2007 por tonelada métrica . . . . . . . . . 44

Tabela 6 - Vendas em porcentagem de 2008 a 2012 por segmento . . . . . . . . . 48

Tabela 7 - Vendas de 2008 a 2012 por combustível . . . . . . . . . . . . . . . 48

Tabela 9 - Distribuição da emissão de $\mathrm{CO}_{2}$ por litro de combustível (g/L) . . . . . 49

Tabela 8 - Algumas variáveis por segmento . . . . . . . . . . . 50

Tabela 10 - Parâmetros estimados . . . . . . . . . . . . . . . . 53

Tabela 11 - Distribuições para preço linear . . . . . . . . . . . . . . . . 55

Tabela 12 - Distribuições para preços com transformação logarítmica . . . . . . . . 55

Tabela 13 - Elasticidade própria, Markup e Custo Marginal por segmento para o caso de preço linear . . . . . . . . . . . . . . . . . 56 56

Tabela 14 - Elasticidade própria, Markup e Custo Marginal por segmento para o caso de preço logarítmico . . . . . . . . . . . . . . . 56

Tabela 15 - Alterações pela implementação do feebate - Resumo - Preço linear . . 58

Tabela 16 - Variação percentual nas vendas por segmento - Preço linear . . . . . . 59

Tabela 17 - Alterações pela implementação do feebate - Resumo - Preço logarítmico 62

Tabela 18 - Variação percentual nas vendas por segmento - Preço logarítmico . . . 63

Tabela 19 - Unidades vendidas entre 2008 a 2012 por segmento . . . . . . . . . . . 71

Tabela 20 - Vendas de 2008 a 2012 por combustível . . . . . . . . . . . . . . . . 71

Tabela 21 - Unidades vendidas entre 2008 a 2012 por fabricante . . . . . . . . . . . 72

Tabela 22 - Vendas percentuais entre os anos de 2008 a 2012 por fabricante . . . . 73

Tabela 23 - Matriz de elasticidades cruzadas a preços lineares para alguns modelos da cidade de São Paulo . . . . . . . . . . . . . . . . . 76

Tabela 24 - Matriz de elasticidades cruzadas a preços logarítmicos para alguns modelos da cidade de São Paulo . . . . . . . . . . . . . . . . . . 77

Tabela 25 - Primeiro Estágio . . . . . . . . . . . . . . . . . . 80

Tabela 26 - Regressão do Custo Marginal . . . . . . . . . . . . . . . . . . 81

Tabela 27 - Alterações pela implementação do feebate - Feebate neutro - Preço linear 85

Tabela 28 - Alterações pela implementação do feebate - Feebate neutro - Preço linear - Alto Impacto Ambiental . . . . . . . . . . . . . . . 86 
Tabela 29 - Alterações pela implementação do feebate - Receita do governo neutra - Preço linear . . . . . . . . . . . . . . . . . . . . . . . 87 87

Tabela 30 - Alterações pela implementação do feebate - Receita do governo neutra - Preço linear - Alto Impacto Ambiental . . . . . . . . . . . . . . . 88

Tabela 31 - Alterações pela implementação do feebate - Bem estar social neutro Preço linear . . . . . . . . . . . . . . . . . . . . . . . . . . . . 89

Tabela 32 - Alterações pela implementação do feebate - Bem estar social neutro Preço linear - Alto Impacto Ambiental . . . . . . . . . . . . . . . . 89

Tabela 33 - Variação percentual nas vendas por segmento - Preço linear . . . . . . 90

Tabela 34 - Alterações pela implementação do feebate - Feebate neutro - Preço logarítmico . . . . . . . . . . . . . . . . . . . . 91

Tabela 35 - Alterações pela implementação do feebate - Feebate neutro - Preço logarítmico - Alto Impacto Ambiental . . . . . . . . . . . . . . . . . . 92

Tabela 36 - Alterações pela implementação do feebate - Receita do governo neutra - Preço logarítmico . . . . . . . . . . . . . . . . . . . . . . . . . 93

Tabela 37 - Alterações pela implementação do feebate - Receita do governo neutra - Preço Logarítmico - Alto Impacto Ambiental . . . . . . . . . . . . . 94

Tabela 38 - Alterações pela implementação do feebate - Bem estar social neutro Preço logarítmico . . . . . . . . . . . . . . . . . . . . . . . 95

Tabela 39 - Alterações pela implementação do feebate - Bem estar social neutro Preço Logarítmico - Alto Impacto Ambiental . . . . . . . . . . . . . . 95

Tabela 40 - Variação percentual nas vendas por segmento - Preço logarítmico . . . 96 


\section{Sumário}

Introdução . . . . . . . . . . . . . . . . . . 15

1 EXTERNALIDADES E POLÍTICAS . . . . . . . . . . . . 17

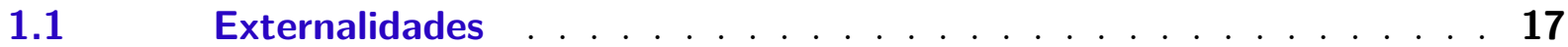

1.2 Políticas de regulamentação e Instrumentos econômicos . . . . . . . 21

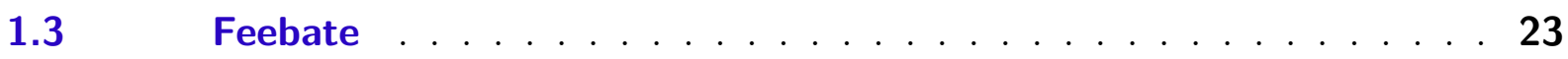

2 ESTIMAÇÃO DA DEMANDA . . . . . . . . . . . . 29

$2.1 \quad$ Demanda . . . . . . . . . . . . . . . . . . . 29

2.2 Selecionando instrumentos com o Lasso . . . . . . . . . . . . . 33

$2.3 \quad$ Elasticidades, Custo Marginal e Markup . . . . . . . . . . . . 36

$2.4 \quad$ Dados para a estimação . . . . . . . . . . . . . . 38

3 SIMULAÇÃO DE UM ESQUEMA DE FEEBATE $\ldots \ldots \ldots$

3.1 Implementação de um feebate . . . . . . . . . . . . . 41

3.2 Impacto no equilíbrio de mercado . . . . . . . . . . . . . . . 42

3.3 Buscando a neutralidade do tributo . . . . . . . . . . . 43

$3.4 \quad$ Análise de Bem Estar . . . . . . . . . . . . . . . . . . 43

4 ESTIMATIVAS DO MERCADO NACIONAL . . . . . . . . . . 47

4.1 Estatísticas Descritivas . . . . . . . . . . . . . 47

$4.2 \quad$ Estimativas dos parâmetros . . . . . . . . . . . . 51

$4.3 \quad$ Elasticidade, Markup e Custo Marginal . . . . . . . . . . . . . . 52

5 RESULTADO DAS SIMULAÇÕES E ANÁLISE DE BEM ESTAR - 57

$5.1 \quad$ Preços Lineares . . . . . . . . . . . . . . . 58

$5.2 \quad$ Preços Logarítmicos .................. 61

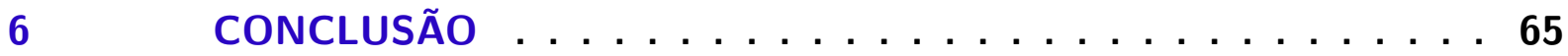

REFERÊNCIAS . . . . . . . . . . . . . . . 67

APÊNDICE A-VENDAS ............... 71

APÊNDICE B - MATRIZ DE ELASTICIDADES CRUZADAS . . . 75

APÊNDICE C - PRIMEIRO ESTÁGIO . . . . . . . . . . 79 
APÊNDICE D - REGRESSÃO - CUSTO MARGINAL . . . . 81

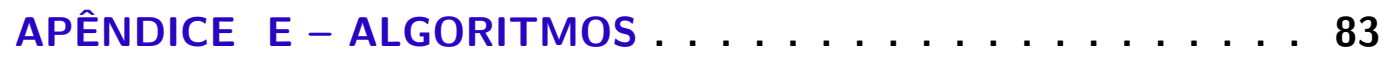

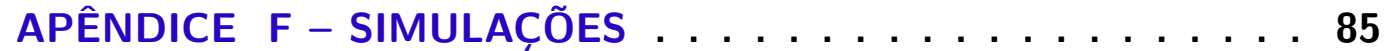




\section{Introdução}

O setor de transportes é o segundo maior consumidor de energia gerada mundialmente e é responsável por cerca de um sexto a um quarto da emissão de gases do efeito estufa. O transporte rodoviário e urbano são responsáveis por $70 \%$ das emissões deste setor. Além disto, o rápido crescimento da classe média de países como Brasil, China e Índia empurram fortemente as vendas de veículos, podendo triplicar até 2050 a frota mundial de automóveis e com isto dobrar as emissões causadas pelo transporte, segundo a International Energy Agency (2017).

As políticas apontadas pela literatura para mitigar estas emissões recaem praticamente em duas categorias: imposição de impostos sobre combustíveis e regulamentação sobre as emissões veiculares. No Brasil, contudo, há pouca margem para um novo tributo sobre combustíveis, já que estes, como veremos adiante, são fortemente taxados; e regulamentações sobre emissões tendem a fazer com que após as firmas atingirem a meta de emissões não tenham mais incentivos, ou ainda em casos mais graves que burlem os resultados de testes de emissão de poluentes como citado por Anderson e Sallee (2016).

Recentemente, discute-se novas propostas para a tributação da poluição, como o feebate e descontos para veículos mais verdes. Nosso objeto de estudo ao longo deste trabalho será o feebate, cuja definição é: tributar veículos mais poluidores e repassar esta receita na forma de subsídios a veículos mais limpos, de forma que o governo não tenha receita alguma, portanto um imposto neutro. Adamou, Clerides e Zachariadis (2014) mostram as implicações deste tipo de esquema no mercado alemão de veículos, e concluem que não há ganhos ambientais significativos, porém frisam que a análise se ateve a um curto prazo de tempo, ou seja, fixando o lado da oferta e não considerando a dinâmica proveniente da reação ao imposto. Por outro lado, Greene et al. (2005) encontram um efeito positivo se considerado o efeito deste de incentivar o progresso tecnológico.

No contexto brasileiro pouco se estudou a respeito da introdução de uma politica para controle de emissões via feebate, e desta forma, esperamos neste trabalho colaborar com mais uma política que o governo brasileiro possa adotar a fim de promover a redução da emissão de gases do efeito estufa. Indiretamente, esta redução pode promover uma melhor eficiência energética, possibilitando um meio para diminuir a dependência externa de petróleo e gás natural. Além disto, o exercício de simulação do mercado brasileiro pode colaborar na compreensão do que pode ocorrer com outros países em desenvolvimento, em especial, como já mencionado China e Índia que poderão se tornar, muito em breve, nos maiores mercados mundiais de veículos.

Portanto, nosso principal intento neste trabalho será o de responder se haveriam 
ganhos ao se aplicar o feebate no Brasil. Para tanto, faremos simulações do mercado brasileiro, requerendo uma modelagem das preferências dos consumidores acerca dos veículos disponíveis. Assim, estimaremos um modelo de escolha discreta com um logit multinomial aninhado com os dados dos veículos vendidos no Brasil entre o início de 2008 ao fim de 2012. Para obtermos estimativas consistentes de demanda, faremos o uso de variáveis instrumentais, e selecionaremos candidatos a instrumento através de um procedimento baseado no lasso. Nossa simulação consistirá em calcularmos as mudanças nas emissões totais dos veículos que teriam suas vendas diminuídas ou aumentadas (mas sem uma suposta introdução de novos modelos nos mercados). Neste sentido, os consumidores e firmas teriam de se adequar à nova estrutura de preços imposta pelo feebate e com isto haveria um novo excedente para o consumidor e produtor, o qual também deve ser calculado, bem como a mudança na receita do governo. Conjuntamente, tentaremos fazer com que o feebate seja um imposto neutro, e adicionalmente a estas simulações, faremos outras com que a receita total do governo permaneça neutra após a implantação, e também uma tentativa de manter o bem estar social total neutro.

Neste esquema de imposto, apenas os veículos novos são taxados na venda, assim como o que ocorre com o IPI e o ICMS, e portanto, não estamos considerando a frota existente e com isto a saída de veículos antigos de circulação. Também não avaliaremos o efeito rebote, que é um efeito colateral deste tipo de tributo. Ocorre, pois ao se subsidiar a compra de veículo com menores emissões e sabendo que geralmente estes são de menor cilindrada e portanto mais baratos e econômicos, os indivíduos podem passar a usar mais seus automóveis se valendo desta economia de combustível, e assim podendo aumentar o nível de emissões no total. Desta forma, o efeito do imposto seria reduzido, mas não teremos como avaliar a magnitude deste efeito no presente trabalho, porque implicaria em observar diretamente e ao longo de um período o comportamento dos consumidores. E, não levaremos em consideração o progresso tecnológico induzido ao se estimular a redução de poluentes, o qual não pode ser desprezado como visto por Greene et al. (2005). Escolhemos não fazê-lo pois partiríamos de suposições as quais, talvez, podem não se concretizar.

Este trabalho está dividido em três partes: Na primeira trataremos da contextualização das externalidades geradas com o uso de automóveis, e veremos as principais propostas de soluções econômicas afim de reduzi-las. A seguir, nos capítulos 2 e 3, falaremos da metodologia que empregaremos para o estudo do mercado nacional, estimando um modelo logit multinomial aninhado para que possamos simular um tributo feebate, e com isto, prever quais seriam os ganhos ambientais, as modificações no excedente do consumidor e produtor. Na terceira (capítulos 4 e 5), apresentaremos o resultado de estimações, simulações, e análises destas, comparando com outros resultados obtidos da literatura. E finalmente, faremos as considerações finais. 


\section{Externalidades e Políticas}

Conforme já mencionamos, o objetivo central de nosso trabalho é simular os ganhos com a implantação de um feebate. Mas antes, faremos um apanhado geral sobre os problemas envolvendo o uso de veículos automotores, tais como poluição a nível local, ou em escala global, custos de espera na locomoção, acidentes, ruídos, e outros.

Veremos brevemente as principais políticas sugeridas pela literatura que se dividem basicamente em três categorias: tributação, preços públicos, e regulamentação de emissões veiculares. Também veremos, quais os comportamentos dos consumidores e fabricantes, e o desgaste político para a aplicação destas políticas. Por último, analisaremos o feebate mais detalhadamente e porque este trabalho se propõe a estudá-lo, bem como o embasamento para sua simulação que veremos nos capítulos seguintes.

\subsection{Externalidades}

Por poluição local entendemos aquela a nível municipal, que é causada principalmente pelo monóxido de carbono $(C O)$, hidrocarbonetos $(H C)$, compostos orgânicos voláteis $(\mathrm{COV})$, ozônio $\left(\mathrm{O}_{3}\right)$, óxidos nítricos $(\mathrm{NOx})$, material particulado (MP), aldeídos (RCHO) e dióxido de enxofre $\left(\mathrm{SO}_{2}\right)$. Todos os veículos a combustão são propensos a emitir $C O$ devido a queima imperfeita do combustível, seja este gasolina, álcool ou diesel. O $C O$, por se tratar de um agente fortemente redutor, combina com a hemoglobina do sangue diminuindo sua disponibilidade para transporte de oxigênio $\left(\mathrm{O}_{2}\right)$ causando dificuldades respiratórias e efeitos cardiovasculares.

Também causado pela combustão incompleta, o $H C$, COV e $N O x$ são precursores potenciais para o ozônio troposférico, principal causador do smog, que é a fumaça proveniente desta queima imcompleta de combustíveis. O ozônio $\left(O_{3}\right)$ é um gás encontrado naturalmente na estratosfera, onde filtra os raios solares dos raios ultravioletas que são nocivos a vida em geral, entretanto, a baixas altitudes reduz a visibilidade e pode provocar irritação em mucosas dos olhos e pulmões agravando quadros de doenças respiratórias e cardiovasculares. Os Aldeídos são formados pela oxidação parcial de álcoois como na queima do etanol de veículos, seus principais efeitos na saúde são a irritação de mucosas como a dos olhos, nariz, e vias respiratórias, além de ser cancerígenos potenciais. O material particulado é uma mistura de sólidos muito pequenos que podem ficar suspensos no ar, e são conhecidos por serem possíveis causas de câncer no sistema respiratório, aterosclerose, inflamações e problemas respiratórios.

A emissão destes poluentes diminuiu grandemente devido ao avanço na legislação e 
regulamentação, com destaque ao Programa de controle de emissões veiculares (Proconve), cujo objetivo é o de reduzir e controlar a contaminação atmosférica e a emissão de ruído por fontes móveis. Temos como exemplo a Tabela 1 com os limites impostos pela atual norma em vigor no Brasil. Graças a essa e outras normas a emissão desse tipo de poluente no país reduziu-se drasticamente, e este fenômeno é observado em todo mundo devido a legislações nacionais.

Tabela 1 - Limites Máximos de Emissão de Poluentes para Veículos Automotores - Veículos Leve de Passageiros

\begin{tabular}{ll}
\hline POLUENTES & LIMITES \\
\hline \hline monóxido de carbono $(\mathrm{CO} \mathrm{em} \mathrm{g} / \mathrm{km})$ & 1,30 \\
hidrocarbonetos (HC em g/km) & $0,30(2)$ \\
hidrocarbonetos não metano $(\mathrm{NMHC}$ em g/km) & 0,05 \\
óxidos de nitrogênio (NOx em g/km) & 0,08 \\
material particulado $(3)(\mathrm{MP} \mathrm{em} \mathrm{g/km)}$ & 0,025 \\
aldeídos(4) (CHO g/ $/ \mathrm{km})$ & 0,02 \\
emissão evaporativa (g/ensaio) & $1,5(6)$ ou 2,0(5)(6) \\
emissão de gás no cárter & nula \\
\hline
\end{tabular}

(1) Em 2014 -> para todos os novos lançamentos; A partir de 2015 -> para todos os veículos comercializados;(2) Aplicável somente a veículos movidos a GNV; (3) Aplicável somente a veículos movidos óleio diesel; (4) Aplicável somente a veículos movidos a gasolina ou etanol; (5) Aplicável aos ensaios realizados em câmera selada de volume variável

O setor de transporte também é responsável por cerca de um sexto da emissão de dióxido de carbono $\left(\mathrm{CO}_{2}\right)$, e deste, o transporte rodoviário e urbano representa $70 \%$. Na Figura 1, mostramos os principais setores emissores bem como o aumentos dos gases do efeito estufa ao longo dos anos. No estudo econômicos sobre o aquecimento de Common (2002) mostra que um aumento de temperatura de $2,5^{\circ} \mathrm{C}$ até 2100 terá um custo para a economia global em $2 \%$ do PIB, sendo que o principal impacto vem dos custos para mitigar os riscos de catástrofe devido a mudanças climáticas, o segundo vem do aumento da disseminação de doenças tropicais principalmente na África causadas pela incapacitação das pessoas; há também os custos de adaptação da agricultura, onde principalmente a Índia, devido ao tamanho de sua população, sentirá os principais efeitos. E há ainda a possibilidade do aumento do nível do mar, que corresponde a um impacto de $6 \%$ causados por realocações de populações, inundações, e infraestrutura de prevenção destas. Os autores estimam que o custo trazido a valor presente da emissão de uma tonelada de $\mathrm{CO}_{2}$ é de US\$20 (em 2005).

Além da poluição do ar, a dependência da importação do petróleo expõe os países a volatilidade dos preços, e a manipulações de algum grande exportador sobre a oferta. Devido a grande volatilidade dos preços é bastante difícil prever preços futuros do petróleo. Além disto existe um custo militar, no caso dos Estados Unidos, a fim de manter pontos 
Figura 1 - Emissão de $C O_{2}$ por setor

a)



b)

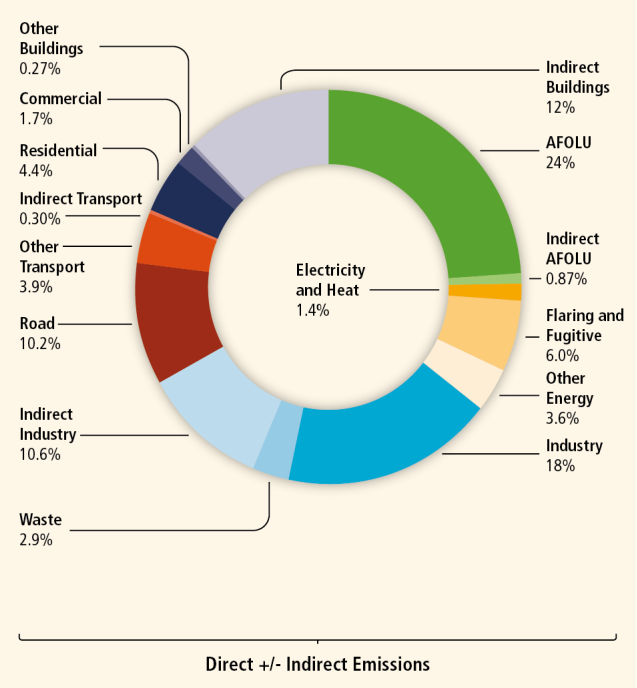

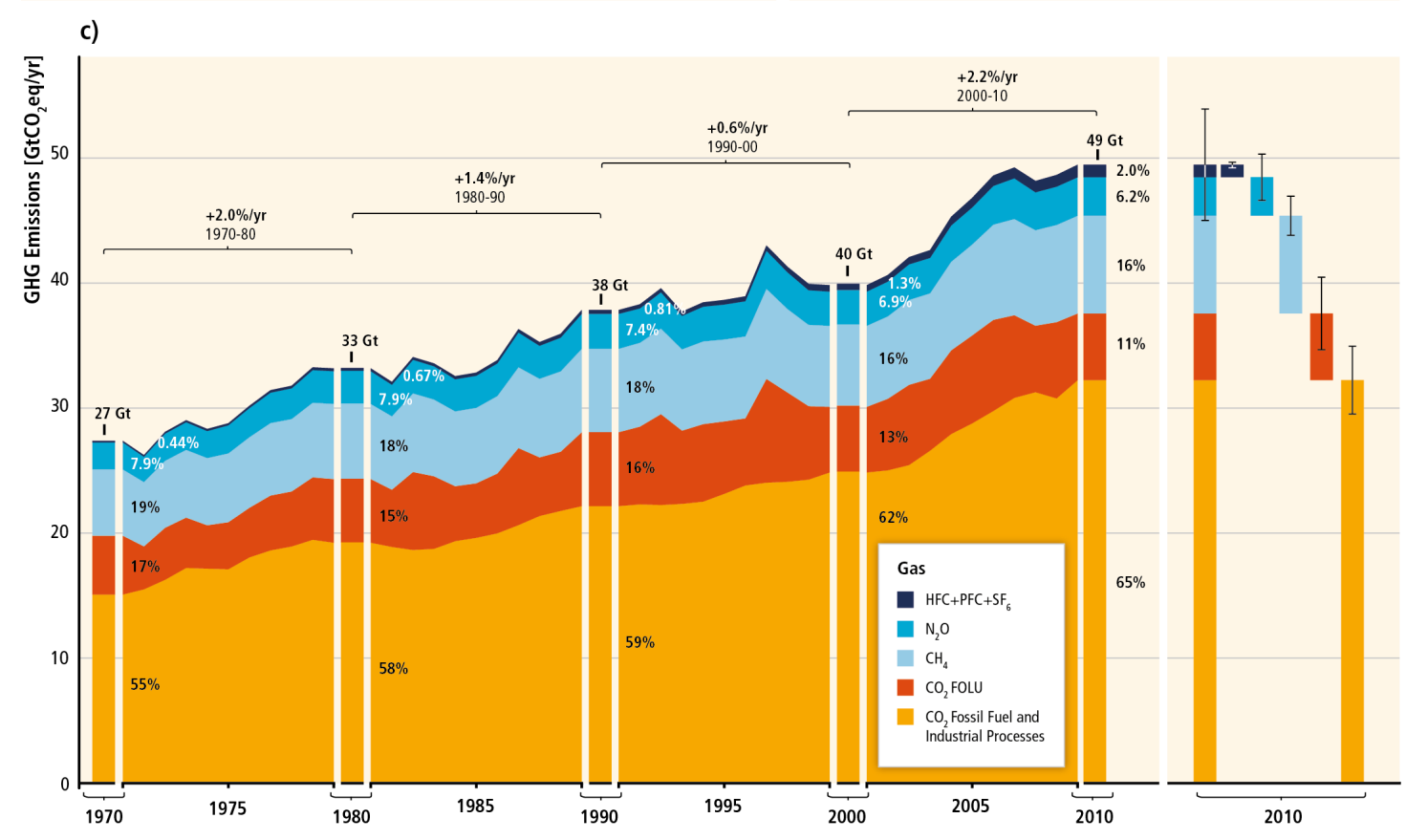

Fonte: IPCC (2014)

estratégicos a salvo no Oriente Médio. Delucchi e Murphy (2008) mostram que os custos militares sobre a gasolina são da ordem de 0,5 a 6 cents por galão de gasolina.

Há ainda custos ligados a lentidão do transito, bem como acidentes, e de acordo com Schrank. et al. (2015) a média de atraso por indivíduo em 471 áreas urbanas nos Estados Unidos foi de 42 horas em 2002, e o desperdício de gasolina foi de 19 galões, chegando a um custo estimado individual de US\$960 por ano, e o custo total em 2014 como sendo de US $\$ 160$ bilhões. No Brasil, o número de fatalidades em 2011 no transito chegou a 7008, e no total de ocorrências de acidentes a 188925 de acordo com DNIT (2011). Este número incluiu tanto aqueles que usam veículos bem como pedestres que também são suscetíveis 
Figura 2 - Emissão de $\mathrm{CO}_{2}$ por meio de transporte

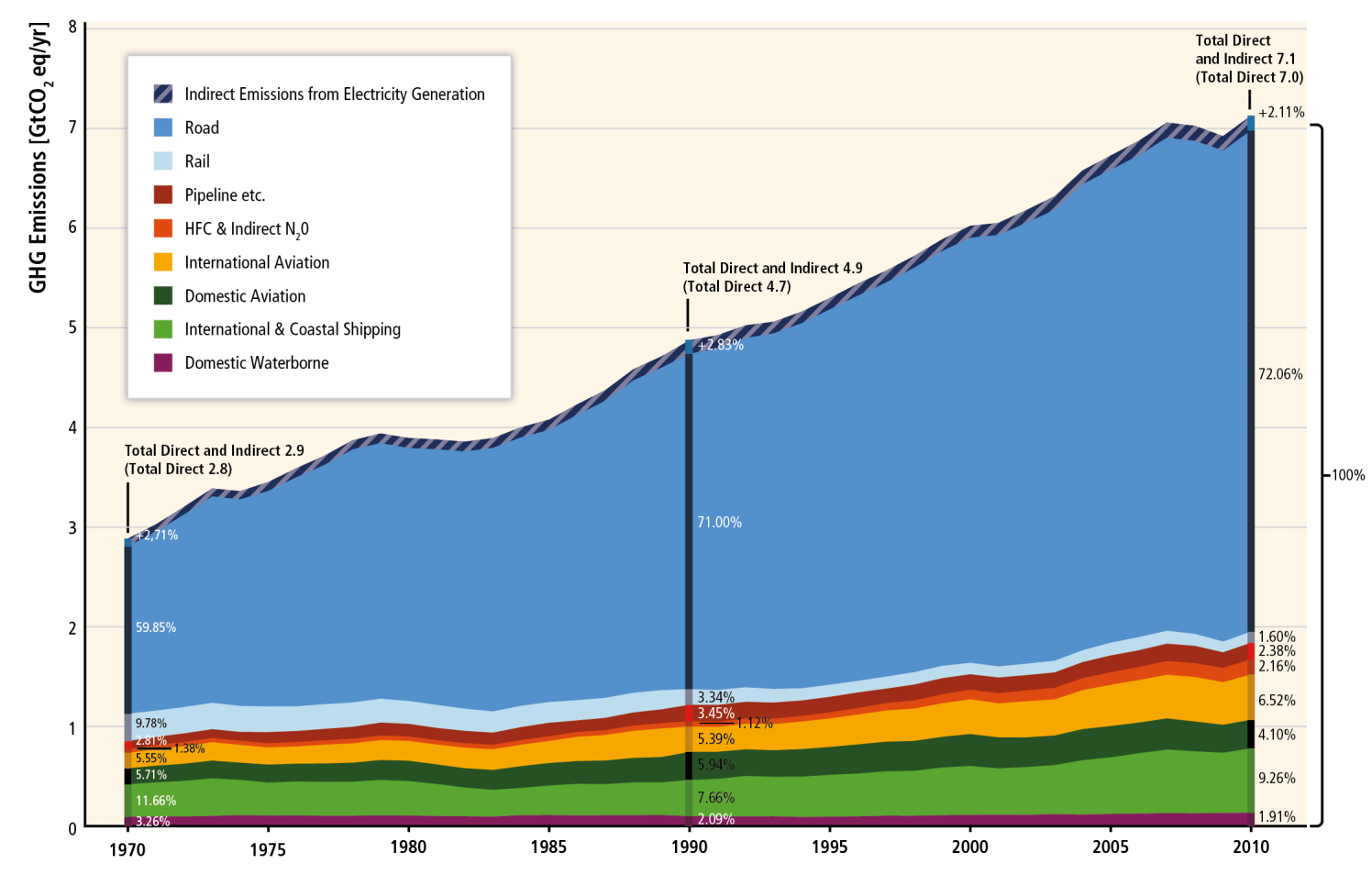

Fonte: IPCC (2014)

a acidentes. É comum assumir que estes custos serão internalizados, com o causador do acidente pagando os custos do acidentado, portanto há um incentivo ao indivíduo dirigir com mais segurança. Entretanto ao dirigir mais cautelosamente, o aumento de trafego fará com que o indivíduo dirija mais vagarosamente, aumentando assim a possibilidade de congestionamento.

Além das que citamos existem muitas outras, como ruído que provem principalmente do contato entre os pneus e o solo, aceleração do motor e frenagem, e trata-se de uma externalidade difícil de se barrar e geralmente existe regulamentação para que o automóvel possa ser homologado. O uso das rodovias pelos veículos acaba desgastando o asfalto e requer um enorme gasto público para a manutenção destas vias. A ocupação de vias públicas para o estacionamento de carros restringe vias diminuindo o fluxo de veículos e colaborando com engarrafamentos.

A seguir reproduzimos de Parry, Walls e Harrington (2007) na Tabela 2 os custos com as externalidades nos Estados Unidos para o ano de 2006: 
Tabela 2 - Custos nos Estados Unidos da externalidade causada pelo uso de automóveis

\begin{tabular}{lrr}
\hline Fonte & cents/gal & cents/mile \\
\hline \hline Custos relacionados a combustíveis & & \\
Aquecimento global & 6 & 0,3 \\
Dependência do petróleo & 12 & 0,6 \\
Total & 18 & 0,9 \\
\hline Custos relacionados a distância percorrida & & \\
Poluição Local & 42 & 2,0 \\
Congestionamento & 105 & 5,0 \\
Acidentes & 63 & 3,0 \\
Total & 210 & 10,0 \\
\hline
\end{tabular}

Em milhas por galão; Fonte: Parry, Walls e Harrington (2007)

\subsection{Políticas de regulamentação e Instrumentos econômicos}

A principal solução para externalidades é tributar o bem que diretamente está a causando, e portanto uma vasta literatura empírica aponta os efeitos positivos da implementação desta política e uma lista extensa pode ser encontrada em Anderson e Sallee (2016), apontando que os indivíduos se tornarão mais propenso a comprar carros menores. Estes mesmos autores sumarizam conclusões importantes a respeito deste tipo de imposto:

1. Nenhuma alternativa regulatória alcança a eficiência de um imposto sobre o combustível.

2. A teoria e experimentos em torno do efeito de rebote têm sido frequentemente incompatíveis. É fundamental compreender a interação entre a qualidade do veículo e as milhas percorridas para determinar quais estimativas empíricas são relevantes para uma análise de política específica.

3. É improvável que os preconceitos na escolha do consumidor sejam fortes o suficiente para revogar a sabedoria tradicional de que um imposto sobre os combustíveis é preferido pelos padrões em termos de eficiência.

4. Na prática, os padrões baseados em atributos funcionam como políticas de forçar a tecnologia, limitando outras opções de conformidade, aumentando assim os custos de mitigação.

5. Os padrões baseados em atributos são pouco adequados para abordar os viés comportamentais, uma vez que preservam os compromissos existentes entre a economia de combustível e outros atributos do carro. 
Neste sentido, Parry e Small (2005) sugerem um imposto Pigouviano $t_{G}^{P}$ dado por:

$$
t_{G}^{P}=E_{F}+E_{M} f \beta
$$

Onde $E_{F}$ é o custo por volume de combustível causado pelo carbono e dependência do petróleo e $E_{M}$ é o custo por distância percorrida da poluição local, $\beta$ é a fração da elasticidade da demanda por combustível devido a redução da distância viajada, e $f$ é a economia média de combustível por veículo resultando em:

$$
f=f^{0} \cdot\left(\frac{p_{G}+t_{G}}{p_{G}+t_{G}^{0}}\right)^{(1-\beta) \eta_{G G}}
$$

Parry, Walls e Harrington (2007) fazem o exercício de calcular o imposto usando os dados da Tabela 2 para estimar o imposto nos EUA, usando os seguintes valores: $\beta=0,4$, $\eta_{G G}=-0,55, p_{G}=1,60, t_{G}^{0}=40$ cents, e $f^{0}=21$, chegando a um imposto de US $\$ 1,11$ por galão, três vezes acima dos impostos no ano de 2005, e portanto podendo gerar um desgate político para a implantação deste. Além disso este tipo de impostos dificilmente poderá endereçar indivíduos de diferentes rendas, e portanto possui caráter regressivo. Por outro lado, um aumento no preço do combustível faz com que os indivíduos diminuam o número de viagens causando menos congestionamentos, e menos acidentes.

No Brasil o Decreto 9.101 de 20/07/2017 estipula os valores da Tabela 3 para combustíveis, mostrando que a alíquota média é de $45 \%$ para a gasolina, $30 \%$ para diesel e $28 \%$ para etanol. O que mostra que os valores são altos para o Brasil, havendo pouca margem para a implementação desta abordagem no caso nacional.

Tabela 3 - Incidencia de impostos sobre combustíveis no Brasil

\begin{tabular}{lccc}
\hline Imposto & Gasolina & Etanol & Diesel \\
\hline \hline ICMS & $25 \%$ a $34 \%$ & $12 \%$ a $30 \%$ & $12 \%$ a $25 \%$ \\
PIS COFINS & $\mathrm{R} \$ 0,7925 / \mathrm{L}$ & $\mathrm{R} \$ 0,1309 / \mathrm{L}(1)$ a $\mathrm{R} \$ 0,1964 / \mathrm{L}(2)$ & $\mathrm{R} \$ 0,4615 / \mathrm{L}$ \\
$\mathrm{CIDE}$ & $\mathrm{R} \$ 0,10$ & não incide & $\mathrm{R} \$ 0,05$ \\
\hline
\end{tabular}

Fonte: Decreto 9.101 de 20/07/2017

Sob a ótica das políticas envolvendo a regulamentação sobre economia de combustível, o CONAMA não especifica níveis máximos de emissão de $\mathrm{CO}_{2}$ liberados para a atmosfera e da mesma forma não especifica níveis máximos de consumo. Mas, ao limitar a emissão de $C O$ e $H C$ está indiretamente controlando a eficiência da queima nos moteres, e com isto, sua eficiência, reduzindo o nível de consumo. Nos EUA o Corporate Average Fuel Economy (CAFE) estabeleceu padrões de consumo, motivados principalmente pelos embargos dos países árabes gerando as crises do petróleo da década de 1970. Board e 
Council (2002) reportaram um efeito de $14 \%$ de aumento caso o CAFE não tivesse sido adotado.

A questão da regulamentação sobre emissão foi bastante discutida nos últimos 50 anos e nos EUA culminou com o Clean Air Act (CAA), impondo limites a emissão de $H C, N O x$ e $C O$ sobre carros novos, colaborando ao longo dos anos com uma redução significativa na emissão de poluentes, e.g. o limite sobre $C O$ foi de $84,0 \mathrm{~g} / \mathrm{milha}$ a $4,2 \mathrm{~g} / \mathrm{milha}$. No Brasil o Decreto 99.274/90 criou o Conselho Nacional do Meio Ambiente (CONAMA), que é um órgão consultivo e deliberativo do Sistema Nacional do Meio Ambiente, cuja coordenação resultou no controle de emissões veiculares de poluentes e no Programa de Controle de Poluição do Ar por Veículos Automotores (PROCONVE). A Tabela 1 mostra os limites atuais para emissão.

Devemos ressaltar que este tipo de política não está isento de manipulações, os fabricantes podem tentar mudar a categoria de seus veículos a fim de caracterizar o seu produto em normas mais brandas; ou ainda mais gravemente, fraudar resultados de testes de emissões, o qual temos como exemplo mais recente o caso Volkswagen em 2015, quando a Agência de Proteção Ambiental (EPA) dos EUA notificou a empresa sobre a violação do CAA. A EPA havia encontrado um software nos veículos que modificava a injeção de combustível durante os testes, resultando na redução de emissão de $N O x$ e no cumprimento dos requisitos, quando, na realidade, os veículos emitiam 40 vezes mais do que o permitido.

No campo das políticas alternativas de combustível, o caso mais importante para o Brasil foi a utilização do etanol da cana de açúcar e o biodiesel produzido a partir de óleos vegetais. Este tipo de combustível acaba por não aumentar os níveis de $\mathrm{CO}_{2}$ da atmosfera pois no processo de fotossíntese, os vegetais capturam este para a composição de sua estrutura e produção de açúcares. No entanto, existe uma crescente preocupação sobre o uso de terras agrícolas voltadas para a produção de alimentos sendo usadas para a geração de combustíveis. Os impostos incidentes sobre o etanol são menores chegando ao caso de não incidência do CIDE (Tabela 3). O governo brasileiro iniciou estudos para a viabilidade do etanol como combustível na década de 1970, motivado pela crise do petróleo, criando o programa Pró-álcool, que consistia em pesquisa em tecnologia e subsídios a produção de alcool a partir da cana de açúcar. Em 1978, a Fiat lançou o 147, o primeiro carro a álcool produzido no país, sendo seguida pelas grandes montadoras automobilísticas da época, Volkswagen, Ford e General Motors, que adaptaram seus carros ao uso do etanol.

\subsection{Feebate}

O feebate consiste em tributar (fee) veículos mais poluentes e proporcionar um desconto (rebate) para os modelos menos poluentes, isto faz com que seja menos impopular do ponto de vista político. Como existe uma relação estreita entre emissão de $\mathrm{CO}_{2}$ e 
eficiência energética, em alguns países, como veremos adiante, costuma-se usar para programas visando a redução do consumo de combustível e consequentemente reduzir a dependência do petróleo.

Esta política taxa veículos que estão acima de um certo nível de emissão estipulado pelo governo, este nível é chamado de 'pivot'. Por exemplo, na Figura 3 mostramos as emissões para alguns veículos, e suponha a escolha de um pivot num nível de emissão de $160 \mathrm{~g} / \mathrm{km}$. Veja que o Astra e o Corsa serão taxados na proporção de $42 \mathrm{~g} / \mathrm{km}$ e 11 $\mathrm{g} / \mathrm{km}$, respectivamente, enquanto que o Fit e o Uno receberão um subsídio na proporção que está abaixo do pivot que são de $16 \mathrm{~g} / \mathrm{km}$ e $60 \mathrm{~g} / \mathrm{km}$. Existem inúmeras formas de transformar essa emissão 'excedente' no valor do imposto, a mais interessante e simples é aquela em que aplicamos uma taxa constante a este excedente, pois se considerarmos que todos os carros viajam em média uma mesma distância por ano, a taxa constante fará com que os fabricantes igualem o custo marginal de economizar um litro de gasolina para todos os veículos. No exemplo anterior se a taxa escolhida pelo governo fosse de $\mathrm{R} \$ 100$ por $\mathrm{g} / \mathrm{km}$, Astra e Corsa teriam de pagar um imposto a mais de $\mathrm{R} \$ 4.200,00$ e $\mathrm{R} \$ 1.100,00$, respectivamente, enquanto que Fit e Uno teriam um subsídio de $\mathrm{R} \$ 1.600,00$ e $\mathrm{R} \$ 6.000,00$. Note que o Fiesta não sofreria nenhuma incidência por estar no pivot.

Figura 3 - Exemplo de Feebate

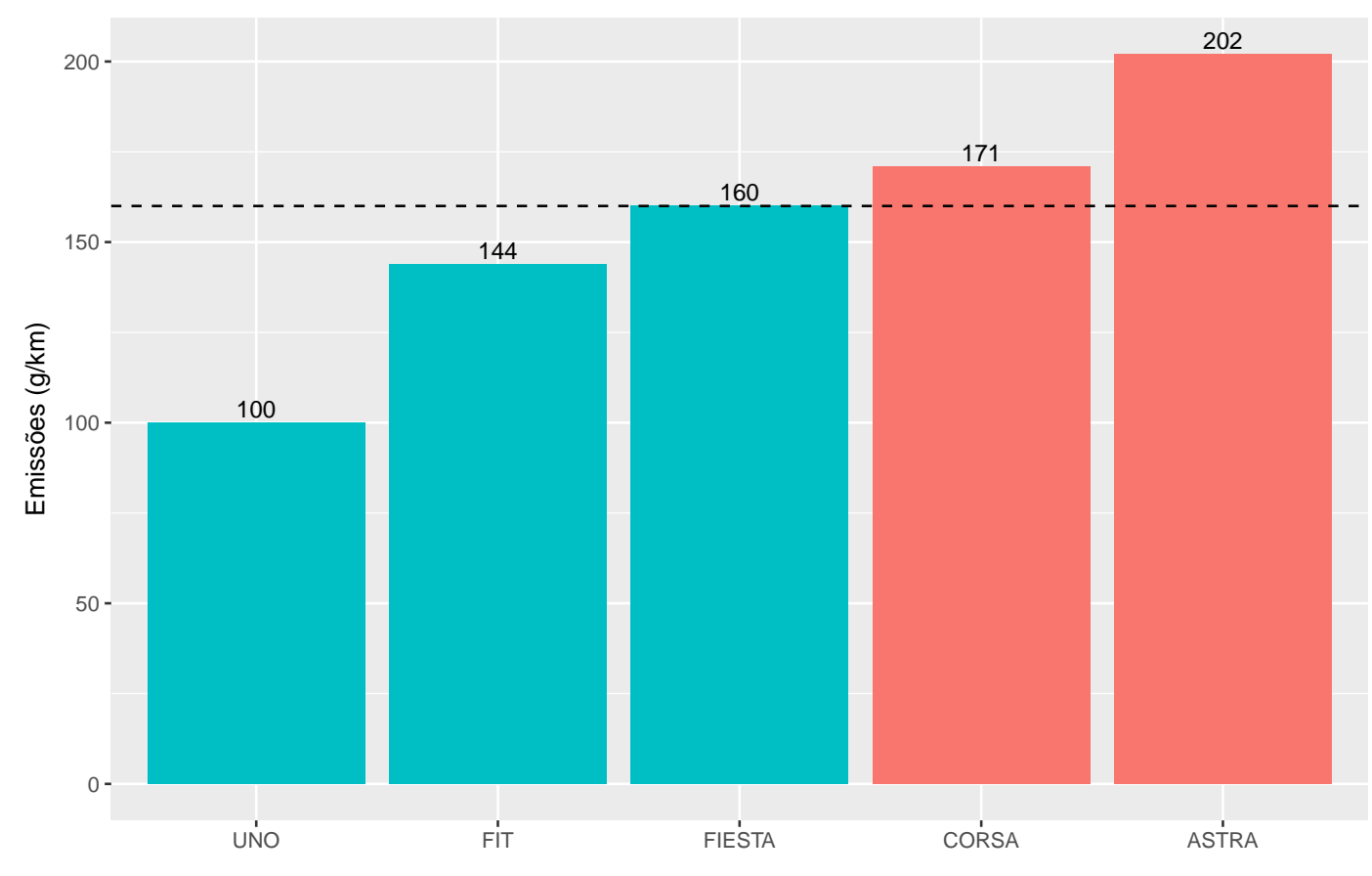

Fonte: Elaboração Própria

O pivot pode ser único, ou seja, usado por todos os veículos, ou pode ser dividido por classes, como por exemplo, veículos de passeio e caminhões, ou até mesmo entre veículos de uso particular ou comercial como táxis, como é o caso de Singapura. 
Esta política é equivalente a regulamentação sobre emissões com um mercado de crédito de carbono, sendo que o pivot funciona como o limite de emissão, ou seja o governo estipula uma emissão média permissível, acima desta o produtor deve negociar no mercado com outra firma a fim de cumprir a meta de emissão. No entanto, esta forma de imposto tem vantagens sobre a regulamentação, pois provê um incentivo contínuo para a melhora na economia de combustíveis e com isso a criação de novas tecnologias. Já a regulamentação, uma vez que as empresas atinjam o objetivo, não há mais incentivos no desenvolvimento. Outra vantagem é que em períodos de incerteza nos custos para implementar as mudanças tecnológicas necessárias, as firmas podem escolher por pagar mais no imposto ou reduzir o subsídio. Entretanto, segundo Greene et al. (2005), as desvantagens são a de que pode ser visto como um novo imposto pelos consumidores ou como um tipo de imposto seletivo pelos fabricantes, uma vez que alguns deles atuam em segmentos distintos. Estas desvantagens podem ser mitigadas ao se fazer com que o imposto seja neutro (pagando-se em descontos tanto quanto foi arrecadado), e ao se criar pivots diferentes para diferentes categorias como já mencionamos. Outra desvantagem, é que na prática, este imposto é mais facilmente implementado em degraus, o que diminui sua eficiência, já que um fabricante pode reduzir marginalmente a especificação de economia ou emissão (reduzindo a potência do motor, por exemplo) e obter uma grande mudança graças ao degrau, caso possua algum de seus modelos próximo de quinas na especificação.

Até o momento deste trabalho sabemos que está em funcionamento na França, Chile, Áustria, Bélgica, Dinamarca, Singapura e Maurício de acordo com a Global Fuel Economy Initiative (GFEI) e a United Nations Environment Assembly (UNEA). E, nos Estados Unidos estuda-se o feebate para substituir o CAFE desde a década de 1990 de acordo com Anderson et al. (2011), e foi implementado em 1991 em Ontário e para ser expandido por todo o Canadá, onde funcionou entre 20 de março de 2007 a 31 de Março de 2009, com o intuito de aumentar a eficiência energética. Foi implementado dividindo-se os veículos em duas categorias, uma para caminhões e outra para veículos de passeio, sendo que o desconto variava entre 1.000 a 2.000 dólares e havia uma taxa entre 1.000 a 4.000 dólares.

Na França é conhecido como programa Bonus-Malus e teve início por volta de 2009, dando um desconto entre €255 a €6.365 para veículos que emitiam até $160 \mathrm{~g} / \mathrm{km}$ e sobretaxando em até €1.800 dependendo do nível de emissão. Foi anualmente sendo mudado e suas taxas aumentaram para até $€ 8.000$ e o pivot reduziu para $60 \mathrm{~g} / \mathrm{km}$ (apenas veículos elétricos ou híbridos) em 2015, mostramos essas mudanças na Figura 4. É implementado em degraus, e é considerado como um caso de sucesso, influenciando fortemente outros países como o programa belga, com a diferença que neste país cada região tem autonomia para definir as alíquotas.

O Chile também se inspirou no programa francês e contou com a ajuda do GFEI 
Figura 4 - Sistema francês de feebate (Sistema Bonus-Malus)

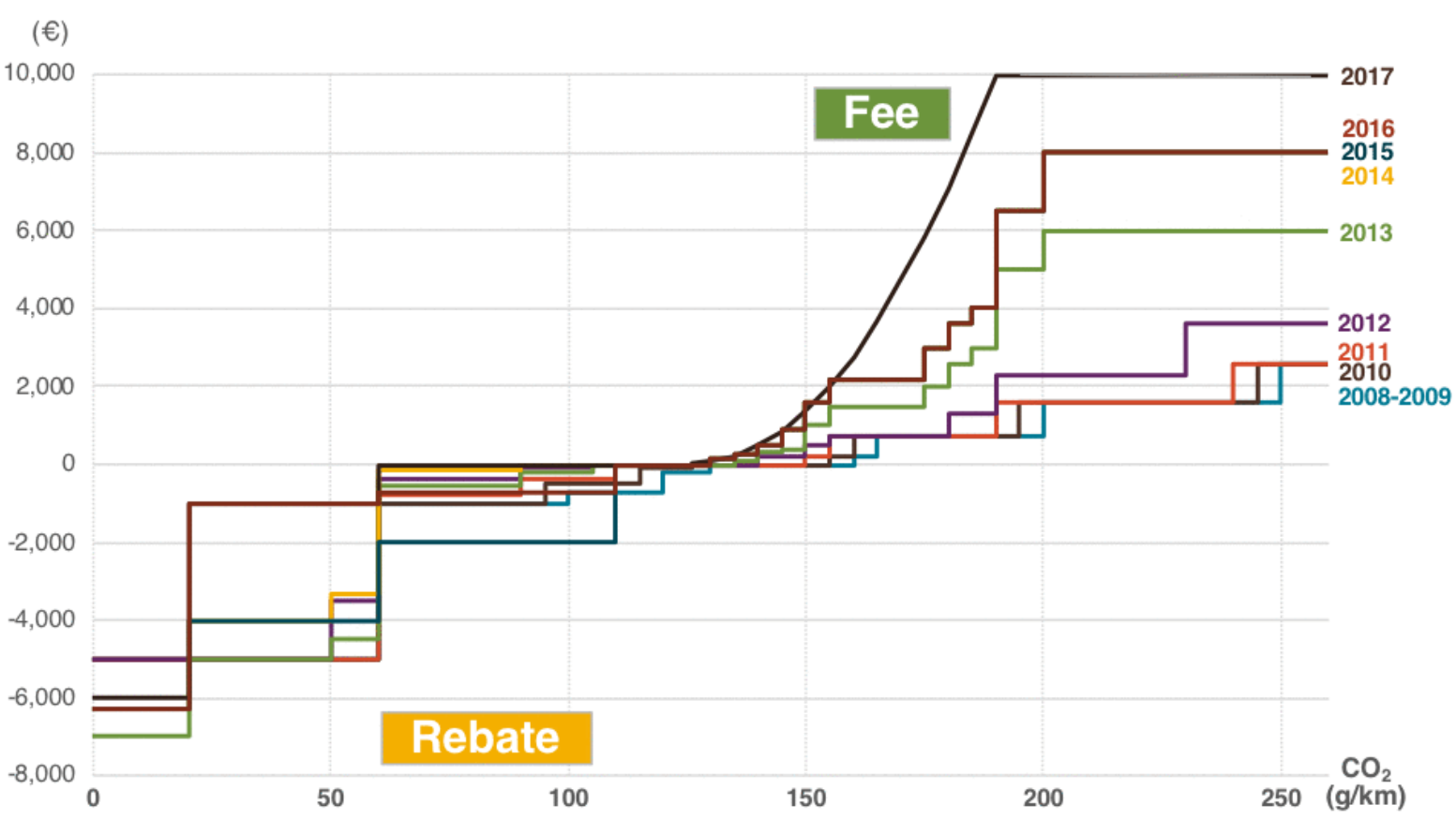

Fonte: Yang (2018)

e o International Council on Clean Transportation (ICCT) para implementá-lo, com a diferença de aplicar uma alíquota linear ao invés de degraus. O pivot escolhido foi de $175 \mathrm{~g} / \mathrm{km}$, obtido adaptando-se o caso francês até se conseguir um imposto neutro, e a alíquota foi obtida através de uma média dos degraus franceses. Além disso introduziram um selo de eficiência energética e com informação sobre emissão de $\mathrm{CO}_{2}$ em meados de abril de 2013. Na Dinamarca há um desconto no imposto total para cada km/L acima do pivot $16 \mathrm{~km} / \mathrm{L}$ de DKK4,000 no caso de carros a gasolina e o pivot de 18km/l para diesel com o mesmo bônus, e um acrécimo de DKK 1,000 acima do pivot. Na Finlândia para veículos de passeio a alíquota situa-se entre 5\% e 50\% aplicando-se a seguinte fórmula:

$$
t \%=52,15-\frac{51,95}{1+e^{0,015\left(\mathrm{CO}_{2}-152\right)}}
$$

Em Maurício foi introduzido por volta de 2011, sedo que em novembro de 2014 o governo local reportou uma melhora no consumo médio de $7 \mathrm{l} / 100 \mathrm{~km}$ para $6,6 \mathrm{l} / 100 \mathrm{~km}$ em 2013, o que foi impotante já que a frota de veículos aumentou em 60\% de 2003 a 2013 segundo o GFEI (2016). E em Singapura divide-se entre carros e taxis, sendo que os últimos tem a alíquota aumentada em 50\% para incentivar as companhias de taxi a adotar modelos de menor emissão de carbono.

Na literatura citamos o trabalho de Adamou, Clerides e Zachariadis (2014), que provavelmente é o primeiro trabalho econométrico de simulação das mudanças de bem estar causado por um esquema de feebate. Os autores, usando os dados da Alemanha 
no período de 2002 a 2008, estimam um modelo de escolha discreta através de um logit multinomial aninhado, e mostram que, no caso de se manter a receita do governo neutra, os benefícios ambientais não são substanciais comparados a perda de bem estar geral. E caso se escolha um esquema em que haja o aumento de bem estar, este será causado pelo aumento da receita do governo em detrimento dos consumidores e das firmas, e ainda assim, o benefício ambiental é pequeno. No entanto, os autores não interpretam esses resultados como uma recomendação contra o feebate, pois, segundo eles, no longo prazo esta política pode incentivar o desenvolvimento tecnológico da indústria.

Também usando um modelo de logit multinomial aninhado, Greene et al. (2005) calibram este modelo para 2000 vendas no Estados Unidos e adotam um modelo de aumento nas vendas devido a adoção de tecnologias mais eficientes. Mas ao contrário do trabalho anterior, os autores analisam também a eficiência energética e economia de combustível, e adotam diferentes pivots para diferentes segmentos de veículos, além de simular sobre um único pivot. Concluem que o feebate é muito mais eficaz do que políticas que apenas ofereçam descontos para veículos eficientes ou que apenas taxam os menos econômicos. 



\section{Estimação da Demanda}

Para que possamos simular o febate precisaremos antes de um modelo de demanda, e, então, neste capítulo e no próximo vamos descrever a metodologia, onde veremos a estimação da demanda e análise de bem estar, respectivamente.

Empregaremos em nossa estimação um logit multinomial aninhado, que se trata de um modelo bastante conhecido que exporemos neste capítulo, e nos basearemos principalmente no trabalho de Berry (1994), Berry, Levinsohn e Pakes (1995) e Verboven (1996). Em linhas gerais o consumidor enfrenta em cada período a possibilidade de comprar um carro de muitos possíveis. Estes consumidores tem preferências sobre as características, e tem uma ideia do segmento que atende suas necessidades, entretanto, não podemos observar todas as preferências do consumidor, gerando assim, para nossa estimação um problema de variáveis omitidas, o que irá requerer o uso de variáveis instrumentais, o que nos gerará um novo problema ao ter que escolher quais instrumentos serão relevantes. E com base nos parâmetros estimados calcularemos a matriz de elasticidades cruzadas a fim de de obtermos os markups e custo marginal de cada veículo, e assim, ser possível simularmos mudanças nos preços e demandas causadas pelo feebate.

E ainda neste capítulo vamos apresentar a base de dados que usaremos.

\subsection{Demanda}

Nossa base de dados contém as vendas de automóveis com suas características, no entanto, não há qualquer informação dos indivíduos que os comprou. Para lidar com isto o método empregado consiste em agregar um modelo de escolha discreta do comportamento individual dos consumidores, e então combiná-lo com uma função custo, gerando assim um modelo de comportamento dos preços num mercado de produtos diferenciados. Primeiramente, vamos especificar a utilidade de um consumidor $i$ para consumir um produto $j$ dado por:

$$
U=U\left(\zeta_{i}, p_{j}, x_{j}, \xi_{j} \mid \theta\right)
$$

Onde $\zeta$ é um vetor de características individuais, $(x, \xi, p)$ é um vetor de características do produto com preço $p$, características observáveis $x$ e não observáveis $\xi$, e $\theta$ é o vetor de parâmetros a ser estimado.

Construímos assim para evidenciar que indivíduos com diferentes $\zeta$ farão escolhas distintas, de forma que o consumidor $i$ escolherá o produto $j$ se e somente se: 


$$
U\left(\zeta_{i}, p_{j}, x_{j}, \xi_{j} \mid \theta\right) \geq U\left(\zeta_{i}, p_{r}, x_{r}, \xi_{r} \mid \theta\right)
$$

para $r=1, \ldots, J$ representando as alternativas possíveis de produtos com 0 sendo a possibilidade de não comprar. A presença desta alternativa nula nos permite agregar a demanda de automóveis como uma função de preços e características e então o conjunto $A_{j}$ de $\zeta$ que fazem com que o indivíduo prefira o produto $j$ sobre todos os outros $(r=1, \ldots, J)$ será:

$$
A_{j}=\left\{U\left(\zeta, p_{j}, x_{j}, \xi_{j} \mid \theta\right) \geq U\left(\zeta, p_{r}, x_{r}, \xi_{r} \mid \theta\right) \mid r \in \mathbb{N}, 0 \leq r \leq J\right\}
$$

Também podemos interpretar a equação acima como o conjunto de indivíduos que fazem a escolha $j$. E considerando que empates tenham probabilidade nula, e que $P_{0}(d \zeta)$ é a densidade de $\zeta$ na população, a fatia de mercado do produto $j$ é dado por:

$$
s_{j}(p, x, \xi \mid \theta)=\int_{\zeta \in A_{j}} P_{0}(d \zeta)
$$

Considerando ainda que este mercado possua $M$ consumidores a demanda total pelo bem $j$ será dada por:

$$
q_{j}=M \cdot s(p, x, \xi \mid \theta)
$$

Em nosso trabalho vamos adotar uma forma funcional para a Equação 2.1 e 2.2:

$$
U\left(\zeta_{i}, p_{j}, x_{j}, \xi_{j} \mid \theta\right)=x_{j} \beta-\alpha p_{j}+\xi_{j}+\epsilon_{i, j} \equiv \delta_{j}+\epsilon_{i, j}
$$

Onde,

$$
\delta_{j}=x_{j} \beta-\alpha p_{j}+\xi_{j}
$$

E assumimos que a média de $\epsilon$ é zero na população.

Que como já mencionado, podemos modelar num nested logit com a seguinte especificação:

$$
u_{i j}=\delta_{j}+\zeta_{i g}+(1-\sigma) \epsilon_{i j}
$$


Em que $\zeta_{i g}$ seja comum para todos os produtos no grupo $g$ para um indivíduo $i$ e $\epsilon_{i j}$ tenha distribuição de valor extremo que depende de $\sigma$, com $0 \leq \sigma<1$, e veja que $\sigma$ mede a correlação entre as utilidades dentro de um grupo $g$ de produtos.

$$
u_{i j}=\delta_{j}+\sum_{g}\left(d_{j g} \zeta_{i g}\right)+(1-\sigma) \epsilon_{i j}
$$

Com $g$ representando um grupo de produtos que se enquadra na renda e atenda as necessidades do consumidor, e $d_{j g}$ uma variável que indique quais são estes produtos. $\mathrm{O}$ share para o nested logit do produto $j$ neste grupo $g$ será:

$$
s_{j / g}(\delta, \sigma)=\frac{e^{\delta_{j} /(1-\sigma)}}{\sum_{j=0}^{J} e^{\delta_{j} /(1-\sigma)}}
$$

Lembrando que a alternativa de ficar fora do mercado é $j=0$, e vamos assumir que ele é o único membro do grupo 0. Para um notação mais clara definiremos:

$$
D_{g} \equiv \sum_{j=0}^{J} e^{\delta_{j} /(1-\sigma)}
$$

Equivalentemente, a probabilidade de escolher um dos produtos do grupo g, ou seja o share do grupo g será:

$$
s_{g}(\delta, \sigma)=\frac{D_{g}^{(1-\delta)}}{\sum_{g} D_{g}^{(1-\delta)}}
$$

E para o grupo 0 teremos:

$$
s_{0}(\delta, \sigma)=\frac{1}{\sum_{g} D_{g}^{(1-\sigma)}}
$$

Resultando na seguinte equação:

$$
\ln \left(s_{j}\right)-\ln \left(s_{0}\right)=x_{j} \beta-\alpha p_{j}+\sigma \ln \left(s_{j / g}\right)+\xi_{j}
$$

Note que $\alpha$ irá representar a utilidade marginal da renda e $\sigma$ captura o grau de substitutibilidade entre os grupos e portanto deverá estar entre $0 \leq \sigma \leq 1$. Se $\sigma=1$ os grupos são substitutos perfeitos, e se $\sigma=0$ não há correlação da preferência do indivíduo entre os grupos. Queremos então estimar $\alpha, \beta$ e $\sigma$.

Para obtermos estimativas consistentes de demanda devemos examinar o problema da endogeneidade dos preços e da fatia de mercado dos produtos. Pois, se as firmas podem observar a características $\xi_{j}$ das quais o econometrista não consegue, e ao omitirmos esta 
de nossa estimação, isto induzirá uma correlação positiva entre o preço e o termo de erro da regressão gerando um viés positivo em $\alpha$ e $\sigma$. Uma possível solução deste problema é o uso de variáveis instrumentais sugeridas por Berry, Levinsohn e Pakes (1995), que consistem: primeiramente na própria característica; num segundo instrumento, na soma de uma características de um produto $j$ ao longo de todos os produtos desta empresa, exceto pelo próprio $j$; e um terceiro instrumento, na soma de uma característica dos produtos de todas as firmas exceto pelos próprios produtos da empresa que produz $j$. Por exemplo, tomemos a aceleração de um fusca, para produzir o primeiro instrumento devemos somar a aceleração de todos os veículos produzidos pela Volkswagen excluindo o fusca; o segundo instrumento será a soma de todas as acelerações de modelos de todas as firmas excluindo os modelos da Volkswagem. Resumimos da seguinte forma:

$$
z_{j k} \quad \sum_{r \neq j, r \in \mathcal{F}_{f}} z_{r k} \quad \sum_{r \notin \mathcal{F}_{f}} z_{r k}
$$

Com $k$ representando a k-ésima característica do produto e $\mathcal{F}_{f}$ representando o conjunto de todos os produtos da firma $f$. Os autores escolheram este instrumento pois ao se excluir a quantidade vendida desta soma, estão fazendo com que o instrumento não esteja correlacionado com as vendas, e desta forma não está correlacionado diretamente com o fatia de mercado. Mas de certa forma está correlacionado com o preço uma vez que foi produzido a partir de características que influenciam no custo de produção do carro.

Adicionalmente aos instrumentos apresentados usamos também a intersecção dos instrumentos no próprio ninho a que pertence cada veículo gerando o seguinte:

$$
\sum_{r \neq j, r \in F_{f} \cap V_{g}} z_{r k} \quad \sum_{r \notin \mathcal{F}_{f}, r \in V_{g}} z_{r k}
$$

Esperamos com isto explicitar a informação dos grupos sobre os instrumentos e assim fazer com que o primeiro estagio tenha a informação sobe os ninhos.

Veja também que criamos um novo problema ao gerar estes instrumentos. Como veremos adiante, nossa base de dados contem muitas características, e podemos construir uma grande quantidade de instrumentos. Testar todas as combinações possíveis seria algo impraticável pois se usarmos todas as variáveis presentes no banco teríamos $2^{500}$ combinações possíveis de regressores e $2^{2500}$ possibilidades de instrumentos, algo infactível manualmente. E, nem todas são úteis para a estimação do problema sendo que muitas delas podem apresentar multicolineridade entre si, ou podem ser irrelevantes para explicar as variáveis endógenas, gerando um viés para os coeficientes das variáveis significantes. Felizmente existe uma extensa literatura de Aprendizado de Máquina (Machine Learning) 
que tentam solucionar este tipo de problema selecionando um subconjunto de variáveis relevantes ao modelo, e explicaremos com mais detalhes a seguir.

\subsection{Selecionando instrumentos com o Lasso}

Uma forma de lidar com o problema da seção anterior é com um estimador que penalize as variáveis que não tenham relevância na estimação, para isto pode-se impor uma penalidade ao tamanho do parâmetro. No nosso problema usaremos o Lasso ${ }^{1}$. Este estimador é definido como:

$$
\hat{\beta}^{\text {lasso }}=\underset{\beta}{\operatorname{argmin}} \sum_{i=1}^{N}\left(y_{i}-\beta_{0}-\sum_{j=1}^{p} x_{i j} \beta_{j}\right)^{2}
$$

sujeito a:

$$
\sum_{j=1}^{p}\left|\beta_{j}\right| \leq t
$$

Podemos ainda escrevê-lo equivalentemente na forma Lagrangiana:

$$
\hat{\beta}^{\text {lasso }}=\underset{\beta}{\operatorname{argmin}}\left\{\frac{1}{2} \sum_{i=1}^{N}\left(y_{i}-\beta_{0}-\sum_{j=1}^{p} x_{i j} \beta_{j}\right)^{2}+\lambda \sum_{j=1}^{p}\left|\beta_{j}\right|\right\}
$$

O problema agora se torna em encontrar o caminho dos parâmetros conforme variamos $\lambda$, e desta forma, o lasso fará uma escolha contínua de subconjuntos que atendam os critérios de minimização. Note ainda que este método impõe uma penalização ao tamanho dos parâmetros dado por $\lambda$, portanto é comum normalizar os regressores para que possamos avaliá-los igualmente. Existem vários algoritmos possíveis para implementa-lo, e não os exporemos aqui, uma vez que foge ao escopo deste trabalho.

No trabalho de Gillen, Shum e Moon (2014), os autores simulam as vendas de um modelo de escolha discreta, e posteriormente usam o lasso para estimar o melhor modelo que o explica. Os autores sugerem o uso de um triplo lasso, seguindo os seguintes estágios:

1. Pré estimação usando um GMM penalizado para a função objetivo BLP que consistentemente recupere o choque de utilidade latente.

2. Três regressões Lasso:

- Lasso linear das utilidades esperadas sobre os atributos do produto;

- Lasso linear dos preços sobre os atributos dos produtos;

1 Para maiores detalhes sobre o lasso veja Hastie, Tibshirani e Friedman (2009) 
- Lasso linear dos preços sobre os atributos selecionados, e instrumentos BLP.

3. Inclusão de todas as variáveis com parâmetros diferentes de zero destas três regressões Lasso num estimador GMM sem penalização

Como aqui não estamos estimando por coeficientes aleatórios adotamos uma abordagem um pouco diferente, relembrando, o problema consiste em estimar:

$$
\ln \left(s / s_{0}\right)=p \alpha+X \beta+\xi
$$

Mas sabemos que $\xi$ não é observado e $\operatorname{Cov}(p, \xi) \neq 0$.

Devemos escolher instrumentos $Z_{i}$ para $p$ que tornem a estimação de $\alpha$ consistente e para isto deve satisfazer duas condições:

- Exogeneidade: $\operatorname{Cov}\left(Z_{i}, \xi\right)=0$

- Relevância: $\operatorname{Cov}\left(Z_{i}, p\right) \neq 0$

A condição de exogeneidade pode ser atendida com os instrumentos BLP que são construídos a partir das características dos veículos não se levando em conta a quantidade vendida, logo não há relação direta com o share de mercado e com isto não estaria correlacionado com $\xi$. Seja $\Omega$ o conjunto de instrumentos BLP.

Temos que incluir o conjunto de características que compõe as colunas de $X$ na equação da forma reduzida do preço, que será portanto:

$$
p=X \eta+Z \zeta+\epsilon
$$

No entanto não sabemos se a condição de relevância é atendida, logo, se todos os elementos conjunto $\Omega$ forem usados como instrumentos, a estimativa de $\alpha$ pode não ser consistente. Devemos selecionar um subconjunto de $\Omega$ de instrumentos relevantes, e usaremos o lasso para tanto.

Mas veja que a matriz $X$ deve estar presente na forma reduzida, pois faz parte da equação estrutural de demanda, então o lasso não deve eliminá-la. Podemos usar o teorema FWL na equação 2.13:

$$
M_{X} p=M_{X} Z \zeta+M_{X} \epsilon
$$

Com as matrizes de projeção sendo:

$$
M_{X}=I-P_{X}
$$




$$
P_{X}=X\left(X^{\prime} X\right)^{-1} X^{\prime}
$$

Como o teorema garante que as regressões efetuadas em (2.13) e (2.14) terão os mesmos parâmetros estimados para Z e mesmos erros, então os instrumentos serão selecionados com os mesmos coeficientes de penalização, que no lasso nada mais é do que próprio parâmetro estimado:

$$
\hat{\gamma}^{\text {lasso }}=\underset{\gamma}{\operatorname{argmin}}\left\{\frac{1}{2}\left\|M_{X} p-M_{X} Z \gamma\right\|^{2}+\lambda\|\gamma\|\right\}
$$

Este retornará $\hat{\gamma}_{i}^{\text {lasso }}=0$ se $Z_{i}$ não for significante na estimação, ou seja, o instrumento fraco será eliminado, o que garantirá a condição de relevância.

Veja que precisaremos de $M_{X} p$ e $M_{X} Z$, os quais podem ser obtidos com as seguintes regressões:

Para $M_{X} p:$

$$
\begin{gathered}
p=X \gamma+\psi_{p} \\
M_{X} p=\hat{\psi}_{p}
\end{gathered}
$$

Para $M_{X} \mathbf{Z}$ :

$$
\begin{gathered}
Z_{i}=X \tau_{i}+\psi_{i} \\
M_{X} Z=\left[\hat{\psi}_{1}, \ldots, \hat{\psi}_{k}\right]
\end{gathered}
$$

A seguir efetuamos o lasso na equação (2.14), e selecionamos os $Z_{i}$ em que $\gamma_{i} \neq 0$. Ou de outra forma, queremos o conjunto $\Gamma=\left\{Z_{i}: \gamma_{i} \neq 0\right\}$.

Como os parâmetros estimados pelo lasso são viesados, efetuamos o GMM em dois estágios sem a penalização do lasso, com os instrumentos do conjunto $\Gamma \cup\left\{X_{i}\right\}$.

\section{Resumindo os passos:}

Primeiramente escolhemos características $x$ para o segundo estágio da regressão, e com estas regredimos o preço contra $x$ :

$$
p=x \gamma+\psi^{p}
$$


E em seguida regredimos cada um dos possíveis instrumentos $z^{i}$ contra $x$ :

$$
z^{i}=x \tau^{z^{i}}+\psi^{z^{i}}
$$

Num segundo passo construímos a matriz $R$ contendo em suas colunas os vetores $\psi^{z^{i}}$, e efetuamos dois estagios do lasso de $\psi^{p}$ da Equação 2.16 contra $R$ :

$$
\psi^{p}=R \delta+\omega
$$

No primeiro estágio efetuamos o lasso com validação cruzada, que consiste em particionar a base de dados em conjuntos mutuamente exclusivos e um desses subconjuntos é utilizado para teste e os outros para as regressões, e assim excluiremos as variáveis que são irrelevantes para a modelagem do preço.

Num terceiro passo efetuamos normalmente o GMM em dois estágios com os instrumentos selecionados do passo anterior para estimar a Equação 2.7.

\subsection{Elasticidades, Custo Marginal e Markup}

Com os parâmetros estimados $\alpha, \beta$ e $\sigma$ podemos calcular as elasticidades dos produtos em determinado mercado através da Equação 2.7 e da definição de elasticidade teremos:

$$
e_{j j} \equiv-\frac{\partial q_{j}}{\partial p_{j}} \frac{p_{j}}{q_{j}}=\alpha p_{j}\left(\frac{1}{1-\sigma}-\frac{\sigma}{1-\sigma} s_{j / g}-s_{j}\right)=\frac{\alpha p_{j}}{1-\sigma}\left[1-\sigma s_{j / g}-(1-\sigma) s_{j}\right]
$$

E elasticidades cruzadas para o mesmo grupo é:

$$
e_{j k} \equiv-\frac{\partial q_{k}}{\partial p_{j}} \frac{p_{j}}{q_{k}}=\alpha p_{j}\left(\frac{\sigma}{1-\sigma} s_{j / g}+s_{j}\right)
$$

E para grupos distintos será:

$$
e_{j k^{\prime}} \equiv-\frac{\partial q_{k^{\prime}}}{\partial p_{j}} \frac{p_{j}}{q_{k^{\prime}}}=\alpha p_{j} s_{j}
$$

Com isto podemos calcular o índice de Lerner, que tenta descrever o poder de mercado das fimas e é definido como:

$$
L \equiv \frac{p_{j}-m c_{j}}{p_{j}}
$$

Onde $m c_{j}$ é o custo marginal para produzir o produto $j$. 
A interpretação do índice é de que quanto maior o seu valor maior é o poder de mercado da firma, ou seja se o índice for 0 a firma está num ambiente perfeitamente competitivo e portanto não tem poder de mercado. Veja que o índice varia de 0 a 1 , e nunca pode ser maior que 1 , já que a elasticidade seria maior que -1, pois uma firma que maximiza seus lucros jamais opera na região inelástica da curva de demanda.

Adicionalmente com equação de demanda poderíamos estimar a curva de oferta das firmas que será dada pela maximização de seus lucros em cada mercado:

$$
\pi_{f}=\sum_{j \in \mathcal{F}_{f}}\left(p_{j}-c_{j}\left(q_{j}\left(p_{j}\right)\right)\right) \cdot q_{j}(p, x, \xi ; \theta)
$$

E a condição de primeira ordem para concorrencia imperfeita Bertrand-Nash será:

$$
q_{j}(p, x, \xi ; \theta)+\sum_{k \in \mathcal{F}_{f}}\left(p_{k}-m c_{k}\right) \cdot \frac{\partial q_{k}(p, x, \xi ; \theta)}{\partial p_{j}}=0
$$

Com $\mathrm{cm}_{j}$ representando o custo marginal do produto $j$ :

$$
c m_{j}=\frac{\partial c_{j}}{\partial q_{j}}
$$

E definindo a elasticidade $e_{k j} \equiv \frac{\partial q_{k}}{\partial p_{j}} \frac{p_{j}}{q_{k}}$ teremos:

$$
p_{j} q_{j}+\sum_{r \in \mathcal{F}_{f}}\left(p_{k}-m c_{k}\right) q_{k} e_{k j}=0
$$

Podemos escrever Equação 2.24 na forma matricial, o que facilita a implementação computacional:

$$
p \circ q+E[(p-m c) \circ q]=0
$$

Em que representamos o produto um a um (ou produto de Hadamard) com o, e a matriz $\boldsymbol{E}$ é construída de forma: $E_{k j}=e_{k j}$ se $k$ e $j$ são produzidos pela mesma firma e $E_{k j}=0$ se $k$ e $j$ são produzidos por firmas diferentes.

O markup será portanto:

$$
\text { Markup } \equiv p-m c=-\left[E^{-1}(p \circ q)\right] \circ q^{-1}
$$

Com a elasticidade $e_{j j}$ da Equação 2.18, as elascitidades cruzadas $e_{j k}$ da Equação 2.19 e a equação acima podemos encontrar o markup do produto de acordo com 
Verboven (1996):

$$
\operatorname{Markup}_{j} \equiv p_{j}-m c_{j}=\frac{1}{1+t} \frac{p_{j}^{1-\mu}}{\alpha} \frac{1-(1-\sigma) \sum_{k \in F_{f} \cap V_{g}}\left(1-\left(\frac{p_{k}}{p_{j}}\right)^{1-\mu}\right) q_{k} r_{g}}{\frac{1}{1-\sigma}-\sum_{k \in F_{f} \cap V_{g}} q_{k} r_{g}}
$$

Em que:

$$
q_{j} r_{g} \equiv \frac{\sigma}{1-\sigma} s_{j / g}+s_{j}
$$

E $\mu$ corresponde a um parâmetro da tranformação de Box-Cox, sedo que para uma especficação linear como o da Equação 2.7 teríamos $\mu=1$, o que faria com que todo o numerador da Equação 2.27 seja igual a 1. Para uma especificação logarítimica teríamos $\mu \rightarrow 0$.

E o custo marginal:

$$
m c_{j}=\frac{p_{j}-\text { Markup }_{j}}{1+V A T_{j}}
$$

Estes números como veremos adiante são importantes para calcularmos a mudança no excedente do produtor que será dado pelo Markup. No próximo capítulo veremos após uma mudança do governo na estrutura dos impostos qual será a mudança do Markup para as firmas.

\subsection{Dados para a estimação}

Nossa base de dados consiste nas vendas entre 2008 a 2013 o que corresponde a 994.368 observações. Existem 526 variáveis sobre as características dos veículos, e citamos algumas de maior relevância: A quantidade vendida mensalmente, preços anuais dos veículos, o local da venda por cidade, tipo de combustível, cilindradas, quantidade de portas, câmbio, aceleração, velocidade máxima, peso, airbag, som, entre outros. Por se tratar de dados cedidos de uma empresa de consultoria de inteligência de mercado e por questões de confidencialidade não podemos divulgar o nome desta. Utilizamos também uma segunda base de dados com o tamanho do mercado potencial de cada cidade, e supusemos que cada consumidor cogita comprar um novo carro a cada cinco anos, e assim dividimos o valor por cinco.

No que concerne aos impostos, a Associação Nacional dos Fabricantes de Veículos Automotores (ANFAVEA) reportou que no ano de 2008 a produção brasileira chegou a ter quedas de 70\%. Diante disto o governo federal reduziu o IPI para automóveis, tentando assim manter a demanda e com isto evitar demissões das montadoras. Além disso, no 
Brasil o período em questão apresentou redução nas taxas de juros para compra parcelada bem como redução do Imposto sobre Operações Financeiras (IOF). No ano de 2012 em especial foram liberados pelo Bacen 18 bilhões de reais para as instituições financeiras com a finalidade de financiamento de automóveis.

Houve várias alterações neste período motivadas principalmente pela crise de 2008 com a finalidade de incentivar o consumo das famílias. Neste sentido, o Decreto № 6.687, de 11 de dezembro de 2008 reduziu a alíquota do IPI para veículos automotores no período de 12 de dezembro a 31 de março de 2009, sendo prorrogada até 31 de março de 2010. E em outubro de 2009 as alíquotas foram reestabelecidas gradativamente. Uma segunda redução ocorreu entre maio de 2012 até o final de 2013. A Tabela 4 mostra as alterações na tabela TIPI.

Sumarizamos abaixo os decretos:

- A partir de 12/12/2008, alíquotas de IPI reduzidas até 31.03.2009, Decreto Federal no 6.687 de 11.12.2008.

- Prorrogação das reduções das alíquotas até 30.06.2009, Decreto Federal no 6.809 de 30.03.2009.

- Prorrogação das reduções das alíquotas até 31.12.2009, Decreto Federal no 6.890 de 29.06.2009.

- Prorrogação das reduções das alíquotas até 31.03.2010. Decreto Federal no 7.017 de 26.11.2009.

- Prorrogação das reduções de alíquotas até 31.12.2010. Decreto Federal no 7.060 de 30.12.2009 e outro

- Decreto № 7.819 de 3.10.2012 - INOVAR AUTO

Podemos notar que as maiores reduções relativas foram as dos veículos com cilindrada menor ou igual 1.0, que no geral emitem menos gases poluentes, sendo esta de $100 \%$. Para as categorias até 2.0 chegou a uma redução de 50\% do IPI, e para utilitários chegou a $75 \%$. 
Tabela 4 - Variações na tabela de IPI de 2004 a 2013

\begin{tabular}{ccccccc}
\hline Ano & \multicolumn{2}{c}{$\leq 1.0$} & \multicolumn{2}{c}{$1.0 \dashv 2.0$} & \multicolumn{2}{c}{$>2.0$} \\
& Normal & Flex & Gasolina & Etanol & Gasolina & Etanol \\
\hline 2004 a 2007 & 7,0 & 7,0 & 13.0 & 11.0 & 25,0 & 18,0 \\
$12 / 12 / 2008$ & 0,0 & 0,0 & 6.5 & 5.5 & 25,0 & 18,0 \\
$01 / 12 / 2009$ & 5,0 & 3,0 & 11.0 & 7.5 & 25,0 & 18,0 \\
$01 / 01 / 2010$ & 7,0 & 3,0 & 13.0 & 7.5 & 25,0 & 18,0 \\
$01 / 04 / 2010$ & 7,0 & 7,0 & 13.0 & 11.0 & 25,0 & 18,0 \\
$15 / 12 / 2011$ & 7,0 & 7,0 & 13.0 & 11.0 & 25,0 & 18,0 \\
$23 / 05 / 2012$ & 0,0 & 0,0 & 6.5 & 5.5 & 25,0 & 18,0 \\
$01 / 01 / 2013$ & 2,0 & 2,0 & 8.0 & 7.0 & 25,0 & 18,0 \\
\hline
\end{tabular}

Fonte: Ferreira (2017) 


\section{Simulação de um Esquema de Feebate}

Após estimarmos nosso modelo com os dados para o Brasil podemos simular alguns esquemas de feebate. Isto mudará o equilíbrio de mercado e teremos assim que calculá-lo. Com este novo equilíbrio teremos como estimar pecuniariamente a mudança nos excedentes do consumidor e produtor, e com este último podemos inferir a nova receita com impostos do governo. Com base nos custos do carbono apresentados pelo International Energy Agency (2017) poderemos quantizar o impacto causado pela redução na emissão de carbono, e assim poder comparar monetariamente com as mudanças causadas nos excedentes mencionados e receitas do governo.

Veremos neste capítulo como implementamos o feebate, o cálculo do novo equilíbrio de mercado e a seleção de equilíbrios que tornarão o imposto neutro. E, nos próximos dois capítulos apresentaremos os resultados.

\subsection{Implementação de um feebate}

Primeiramente vamos considerar que os demais impostos incidentes sobre veículos continuarão os mesmos, e que o consumidor continuará com as mesmas opções de veículos antes da introdução do feebate, ou seja, não haverá a entrada de novos veículos nos mercados. Consideraremos que o feebate será um custo adicional no custo marginal do produtor, e com isto, a simulação consistirá apenas na adição do feebate ao custo marginal e no calculo da demanda através da Equação 2.7.

Estudaremos o caso mais simples de um feebate, o simétrico, onde a mesma alíquota é aplicada para cobrança ou subsídio se os carros emitem níveis de $\mathrm{CO}_{2}$ com a mesma distância do pivot. Isto é:

$$
a_{j}=t \times\left(e m i s_{j}-p p\right)
$$

Onde, emis ${ }_{j}$ é a emissão de $\mathrm{CO}_{2}$ em $\mathrm{g} / \mathrm{km}$ do modelo $j, t$ a alíquota do imposto em reais a cada $\mathrm{g} / \mathrm{km}$ e $p p$ é o pivot a ser escolhido de forma discricionária ou atrelado a $t$ de forma a manter a neutralidade do imposto. Este esquema simétrico é interessante pois impões custos iguais de abatimento para todas as firmas, resultando numa solução eficiente economicamente, e a neutralidade faz com que o custo político seja reduzido. Como nossa base contém apenas veículos de passeio, não consideramos outros pivots para caminhões e motos, por exemplo. 


\subsection{Impacto no equilíbrio de mercado}

A equação resultante para a mudança nos preços será:

$$
P=M C+M U(P)
$$

Onde $P$ é o vetor de preços $p_{j}, M C$ o vetor de custos marginais $m c_{j}$ e $M U$ o vetor de markups $\operatorname{Markup}_{j}$. Veja que uma mudança no preço $P_{0}$ levará inicialmente a uma mudança no markup da firma $M U\left(P_{0}\right)$. A empresa visando maximizar seus lucros fixará um novo preço dado pela Equação 3.2, os consumidores por causa desta mudança de preços demandarão quantidades diferentes novamente modificando o markup dos produtos, e assim sucessivamente, o que pode ser mostrado por:

$$
P^{n+1}=M C^{\text {feebate }}+M U\left(P^{n}\right)
$$

Com $M C^{\text {feebate }}=M C^{0}+a$, em que $M C^{0}$ é o custo marginal estimado com a Equação 2.28 .

No limite desta, e acreditando que estes mercados sejam bem comportados, podemos supor que $P^{n}$ convergirá para algum $P^{*}$ no equilíbrio, ou seja, $\lim _{n \rightarrow \text { inf }} P^{n}=P^{*}$, com $P_{0}$ sendo o preço inicial em que incidiu o imposto $a_{j}$ sobre os preços anteriores ao feebate Pantes:

$$
P_{0}=P_{\text {antes }}+A
$$

Com as hipoteses que adotamos pode-se mostrar que $P^{*}$ é um ponto fixo da transformação $T(P)=M C+M U(P)$, mas não o faremos aqui. E como não estamos interessados na dinâmica do imposto, fazemos um suficiente número de iterações para fazer com que a soma do erro quadrático do preço seja menor que 0.001.

Para o Markup vamos computar a Equação 2.27 e com isto será necessário encontrar o share $s_{j}$ para uma mudança no preço. Poderíamos usar a Equação 2.7, mas teríamos que calcular o novo share do grupo, o qual não temos. Poderíamos usar como aproximação o share do grupo a preços antigos, mas também é possível calcular o share exato sem a necessidade disto com:

$$
s_{j}=\frac{e^{\delta_{j} /(1-\sigma)}}{e^{I_{g} /(1-\sigma)}} \frac{e^{I_{g}}}{\sum_{g=0}^{G} e^{I_{g}}}
$$

Em que: 


$$
I_{g} \equiv(1-\sigma) \ln \sum_{l \in V_{g}} e^{\delta_{l} /(1-\sigma)}
$$

E lembrando que:

$$
\delta_{j}=x_{j} \beta-\alpha p_{j}+\xi_{j}
$$

Note que não estamos introduzindo novos produtos (se fosse o caso teríamos de levantar hipótese sobre $\xi$ para estes novos modelos), e, assim a simulação consistirá apenas na mudança nas vendas nos veículos disponíveis em cada mercado.

Para a implementação computacional do modelo de preços lineares usamos no STATA o pacote RCL (Lorincz (2016)) usando a função msimulation. No entanto para preços logarítmicos foi necessário implementar as equações acima, o que resultou no Algoritmo 1, apresentado no Apêndice E, e escolhemos o R para tanto.

\subsection{Buscando a neutralidade do tributo}

A seguir queremos dada uma alíquota $t$ escolhida arbitrariamente, encontrar um pivot $p p$ para que o feebate seja neutro. Neste caso queremos apenas a neutralidade deste tributo, portanto não consideraremos mudanças na receitas de outros impostos. Teremos então:

$$
R^{\text {feebate }}=\sum_{m=1}^{M} \sum_{j=1}^{J} a_{m j} q_{m j}
$$

Em que $R^{\text {feebate }}$ é a receita do governo com feebate, e note que esta é uma função do pivot e da alíquota: $R^{\text {feebate }}=R^{\text {feebate }}(p p, t)$. E portanto queremos encontrar $p p^{*}$ e $t^{*}$ que façam com que $R^{\text {feebate }}\left(p p^{*}, t^{*}\right)=0$. Para encontrar este zero podemos usar o método da bisseção, que apesar de computacionalmente menos eficiente com relação a métodos que envolvem o cálculo do gradiente e que seja usado apenas como uma aproximação, é um métodode fácil implementação e robusto exatamente por não requerer a computação dos gradientes. O algorítimo que implementamos pode ser visto no Apêndice E. Adicionalmente, calculamos também o pivot para que toda a receita do governo não sofra alteração e também para que o bem estar social não mude.

\subsection{Análise de Bem Estar}

Ao encontramos o pivot e alíquota para tornar o feebate neutro, podemos calcular as variações decorrentes da implementação deste imposto que serão ambientais, receitas 
do governo, excedente do consumidor e lucro dos fabricantes.

$$
G_{\text {Total }}=G_{\text {Ambiental }}+G_{\text {Governo }}+G_{\text {consumidor }}+G_{\text {Firmas }}
$$

Os ganhos ambientais serão calculados como a diferença entre a emissão estimada dos veículos que seriam vendidos no esquema de um feebate e os realmente observados:

$$
G_{\text {Ambiental }}=C_{\mathrm{CO}_{2}} \cdot\left(\mathrm{CO}_{2}^{\text {sim }}-\mathrm{CO}_{2}^{\text {real }}\right)
$$

A este valor multiplicamos o custo da emissão $C_{\mathrm{CO}_{2}}$ que é calculado com base na vida útil estimada de $250.000 \mathrm{~km}$ para um carro vezes o custo social da emissão de $C O 2$ sugerido pelo Interagency Working Group on Social Cost of Greenhouse Gases (2016) apresentada na Tabela 5. Os valores se baseiam na média de simulações do impacto econômico e social da emissão de uma tonelada de gás carbônico a taxas de desconto de $5 \%, 3 \%$ e 2,5\%. Adicionalmente é apresentado o valor do $95^{\circ}$ percentil da simulação a uma taxa de desconto de $3 \%$ que embora a probabilidade de ocorrência seja baixa, apresenta um alto impacto econômico. Usaremos neste trabalho os valores do ano de 2010 para uma taxa de desconto de $3 \%$ na média e em seu valor extremo que correspondem a US $\$ 31$ e US\$86, respectivamente. Escolhemos tais valores pois correspondem ao período de nossas análises e o Interagency Working Group on Social Cost of Greenhouse Gases (2016) sugere a taxa de desconto de $3 \%$. Estes valores irão corresponder a aproximadamente $\mathrm{R} \$ 15$ e a $\mathrm{R} \$ 43$ por grama da emissão de um carro novo na cotação média do dólar de 2012.

Tabela 5 - Custo do $\mathrm{CO}_{2}$ em US $\$$ de 2007 por tonelada métrica

\begin{tabular}{ccccc}
\hline Ano & $\begin{array}{c}5 \% \\
\text { Média }\end{array}$ & $\begin{array}{c}3 \% \\
\text { Média }\end{array}$ & $\begin{array}{c}2,5 \% \\
\text { Média }\end{array}$ & $\begin{array}{c}\text { Alto Impacto } \\
\left(95^{\mathrm{o}} \text { pct a } 3 \%\right)\end{array}$ \\
\hline \hline 2010 & 10 & 31 & 50 & 86 \\
2015 & 11 & 36 & 56 & 105 \\
2020 & 12 & 42 & 62 & 123 \\
2025 & 14 & 46 & 68 & 138 \\
2030 & 16 & 50 & 73 & 152 \\
2035 & 18 & 55 & 78 & 168 \\
2040 & 21 & 60 & 84 & 183 \\
2045 & 23 & 64 & 89 & 197 \\
2050 & 26 & 69 & 95 & 212 \\
\hline
\end{tabular}

Fonte: Interagency Working Group on Social Cost of Greenhouse Gases (2016)

A mudança na receita do governo é a diferença dos impostos que compõe o imposto sobre valor agregado (ICMS, IPI, PIS, COFINS) mais o feebate. A receita do governo é 
dada por:

$$
R_{\text {Governo }}=\sum_{j}\left(I V A_{j} \cdot v e n d a_{j}\right)
$$

Em que

$$
I V A_{i}=p_{i} \times \operatorname{aliquota}_{i}^{I V A}
$$

A mudança na receita do governo será dada por:

$$
G_{\text {Governo }}=R_{I V A}^{\text {sim }}-R_{I V A}^{\text {real }}+R_{\text {feebate }}
$$

De acordo com Small e Rosen (1981) o excedente do consumidor para um modelo de escolha discreta será dado por:

$$
E=\sum_{m}^{M} \sum_{j}^{J} \frac{p_{j}^{1-\mu}}{\alpha} \cdot \ln \left(1 / s_{0}^{m}\right) \cdot v_{e n d} a_{j}
$$

Em que $s_{0}^{m}$ representa o share do bem externo do mercado $m$.

A variação no excedente do consumidor será dado por:

$$
G_{\text {consumidor }}=E^{\text {sim }}-E^{\text {real }}
$$

O lucro das montadoras é dado pela soma dos markups:

$$
\Pi=\sum_{j} \text { Markups }_{j} \cdot \text { vendas }_{j}
$$

E a mudança nos lucros obtidos pelas firmas será dados por:

$$
G_{\text {Firmas }}=\Pi^{\text {sim }}-\Pi^{\text {real }}
$$

Resumindo, os passos que seguiremos são:

1. Escolhemos uma alíquota $t$ e um pivot $p p$ qualquer, e calculamos o feebate para cada veículo;

2. Adicionamos o feebate ao custo marginal do carro. Isto levará a um novo equilíbrio de preços e shares.

3. Calculamos a receita ou despesa com o imposto. 
4. Com algum método numérico executamos os passos de 1 a 3 até encontrar um pivot que faça com que a receita do feebate seja nula.

5. Com base neste $t^{*}$ e $p p^{*}$ que tornam o imposto neutro calculamos a mudança no excedente do consumido, lucros das empresas, receitas do governo e diminuição do custo da emissão de gás carbônico. 


\section{Estimativas do Mercado Nacional}

Neste capítulo veremos os resultados das regressões propostas no Capítulo 2, para que no próximo possamos apresentar os resultados finais das simulações. Para relembrarmos, fizemos a estimação da demanda por mínimos quadrados ordinários e por GMM em dois estágios, sendo que para cada uma estimaremos com preços lineares e com uma transformação logarítmica. Com base nesta estimação calculamos as matrizes de elasticidade cruzada para cada mercado, os markups para cada modelo e seus custos marginais.

Adicionalmente, apresentaremos algumas estatísticas descritivas da base de dados sobre a qual realizamos a estimação.

\subsection{Estatísticas Descritivas}

Nossa base de dados para o presente estudo engloba o período dos anos de 2008 a 2013, entretanto, no último ano a base contem dados apenas até abril. Isto faz com que este ano apresente menos vendas que os demais, logo, no momento em que realizássemos o logit em painel empilhado por mercados e anos, fariam surgir mercados com as mesmas características mas com fatias de mercado muito menores, o que poderia levar a um viés nos parâmetros a serem estimados, portanto, excluímos da regressão o último ano.

Apresentamos na Tabela 21 as unidades vendidas por fabricante ao longo dos anos. Observe que não há decréscimo nas vendas totais ao longo do período e que quase 12 milhões de veículos foram vendidos nestes 5 anos, correspondendo a uma média de quase 2,4 milhões de unidades por ano. Podemos ver claramente pela Tabela 22 que três marcas dominam mais de $60 \%$ do mercado total, tendo por vota de $20 \%$ do mercado cada uma, que são Fiat, Volkswagen e Chevrolet, e 11 das 41 marcas presentes detém 95\% do mercado de automóveis brasileiro. Note que entre as marcas populares há a entrada de três marcas chinesas, Cherry, JAC e Lifan, cujas vendas cresceram rapidamente mas com um decréscimo em 2012, provavelmente causado pelas políticas protecionistas do governo brasileiro neste período. Notamos também que marcas consideradas de luxo, como Ferrari, Aston Martin, Bentley, Jaguar, Lamborghini, Lexus, Maserati, e Rolls-Royce, apresentam vendas que correspondem a menos $0,006 \%$ do total.

Na Tabela 19 mostramos as vendas por segmento, e podemos perceber que a categoria 'Pequeno' corresponde a $51 \%$ das vendas totais, enquanto que as categorias 'Perua' correspondem a aproximadamente $0,02 \%$ do mercado. A grosso modo as participações significantes são as categorias que englobam Médio +, Médio -, MPV, Pequeno, Popular e 
SUV que representam 99,03\% do mercado total. Há um predomínio de carros a álcool com um share médio de 89,3\% (Tabela 7), embora, estejam presentes nesta categoria os carros que também são flex.

Tabela 6 - Vendas em porcentagem de 2008 a 2012 por segmento

\begin{tabular}{lrrrrrr}
\hline Segmento & 2008 & 2009 & 2010 & 2011 & 2012 & TODOS \\
\hline \hline Carro Grande & 0,17 & 0,12 & 0,13 & 0,40 & 0,15 & 0,19 \\
Carro Luxo & 0,38 & 0,52 & 0,56 & 0,55 & 0,43 & 0,49 \\
Carro Médio + & 7,29 & 6,69 & 6,24 & 5,14 & 5,53 & 6,12 \\
Carro Médio - & 12,63 & 15,99 & 15,05 & 17,44 & 18,74 & 16,12 \\
Esporte & 0,05 & 0,05 & 0,08 & 0,31 & 0,27 & 0,16 \\
MPV & 4,13 & 4,23 & 3,96 & 4,49 & 4,08 & 4,18 \\
Pequeno & 54,65 & 51,47 & 54,14 & 49,09 & 49,03 & 51,54 \\
Perua Grande & 0,01 & 0,01 & 0,00 & 0,00 & 0,00 & 0,00 \\
Perua Luxo & 0,00 & 0,00 & 0,00 & 0,00 & 0,00 & 0,00 \\
Perua Média & 0,12 & 0,00 & 0,00 & 0,00 & 0,00 & 0,02 \\
Popular & 14,07 & 14,28 & 12,33 & 14,07 & 12,87 & 13,49 \\
SUV & 6,49 & 6,65 & 7,51 & 8,52 & 8,89 & 7,68 \\
\hline TOTAL & 100 & 100 & 100 & 100 & 100 & 100 \\
\hline
\end{tabular}

Valores em porcentagem. Fonte: Elaborção Própria

Tabela 7 - Vendas de 2008 a 2012 por combustível

\begin{tabular}{lrrrrrr}
\hline Combustível & 2008 & 2009 & 2010 & 2011 & 2012 & TOTAL \\
\hline \hline Diesel & 0,9 & 0,7 & 0,8 & 0,9 & 0,7 & 0,8 \\
Gasolina & 9,3 & 8,5 & 9,9 & 12,9 & 9,1 & 10,0 \\
Álcool & 89,8 & 90,9 & 89,3 & 86,2 & 90,2 & 89,3 \\
\hline TOTAL & 100 & 100 & 100 & 100 & 100 & 100 \\
\hline
\end{tabular}

Fonte: Elaboração própria

O segmento 'Popular' e 'Pequeno' apresentam os menores preços médios (Tabela 8), em torno de $\mathrm{R} \$ 25.000,00$ e $\mathrm{R} \$ 31.000,00$, respectivamente, o que podem explicar a maior fatia de mercado destas que equivale a $65 \%$. E segmentos mais caros tais como 'Luxo' $(\mathrm{R} \$ 173.000,00)$ e 'Esporte' ( $\mathrm{R} \$ 190.000,00)$ apresentam fatias menores, correspondendo a $0,49 \%$ e $0,16 \%$.

A emissão média de $\mathrm{CO}_{2}$ é de $164 \mathrm{~g} / \mathrm{km}$, apresentada também na Tabela 8, e os segmentos de menor emissão são o 'Pequeno' e 'Popular' (163g/km, 129 g/km) e, consequentemente, seriam os maiores beneficiados caso o feebate fosse implementado. Por outro lado, os segmentos 'Grande' e 'Luxo' (227 g/km, 182 g/km) apresentam os maiores níveis de emissão e desta forma seriam os maiores pagadores. Sabemos que a cilindrada está 
intimamente relacionada com a emissão, e podemos verificar isso ao comparar a emissão média para 'Médio +' de $175 \mathrm{~g} / \mathrm{km}$ e Popular de $129 \mathrm{~g} / \mathrm{km}$, e suas respectivas cilindradas de $1.790 \mathrm{~cm}^{3}$ e $1.022 \mathrm{~cm}^{3}$. O mesmo vale para variáveis de desempenho e conforto do carro, ou seja, conforme aumenta-se o desempenho e tamanho do carro aumenta-se o consumo energético e com isto aumentam-se as emissões.

Nossa base fornece o consumo em $\mathrm{km} / \mathrm{L}$ e a emissão de $\mathrm{CO}_{2} \mathrm{em} \mathrm{g} / \mathrm{km}$, logo podemos realizar uma estimativa da emissão por litro de combustível com a equação abaixo:

$$
\text { emissao }_{\text {litro }}=\text { consumo } \times \text { emissao }_{\mathrm{km}}
$$

Apresentamos na Tabela 9 a emissão em gramas por litro.

Tabela 9 - Distribuição da emissão de $\mathrm{CO}_{2}$ por litro de combustível (g/L)

\begin{tabular}{cccccccccccc}
\hline & mín. & $1 \%$ & $5 \%$ & $10 \%$ & $25 \%$ & $50 \%$ & $75 \%$ & $90 \%$ & $95 \%$ & $99 \%$ & máx. \\
\hline \hline Álcool & 836 & 882 & 1.042 & 1.079 & 1.216 & 1.349 & 1.502 & 1.590 & 1.711 & 2.218 & 2.218 \\
Gasolina & 1.209 & 1.209 & 1.270 & 1.572 & 1.800 & 1.818 & 1.997 & 2.153 & 2.202 & 2.330 & 2.330 \\
\hline
\end{tabular}

Fonte: Elaborção Própria

Com a queima de gasolina sabemos por balanço estequiométrico que para cada litro serão gerados aproximadamente $2280 \mathrm{~g}$ de $\mathrm{CO}_{2}$, e o etanol hidratado liberará $1440 \mathrm{~g} / \mathrm{L}$. Como no Brasil há uma mistura na proporção de $25 \%$ de etanol anidro $(1510 \mathrm{~g} / \mathrm{L})$ à gasolina teremos uma emissão entre $2000 \mathrm{~g} / \mathrm{L}$ a $2100 \mathrm{~g} / \mathrm{L}$. Portanto, para os veículos brasileiros teremos emissões que variam entre um limite mínimo de $1440 \mathrm{~g} / \mathrm{L}$ no caso do veículo usar álcool puro, e de $2100 \mathrm{~g} / \mathrm{L}$ se usar apenas a mistura de gasolina disponível nos postos.

Veja que para a gasolina o maior valor obtido da base de dados é de $2330 g / L$ o que excede até mesmo o valor máximo para a gasolina pura, e o mesmo pode ser dito para o álcool $(2218 g / L)$. Quanto aos valores mínimos a Tabela 9 mostra inconsistência nos valores da gasolina, já que deveriam estar próximos do obtido com a queima estequiométrica, do contrário estariam emitindo mais $C O$ (que tem uma regulação bastante estrita), ou haveria a não queima de pelo menos metade da gasolina para alguns casos. O mesmo pode ser dito dos carros a álcool que apresentaram um mínimo de $836 \mathrm{~g} / \mathrm{L}$, sendo quase a metade da emissão com etanol hidratado.

Uma explicação possível é que os regimes em que foram testados os carros com relação a consumo e emissão por quilômetro são diferentes, por exemplo: o consumo foi testado como uma média ao longo da vida do veículo e a emissão por km foi obtida através do valor máximo. Outra explicação é que foram utilizadas misturas diferentes de álcool e gasolina para testar diferentes carros, e portanto não havendo uniformidade nos ensaios. 


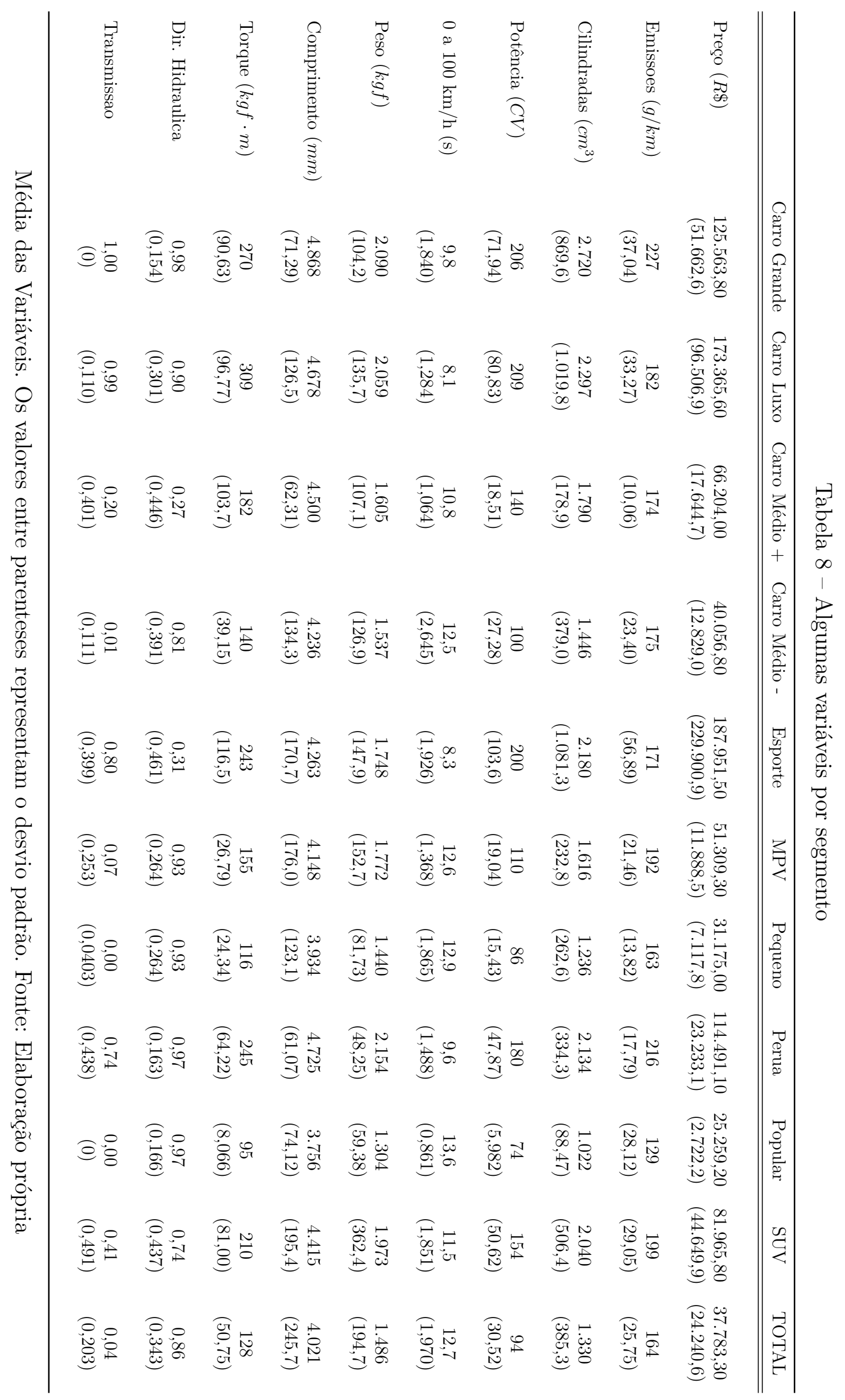




\subsection{Estimativas dos parâmetros}

Primeiramente, eliminamos as marcas consideradas de luxo, uma vez que assumimos que sua demanda é pouco dependente do preço. Alguém disposto a comprar um veículo da Ferrari é muito menos afetado por variações no preço desta do que alguém que compraria um veículo de entrada como um Ford Ka. Se permitirmos sua presença, muito provavelmente pela pouca amostragem, a regressão não seria afetada, no entanto o significado do resultado das regressões para estas marcas seria baixo, justificando assim nossa escolha.

Retiramos também da base os segmentos com fatias de mercado muito pequenas como 'Peruas', 'Esporte', 'Grande' e 'Luxo' que detém em conjunto menos de 1\% das unidades vendidas. Pois, em mercados de menor tamanho caso ocorra a venda destes poderiam evidenciar o domínio destas categorias, quando na realidade foi pela venda de um ou dois veículos, ou seja, por mero acaso.

A seguir eliminamos os veículos a diesel uma vez que representavam $0,8 \%$ de nossa base, e, no Brasil apresentam características bastante diferentes dos demais, uma vez que não é permitido o uso deste combustível em veículos de passeio.

Retiramos cidades com menos de 40.000 habitantes a fim de evitar mercados dominados por um único segmento ou marca, já que em cidades pequenas as vendas de poucas unidades podem mostrar um share significativo na população que compõe o mercado potencial destas. E também removemos veículos com preço deflacionado maior que $\mathrm{R} \$ 90.000,00$, o que corresponde a aproximadamente $3 \%$ dos veículos restantes, já que usamos uma especificação linear e grandes variações de preço podem não se adequar a esta.

A partir da Equação 2.7 realizamos 4 regressões diferentes: nas duas primeiras aplicamos mínimos quadrados ordinário (MQO), na primeira aplicamos preços lineares e na segunda aplicamos no preço uma transformação logarítmica; nos dois últimos usamos variáveis instrumentais construídas conforme explicado na seção 2.1, e selecionadas usandose o estimador lasso de acordo com a seção 2.2, lembrando que o instrumento da constante é o número de competidores num segmento.

De 252 instrumentos o nosso algoritmo com base no lasso selecionou 62 no primeiro estágio e no segundo reduziu para 28: torque, logaritmo do PIB per capta, airbag, logaritmo do espaço interno, distância entre eixos, direção, transmissão, ABS, litros, logaritmo carga, $\mathrm{CO}_{2}$, ar condicionado, portas, importado, dummies de ano, VAT, consumo, carga, aceleração de 0 a $100 \mathrm{~km} / \mathrm{h}$, volume externo, logaritmo da distância entre eixos, peso bruto, $\sum_{r \neq j, r \in \mathcal{F}_{f}}$ potência específica, $\sum_{r \notin \mathcal{F}_{f}} C O_{2}, \sum_{r \notin \mathcal{F}_{f}, r \in V_{g}}$ carga carro. Adicionamos a este conjunto de variáveis escolhidas outros que acreditamos ser relevantes para o problema, mas que foram excluídos no processo, que foram os instrumentos construídos a partir da constante e construídos a partir do torque, distância entre eixos, aceleração, volume 
externo, consumo e emissão de $\mathrm{CO}_{2}$, que são variáveis que estão intimamente relacionadas com a eficiência energética do veículo.

O método que aplicamos para a regressão com variáveis instrumentais foi o GMM em dois estágios, e a estrutura de aninhamento adotada foi com base nos segmentos restantes após as eliminações mencionadas, que foram Médio +, Médio -, MPV, Pequeno, Popular e $S U V$. Os mercados adotados foram a nível municipal por ano resultando num painel empilhado, que após as eliminações, anteriormente mencionadas, resultaram em 1983 mercados. Apresentamos no Apêndice C a regressão do preço contra os instrumentos selecionados, o que seria o primeiro estágio da estimação da equação de demanda, apesar de termos estimado usando o GMM. E na Tabela 10 apresentamos os resultados, e observamos que tanto o MQO com preço linear quanto logarítmico apresentaram coeficientes para o preço mais próximos de 0 quando comparados com os parâmetros do IV, algo esperado, já que existe um viés causado pelas variáveis não observadas. Observamos que o parâmetro de $\sigma$ foi semelhante no caso linear em relação ao logarítmico tanto para o MQO quanto para o IV, exceto, novamente, por apresentar um viés aumentando seu valor no caso do MQO.

Para as variáveis discretas, em especial o ar condicionado apresentou coeficiente significativo de sinal inverso ao esperado. Acreditamos que seja causado pelo consumo extra que este tende a gerar, entretanto, não explica totalmente, pois este pode ser desligado. A transmissão automática, ABS, Quatro portas e importado apresentaram coeficientes positivos conforme o esperado. Já o coeficiente do Airbag para o IV logarítmico apresentou coeficiente negativo e significante, inverso ao esperado. Incluímos também nas regressões dummies de ano tentando capturar efeitos temporais com relação ao ano de 2012. Notamos que os sinais de todas são positivas e decrescente conforme avançamos ao logo dos anos, mostrando que a demanda foi maior próximo de 2008.

Para as variáveis contínuas todas apresentaram sinais condizentes exceto: Eficiência e $\ln$ (Carga) apresentando sinal negativo para IV a preço logarítmico. O coeficiente de Dist. entre Eixos apresentou sinal negativo para todas as regressões, talvez evidenciando a preferência do consumidor por veículos mais compactos.

\subsection{Elasticidade, Markup e Custo Marginal}

Para esta sessão utilizamos apenas as regressões feitas com IV sendo a diferença entre a especificação linear da logarítmica tem grandes implicações nas elasticidades. Como veremos adiante a especificação linear faz com que as elasticidades próprias sejam menores para veículos mais baratos, enquanto que na logarítmica os as elasticidades serão muito próximas. Além disso, uma especificação logarítmica implica em gastos constantes para carros por parte dos consumidores, o que parece pouco plausível. No entanto, se existe uma 
Tabela 10 - Parâmetros estimados

\begin{tabular}{|c|c|c|c|c|}
\hline & \multicolumn{2}{|c|}{ MQO } & \multicolumn{2}{|c|}{ IV } \\
\hline & (1) & $(2)$ & $(3)$ & (4) \\
\hline & Linear & $\log$ & Linear & $\log$ \\
\hline $\operatorname{Preço}(R \$ 1.000)$ & $\begin{array}{c}-0,0604^{* * *} \\
(0,001)\end{array}$ & & $\begin{array}{c}-0,105^{* * *} \\
(0,001)\end{array}$ & \\
\hline $\ln$ (Preço) & & $\begin{array}{c}-3,34^{* * *} \\
(0,03)\end{array}$ & & $\begin{array}{c}-4,21^{* * *} \\
(0,07)\end{array}$ \\
\hline$\sigma$ & $\begin{array}{c}0,609^{* * *} \\
(0,002)\end{array}$ & $\begin{array}{c}0,604^{* * *} \\
(0,002)\end{array}$ & $\begin{array}{c}0,427^{* * *} \\
(0,004)\end{array}$ & $\begin{array}{c}0,358^{* * *} \\
(0,004)\end{array}$ \\
\hline Torque $(k g f \cdot m)$ & $\begin{array}{c}0,01^{\text {*** }} \\
(0,0004)\end{array}$ & $\begin{array}{c}0,01^{* * *} \\
(0,0004)\end{array}$ & $\begin{array}{l}0,026^{* * *} \\
(0,0005)\end{array}$ & $\begin{array}{l}0,022^{* * *} \\
(0,0005)\end{array}$ \\
\hline $\ln$ (Espaço Interno) & $\begin{array}{c}2,19^{* * *} \\
(0,14)\end{array}$ & $\begin{array}{c}2,80^{* * *} \\
(0,14)\end{array}$ & $\begin{array}{c}3,68^{* * *} \\
(0,20)\end{array}$ & $\begin{array}{c}1,68^{* * *} \\
(0,19)\end{array}$ \\
\hline Dist. entre Eixos $(m m)$ & $\begin{array}{c}-0,002^{* * *} \\
(0,0001)\end{array}$ & $\begin{array}{c}-0,003^{* * *} \\
(0,0001)\end{array}$ & $\begin{array}{c}-0,001^{* * *} \\
(0,0002)\end{array}$ & $\begin{array}{c}-0,001^{* * *} \\
(0,0001)\end{array}$ \\
\hline Cilindradas $\left(\mathrm{cm}^{3}\right)$ & $\begin{array}{c}-0,90^{* * *} \\
(0,03)\end{array}$ & $\begin{array}{c}-0,86^{* * *} \\
(0,03)\end{array}$ & $\begin{array}{c}-1,67^{* * *} \\
(0,04)\end{array}$ & $\begin{array}{c}-1,42^{* * *} \\
(0,04)\end{array}$ \\
\hline Eficiência $(k m / l)$ & $\begin{array}{c}-0,02^{* * *} \\
(0,002)\end{array}$ & $\begin{array}{c}-0,04^{* * *} \\
(0,002)\end{array}$ & $\begin{array}{c}0,002 \\
(0,003)\end{array}$ & $\begin{array}{c}-0,03^{* * *} \\
(0,003)\end{array}$ \\
\hline $\mathrm{CO}_{2}(\mathrm{~g} / \mathrm{km})$ & $\begin{array}{c}-0,003^{* * *} \\
(0,0002)\end{array}$ & $\begin{array}{c}-0,003^{* * *} \\
(0,0002)\end{array}$ & $\begin{array}{l}-0,01^{* * *} \\
(0,0002)\end{array}$ & $\begin{array}{c}-0,01^{* * *} \\
(0,0002)\end{array}$ \\
\hline $\ln ($ Carga $)$ & $\begin{array}{c}0,22^{* * *} \\
(0,02)\end{array}$ & $\begin{array}{c}0,02 \\
(0,02)\end{array}$ & $\begin{array}{l}0,14^{* *} \\
(0,03)\end{array}$ & $\begin{array}{c}-0,07^{* * *} \\
(0,03)\end{array}$ \\
\hline $\ln ($ PIB per capta $)$ & $\begin{array}{l}0,43^{* * *} \\
(0,004)\end{array}$ & $\begin{array}{l}0,43^{* * *} \\
(0,004)\end{array}$ & $\begin{array}{c}0,37^{* * *} \\
(0,01)\end{array}$ & $\begin{array}{l}0,35^{* * *} \\
(0,005)\end{array}$ \\
\hline Ar Condicionado & $\begin{array}{c}-0,05^{* * *} \\
(0,01)\end{array}$ & $\begin{array}{l}0,02^{* *} \\
(0,01)\end{array}$ & $\begin{array}{c}-0,03^{* * *} \\
(0,01)\end{array}$ & $\begin{array}{c}-0,10^{* * *} \\
(0,01)\end{array}$ \\
\hline Direção Hidraulica & $\begin{array}{c}0,21^{* * *} \\
(0,01)\end{array}$ & $\begin{array}{c}0,38^{* * *} \\
(0,01)\end{array}$ & $\begin{array}{c}0,62^{* * *} \\
(0,01)\end{array}$ & $\begin{array}{c}0,60^{* * *} \\
(0,02)\end{array}$ \\
\hline Transmissão Automática & $\begin{array}{c}0,51^{* * *} \\
(0,02)\end{array}$ & $\begin{array}{c}0,36^{* * *} \\
(0,02)\end{array}$ & $\begin{array}{c}1,17^{* * *} \\
(0,02)\end{array}$ & $\begin{array}{c}0,81^{* * *} \\
(0,02)\end{array}$ \\
\hline Airbag & $\begin{array}{c}0,05^{* * *} \\
(0,01)\end{array}$ & $\begin{array}{c}0,10^{* * *} \\
(0,01)\end{array}$ & $\begin{array}{c}0,10 \\
(0,02)\end{array}$ & $\begin{array}{c}-0,05^{* *} \\
(0,02)\end{array}$ \\
\hline ABS & $\begin{array}{c}0,52^{* * *} \\
(0,01)\end{array}$ & $\begin{array}{c}0,38^{* * *} \\
(0,01)\end{array}$ & $\begin{array}{c}0,68^{* * *} \\
(0,02)\end{array}$ & $\begin{array}{c}0,43^{* * *} \\
(0,01)\end{array}$ \\
\hline Quatro portas & $\begin{array}{c}0,03^{* * *} \\
(0,01)\end{array}$ & $\begin{array}{c}0,15^{* * *} \\
(0,01)\end{array}$ & $\begin{array}{c}0,04^{* * *} \\
(0,01)\end{array}$ & $\begin{array}{c}0,12^{* * *} \\
(0,01)\end{array}$ \\
\hline Importado & $\begin{array}{c}0,0004 \\
(0,01)\end{array}$ & $\begin{array}{c}0,01 \\
(0,01)\end{array}$ & $\begin{array}{c}0,19^{* * *} \\
(0,02)\end{array}$ & $\begin{array}{l}0,04^{*} \\
(0,02)\end{array}$ \\
\hline 2008 & $\begin{array}{c}0,61^{* * *} \\
(0,01)\end{array}$ & $\begin{array}{c}0,82^{* * *} \\
(0,01)\end{array}$ & $\begin{array}{c}1,20^{* * *} \\
(0,02)\end{array}$ & $\begin{array}{c}1,10^{* * *} \\
(0,02)\end{array}$ \\
\hline 2009 & $\begin{array}{c}0,60^{* * *} \\
(0,01)\end{array}$ & $\begin{array}{c}0,74^{* * *} \\
(0,01)\end{array}$ & $\begin{array}{l}1,01^{* * *} \\
(0,01)\end{array}$ & $\begin{array}{c}0,93^{* * *} \\
(0,02)\end{array}$ \\
\hline 2010 & $\begin{array}{c}0,50^{* * *} \\
(0,01)\end{array}$ & $\begin{array}{c}0,59^{* * *} \\
(0,01)\end{array}$ & $\begin{array}{c}0,81^{* * *} \\
(0,01)\end{array}$ & $\begin{array}{c}0,73^{* * *} \\
(0,01)\end{array}$ \\
\hline 2011 & $\begin{array}{l}0,36^{* * *} \\
(0,01)\end{array}$ & $\begin{array}{c}0,41^{* * *} \\
(0,01)\end{array}$ & $\begin{array}{c}0,53^{* * *} \\
(0,01)\end{array}$ & $\begin{array}{c}0,50^{* * *} \\
(0,01)\end{array}$ \\
\hline Constante & $\begin{array}{c}-31,27^{* * *} \\
(1,93)\end{array}$ & $\begin{array}{c}-4,78^{* * *} \\
(1,85)\end{array}$ & $\begin{array}{c}-55,34^{* * *} \\
(2,87)\end{array}$ & $\begin{array}{c}16,36^{* * *} \\
(2,35)\end{array}$ \\
\hline $\mathrm{R}^{2}$ & 0,63 & 0,64 & 0,56 & 0,56 \\
\hline Residual Std. Error & 0,91 & 0,90 & 1,00 & 0,99 \\
\hline Estatistica F $(21,113339)$ & $10.170^{* * *}$ & $10.019^{* * *}$ & $4.317^{* * *}$ & $4.410^{* * *}$ \\
\hline
\end{tabular}

Fonte: Elaboração própria 
estrutura de financiamento, é esperado que os indivíduos tentem suavizar seu dispêndio, o que ocorre no Brasil, onde a maior parte das vendas de veículos é feita a prazo.

Com os valores de $\alpha, \sigma$, a fatia dentro dos segmentos $s_{j / g}$ e a fatia absoluta $s_{j}$, calculamos através da Equação 2.18 as elasticidades próprias. E com base nesta última calculamos o markup através da Equação 2.27, com o resultado desta o custo marginal com a Equação 2.28. Mostramos a distribuição destes entre os modelos na Tabela 11 para o caso linear, e na Tabela 12 para logarítmico. E calculamos a média ponderada por veículos vendidos para os segmentos na Tabela 13 e Tabela 14.

As elasticidades se distribuem entre -16,4 e -2,23 (Tabela 11), o que se traduz num índice de Lerner entre 0,077 e 0,223 para os percentis 5\% e 95\% respectivamente. Note que o segmento mais inelástico corresponde ao 'Popular' (Tabela 13) com -4,29, sendo que este apresenta o menor preço médio, condizente com o estudo de Fiuza (2002) para o mercado brasileiro de 1989 a 1997. Isto condiz com a escolha linear para o preço o que faz com que veículos mais baratos tenham elasticidade absoluta menor e veículos mais caros elasticidade maior. Quando observamos as elasticidades através dos preços com a transformação logarítmica (Tabela 12 e Tabela 14) verificamos que apresentam-se muito próximas e em torno de -6,4, enquanto que o índice de Lerner fica entre 0,153 e 0,185 para os percentis entre $5 \%$ e $95 \%$, e as elasticidades médias para os segmentos são muito próximas da média.

No que diz respeito ao Markup, estes são percentualmente maiores para os veículos de menor valor no caso de preço linear, em torno de $21 \%$ e menores para a categoria Médio + correspondendo a 9,4\%, e com valores em reais muito próximos quando observamos sua distribuição, que varia entre $\mathrm{R} \$ 4.259,81$ e $\mathrm{R} \$ 6.959,40$, algo inesperado, pois as firmas tendem a ter margens de lucros por veículo parecidas entre os modelos. Diferentemente do que observamos no modelo logarítmico onde os Markups percentuais são próximos entre os modelo, em média 14,6\%, e os em reais variam grandemente, com desvio padrão em torno de $\mathrm{R} \$ 2.200,03$, sendo menores para veículos mais baratos, no caso popular de $\mathrm{R} \$ 4.326,38$, e o oposto para os mais caros, no caso Médio + que foi de $\mathrm{R} \$ 11.848,99$, o esperado.

Com relação ao custo marginal, este situou-se entre $58 \%$ e $70 \%$ para os percentis entre $5 \%$ e $95 \%$ tanto para o caso linear quanto para o caso logarítmico, e com média em torno de $65 \%$, e o valor médio em reais de $\mathrm{R} \$ 30.000,00$, e além disso, os segmentos apresentaram correspondência entre os modelos linear e logarítmico. Como o custo marginal tem um papel de destaque na simulação do feebate, acreditamos que a convergência para quase os mesmos valores mostra a robustez da estimação. No entanto, devido aos valores dos Markups apresentados acreditamos que o modelo de preços logarítmicos seja mais razoável, pois estes foram consistentes com a hipótese de que as firmas tem margem de lucro parecidas percentualmente para os modelos, mas, ao longo deste trabalho, seguiremos com as duas especificações. 
Tabela 11 - Distribuições para preço linear

\begin{tabular}{lccccc}
\hline Percentil & Elasticidade & \multicolumn{2}{c}{ Markup } & \multicolumn{2}{c}{$\mathrm{CM}$} \\
& Própria & $\%$ & $\mathrm{R} \$$ & $\%$ & $\mathrm{R} \$$ \\
\hline \hline Mín. & $-16,4$ & 4,09 & $3.675,50$ & 43,1 & $11.279,31$ \\
$1 \%$ & $-15,2$ & 5,06 & $3.813,99$ & 55,5 & $14.336,38$ \\
$5 \%$ & $-13,0$ & 6,31 & $4.259,81$ & 58,9 & $15.843,64$ \\
$10 \%$ & $-11,7$ & 7,37 & $4.308,41$ & 60,4 & $17.258,38$ \\
$25 \%$ & $-9,47$ & 9,10 & $4.427,97$ & 63,4 & $21.174,62$ \\
$50 \%$ & $-7,40$ & 12,1 & $4.768,50$ & 66,1 & $27.534,43$ \\
$75 \%$ & $-5,87$ & 15,1 & $5.622,98$ & 68,9 & $38.011,74$ \\
$90 \%$ & $-4,90$ & 18,8 & $6.397,35$ & 70,4 & $46.888,09$ \\
$95 \%$ & $-4,48$ & 20,8 & $6.959,40$ & 71,2 & $52.075,83$ \\
$99 \%$ & $-3,81$ & 24,1 & $7.625,28$ & 72,7 & $61.740,21$ \\
Máx. & $-2,23$ & 38,0 & $10.643,74$ & 75,6 & $64.725,27$ \\
\hline Média & $-7,86$ & 12,5 & $5.109,86$ & 65,8 & $30.194,33$ \\
D.P. & 2,62 & 4,41 & 882,04 & 3,92 & $11.467,76$ \\
\hline
\end{tabular}

Fonte: Elaboração própria

Tabela 12 - Distribuições para preços com transformação logarítmica

\begin{tabular}{lccccc}
\hline Percentil & Elasticidade & \multicolumn{2}{c}{ Markup } & \multicolumn{2}{c}{$\mathrm{CM}$} \\
& Própria & $\%$ & $\mathrm{R} \$$ & $\%$ & $\mathrm{R} \$$ \\
\hline \hline Mín. & $-6,56$ & 10,2 & $2.857,41$ & 50,6 & $14.371,01$ \\
$1 \%$ & $-6,55$ & 10,6 & $3.221,52$ & 57,7 & $16.085,92$ \\
$5 \%$ & $-6,55$ & 11,9 & $3.616,09$ & 60,0 & $17.331,23$ \\
$10 \%$ & $-6,54$ & 12,0 & $3.939,84$ & 61,3 & $18.509,90$ \\
$25 \%$ & $-6,52$ & 12,3 & $4.474,80$ & 63,3 & $21.573,85$ \\
$50 \%$ & $-6,45$ & 13,1 & $5.646,53$ & 65,0 & $26.800,60$ \\
$75 \%$ & $-6,25$ & 15,1 & $7.376,56$ & 65,9 & $35.539,52$ \\
$90 \%$ & $-5,81$ & 16,8 & $9.653,16$ & 66,9 & $42.498,09$ \\
$95 \%$ & $-5,41$ & 18,0 & $11.087,04$ & 67,3 & $46.954,46$ \\
$99 \%$ & $-4,33$ & 19,1 & $14.144,77$ & 68,6 & $55.546,41$ \\
Máx. & $-3,47$ & 27,3 & $16.399,34$ & 69,4 & $58.364,81$ \\
\hline Média & $-6,29$ & 13,4 & $6.258,51$ & 64,5 & $29.045,68$ \\
D.P. & 0,414 & 1,97 & $2.341,51$ & 2,27 & $9.412,26$ \\
\hline
\end{tabular}

Fonte: Elaboração própria 
Tabela 13 - Elasticidade própria, Markup e Custo Marginal por segmento para o caso de preço linear

\begin{tabular}{lccccc}
\hline Fabricante & Elasticidade & \multicolumn{2}{c}{ Markup } & \multicolumn{2}{c}{$\mathrm{CM}$} \\
& Própria & $\%$ & $\mathrm{R} \$$ & $\%$ & $\mathrm{R} \$$ \\
\hline \hline Medio + & $-10,2$ & 9,4 & $6.549,08$ & 68,7 & $48.488,10$ \\
& $(1,62)$ & $(1,81)$ & $(1.008,55)$ & $(1,70)$ & $(6.674,73)$ \\
Medio - & $-7,06$ & 13,7 & $5.353,39$ & 64,9 & $27.492,22$ \\
& $(2,08)$ & $(4,07)$ & $(728,22)$ & $(3,66)$ & $(8.223,01)$ \\
MPV & $-9,09$ & 10,1 & $5.447,81$ & 67,9 & $37.354,17$ \\
& $(1,92)$ & $(1,84)$ & $(714,56)$ & $(1,82)$ & $(6.931,42)$ \\
Pequeno & $-6,22$ & 15,4 & $5.152,61$ & 63,5 & $22.653,97$ \\
& $(1,54)$ & $(4,10)$ & $(733,96)$ & $(3,57)$ & $(6.425,92)$ \\
Popular & $-4,29$ & 21,0 & $5.829,11$ & 58,6 & $16.415,70$ \\
& $(0,77)$ & $(3,08)$ & $(659,46)$ & $(2,85)$ & $(2.400,44)$ \\
SUV & $-9,78$ & 9,61 & $5.864,55$ & 67,9 & $43.957,59$ \\
& $(3,09)$ & $(2,84)$ & $(1.118,47)$ & $(2,41)$ & $(10.346,09)$ \\
\hline Total & $-6,50$ & 15,2 & $5.392,22$ & 63,6 & $25.150,66$ \\
& $(2,21)$ & $(4,84)$ & $(845,01)$ & $(4,21)$ & $(10.292,12)$ \\
\hline
\end{tabular}

Nota: Desvio padrão em parênteses

Fonte: Elaboração própria

Tabela 14 - Elasticidade própria, Markup e Custo Marginal por segmento para o caso de preço logarítmico

\begin{tabular}{lccccc}
\hline Fabricante & Elasticidade & \multicolumn{2}{c}{ Markup } & \multicolumn{2}{c}{$\mathrm{CM}$} \\
& Própria & $\%$ & $\mathrm{R} \$$ & $\%$ & $\mathrm{R} \$$ \\
\hline \hline Medio + & $-5,41$ & 16,8 & $11.848,99$ & 61,3 & $43.188,20$ \\
& $(0,63)$ & $(2,08)$ & $(2.025,55)$ & $(2,01)$ & $(5.496,30)$ \\
Medio - & $-6,06$ & 14,4 & $5.966,79$ & 64,2 & $26.878,82$ \\
& $(0,37)$ & $(1,66)$ & $(1.303,53)$ & $(2,21)$ & $(6.775,56)$ \\
MPV & $-6,01$ & 14,5 & $7.991,92$ & 63,5 & $34.810,05$ \\
& $(0,36)$ & $(1,55)$ & $(1.694,70)$ & $(1,61)$ & $(5.615,02)$ \\
Pequeno & $-6,31$ & 14,1 & $4.936,77$ & 64,8 & $22.869,80$ \\
& $(0,23)$ & $(1,79)$ & $(1.067,90)$ & $(1,78)$ & $(5.318,82)$ \\
Popular & $-5,63$ & 15,5 & $4.326,38$ & 64,1 & $17.918,42$ \\
& $(0,51)$ & $(1,47)$ & $(510,14)$ & $(1,77)$ & $(1.921,57)$ \\
SUV & $-5,56$ & 15,3 & $9.736,49$ & 62,2 & $40.085,65$ \\
& $(0,73)$ & $(2,38)$ & $(1.774,69)$ & $(2,07)$ & $(8.752,38)$ \\
\hline Total & $-6,09$ & 14,6 & $5.656,14$ & 64.2 & $24.886,74$ \\
& $(0,48)$ & $(1,91)$ & $(2.200,03)$ & $(2.06)$ & $(8.323,52)$ \\
\hline
\end{tabular}

Nota: Desvio padrão em parênteses

Fonte: Elaboração própria 


\section{Resultado das Simulações e Análise de Bem Estar}

Apresentamos aqui os resultados finais do estudo da simulação de uma política de feebate. Relembrando que estamos num esquema de feebate linear e que queremos a principio torná-lo neutro:

$$
a_{j}=t \times\left(e m i s_{j}-p p\right)
$$

Primeiramente, vamos ver o caso em que consideraremos a regressão da Equação 2.7 com preços lineares e a seguir com preços logarítmicos. Em cada um dos destes apresentaremos:

- Feebate Neutro: O feebate não deve gerar renda tampouco prejuízo ao governo:

$$
R^{\text {feebate }}=\sum_{m=1}^{M} \sum_{j=1}^{J} a_{m j} q_{m j}=0
$$

- Receita do Governo Neutra: A soma do feebate com a receita dos outros impostos não deverá variar com a política:

$$
R^{\text {governo }}=\sum_{m=1}^{M} \sum_{j=1}^{J}\left[a_{m j}+I V A_{m j} p_{m j}\right] q_{m j}=0
$$

- Bem Estar Social Neutro: A mudança no bem estar social como um todo e os ganhos ambientais devem ter soma zero.

Além disto para cada uma das especificações apresentadas mostraremos os resultados para o custo ambiental do $\mathrm{CO}_{2}$ da Tabela 5 a uma taxa de desconto de $3 \%$ tanto para o custo médio quanto para o custo do $95^{\circ}$ percentil. Como já mencionamos a escolha da taxa média de $3 \%$ é uma recomendação da Interagency Working Group on Social Cost of Greenhouse Gases (2016), e adicionalmente calculamos para o 95º , pois apesar de ser um evento pouco provável seu impacto é significativo. Estes valores são equivalentes a $\mathrm{R} \$ 62 \mathrm{e}$ $\mathrm{R} \$ 172$ por tonelada de $\mathrm{CO}_{2}$ liberada para a atmosfera adotando uma cotação de $\mathrm{R} \$ 2,00$ para o dólar, correspondendo a aproximadamente a média de 2010. Portanto, considerando a vida média de um carro equivalente a $250.000 \mathrm{~km}$, o custo ambiental de cada grama de gás carbônico por quilômetro acumulado ao longo de sua vida útil será de $\mathrm{R} \$ 15,50$ para o custo médio e de $\mathrm{R} \$ 43,00$ para o evento de alto impacto ambiental. 


\subsection{Preços Lineares}

Na Tabela 15 apresentamos o resultado resumido para preços lineares, e no Apêndice $\mathrm{F}$ apresentamos de forma completa. Os subtítulo na Tabela 15 mostram cada tipo de busca por neutralidade (Feebate Neutro, Receita do governo Neutra, e Bem Estar Social Neutro). As colunas de Médio dizem respeito aos custos ambientais médios para a emissão de $\mathrm{CO}_{2}$, e a coluna Alto ao alto custo. A coluna Total se refere a mudança total no bem estar juntamente com os custos ambientais, como apresentado na Equação 3.5. A coluna Cons. e Prod. são respectivamente a variação no bem estar do consumidor e produtor e na coluna Gov. apresentamos a variação na receita do governo, incluindo as receitas que compõe o VAT juntamente com o feebate, e apresentamos uma coluna exclusiva apenas com a receita deste último. A coluna Vendas da Tabela 15 mostra a variação nas vendas, e na Tabela 16 e Tabela 33 apresentamos a variação em cada segmento. As colunas Aliq. e Pivot são os valores da relação alíquota x pivot que tornam o imposto projetado neutro para cada caso que estamos estudando.

Nas Tabela 15 e Tabela 27 (pg. 85) mostramos o caso mais simples: apenas o feebate neutro. Note que o pivot encontrado para uma alíquota de 0,5 foi de $162,1 \mathrm{~g} / \mathrm{km}$, que é próximo da média de emissões de $\mathrm{CO}_{2}$ ponderada pela venda de cada modelo que foi de $162,2 \mathrm{~g} / \mathrm{km}$, o que era esperado, já que o imposto é simétrico e uma pequena variação da alíquota não deve influenciar significativamente nos preços e shares dos mercados.

Tabela 15 - Alterações pela implementação do feebate - Resumo - Preço linear

\begin{tabular}{|c|c|c|c|c|c|c|c|c|c|c|}
\hline \multirow[b]{2}{*}{ Aliq. } & \multirow[b]{2}{*}{ Pivot } & \multirow[b]{2}{*}{ Vendas } & \multirow[b]{2}{*}{ Feebate } & \multirow[b]{2}{*}{ Gov. } & \multirow[b]{2}{*}{ Cons. } & \multirow[b]{2}{*}{ Prod. } & \multicolumn{2}{|c|}{ Médio } & \multicolumn{2}{|c|}{ Alto } \\
\hline & & & & & & & Amb. & Total & Amb. & Total \\
\hline \multicolumn{11}{|c|}{ Feebate Neutro } \\
\hline 0,5 & 162,1 & $\begin{array}{c}0,00 \\
(0,00)\end{array}$ & $-0,00$ & $\begin{array}{c}-2,1 \\
(-0,02)\end{array}$ & $\begin{array}{c}-0,2 \\
(-0,00)\end{array}$ & $\begin{array}{c}0,2 \\
(0,00)\end{array}$ & $\begin{array}{c}0,5 \\
(0,02)\end{array}$ & $\begin{array}{c}-1,6 \\
(-0,01)\end{array}$ & $\begin{array}{c}1,4 \\
(0,02)\end{array}$ & $\begin{array}{c}-0,7 \\
(-0,00)\end{array}$ \\
\hline 20 & 160,6 & $\begin{array}{c}-0,6 \\
(-0,1)\end{array}$ & 0,00 & $\begin{array}{l}-90,9 \\
(-1,0)\end{array}$ & $\begin{array}{l}-18,6 \\
(-0,3)\end{array}$ & $\begin{array}{c}4,5 \\
(0,1)\end{array}$ & $\begin{array}{l}22,5 \\
(1,1)\end{array}$ & $\begin{array}{l}-82,5 \\
(-0,4)\end{array}$ & $\begin{array}{l}62,3 \\
(1,1)\end{array}$ & $\begin{array}{l}-42,6 \\
(-0,2)\end{array}$ \\
\hline 40 & 158,9 & $\begin{array}{l}-2,9 \\
(-0,4)\end{array}$ & 0,00 & $\begin{array}{c}-194,9 \\
(-2,2)\end{array}$ & $\begin{array}{l}-61,3 \\
(-1,1)\end{array}$ & $\begin{array}{c}2,8 \\
(0,1)\end{array}$ & $\begin{array}{l}49,9 \\
(2,3)\end{array}$ & $\begin{array}{c}-203,5 \\
(-1,1)\end{array}$ & $\begin{array}{l}138,4 \\
(2,3)\end{array}$ & $\begin{array}{r}-115,0 \\
(-0,6)\end{array}$ \\
\hline 60 & 157,2 & $\begin{array}{c}-7,1 \\
(-0,8) \\
\end{array}$ & 0,00 & $\begin{array}{c}-313,3 \\
(-3,5) \\
\end{array}$ & $\begin{array}{c}-129,8 \\
(-2,4)\end{array}$ & $\begin{array}{c}-5,5 \\
(-0,1) \\
\end{array}$ & $\begin{array}{l}82,6 \\
(3,9) \\
\end{array}$ & $\begin{array}{c}-366,1 \\
(-1,9) \\
\end{array}$ & $\begin{array}{c}229,0 \\
(3,9)\end{array}$ & $\begin{array}{r}-219,6 \\
(-1,2)\end{array}$ \\
\hline \multicolumn{11}{|c|}{ Receita do Governo Neutra } \\
\hline 20 & 152,8 & $\begin{array}{c}-7,7 \\
(-0,9)\end{array}$ & 130,4 & $\begin{array}{c}0,00 \\
(0,00)\end{array}$ & $\begin{array}{c}-122,0 \\
(-2,2)\end{array}$ & $\begin{array}{l}-35,1 \\
(-0,8)\end{array}$ & $\begin{array}{l}40,0 \\
(1,9)\end{array}$ & $\begin{array}{c}-117,0 \\
(-0,6)\end{array}$ & $\begin{array}{l}111,1 \\
(1,9)\end{array}$ & $\begin{array}{l}-46,0 \\
(-0,2)\end{array}$ \\
\hline 40 & 150,4 & $\begin{array}{l}-18,4 \\
(-2,2)\end{array}$ & 280,6 & $\begin{array}{c}0,00 \\
(0,00)\end{array}$ & $\begin{array}{c}-283,4 \\
(-5,2)\end{array}$ & $\begin{array}{l}-83,7 \\
(-1,8)\end{array}$ & $\begin{array}{l}87,8 \\
(4,1)\end{array}$ & $\begin{array}{c}-279,3 \\
(-1,5)\end{array}$ & $\begin{array}{c}243,5 \\
(4,1)\end{array}$ & $\begin{array}{c}-123,5 \\
(-0,7)\end{array}$ \\
\hline 60 & 147,8 & $\begin{array}{l}-32,4 \\
(-3,8)\end{array}$ & 453,7 & $\begin{array}{c}0,00 \\
(0,00)\end{array}$ & $\begin{array}{c}-488,1 \\
(-8,9)\end{array}$ & $\begin{array}{c}-147,9 \\
(-3,3)\end{array}$ & $\begin{array}{l}144,1 \\
(6,5)\end{array}$ & $\begin{array}{c}-492,0 \\
(-2,6)\end{array}$ & $\begin{array}{l}399,7 \\
(6,5)\end{array}$ & $\begin{array}{c}-236,3 \\
(-1,2)\end{array}$ \\
\hline
\end{tabular}

Nota 1: Vendas em milhares de unidades, outras variações em milhões de reais Nota 2: Percentuais entre parêntese

Fonte: Elaboração própria

Adicionamos a coluna Feebate para evidenciar que buscamos a neutralidade do imposto, o que não significa que o governo tanto na esfera federal quanto na estadual não sofrerão mudanças em suas receitas, muito pelo contrário, ao observarmos a coluna Gov. 
Tabela 16 - Variação percentual nas vendas por segmento - Preço linear

\begin{tabular}{|c|c|c|c|c|c|c|c|}
\hline \multirow[b]{2}{*}{ Aliq. } & \multirow[b]{2}{*}{ Pivot } & \multicolumn{6}{|c|}{ Segmento } \\
\hline & & Médio - & Médio + & MPV & Pequeno & Popular & SUV \\
\hline \multicolumn{8}{|c|}{ Feebate Neutro } \\
\hline 0,5 & 162,1 & $-0,1$ & $-0,1$ & $-0,1$ & $-0,01$ & 0,2 & $-0,1$ \\
\hline 20 & 160,6 & $-2,4$ & $-2,7$ & $-5,5$ & $-0,5$ & 7,4 & $-4,8$ \\
\hline 40 & 158,9 & $-4,9$ & $-5,7$ & $-11,0$ & $-1,3$ & 15,0 & $-9,6$ \\
\hline 60 & 157,2 & $-7,5$ & $-9,1$ & $-16,4$ & $-2,5$ & 22,7 & $-14,3$ \\
\hline \multicolumn{8}{|c|}{ Receita do Governo Neutra } \\
\hline 20 & 152,8 & $-3,3$ & $-3,5$ & $-6,3$ & $-1,3$ & 6,4 & $-5,6$ \\
\hline 40 & 150,4 & $-6,7$ & $-7,4$ & $-12,6$ & $-3,1$ & 12,8 & $-11,2$ \\
\hline 60 & 147,8 & $-10,3$ & $-11,8$ & $-18,9$ & $-5,5$ & 18,9 & $-16,9$ \\
\hline
\end{tabular}

Nota: Variação em porcentagem

Fonte: Elaboração própria

vemos que esta cai conforme aumentamos a alíquota. Isto ocorre pois os veículos com maior cilindradas são geralmente os que emitem maiores poluentes e são também os que tem alíquota de IPI maior impactando mais significativamente na receita do governo. Pela Tabela 16 verificamos que as maiores quedas nas vendas são $M P V$ e $S U V$, os veículos de maior cilindrada. Por outro lado o segmento popular, que apresenta a menor cilindrada, potência e emissão, seria o maior beneficiado, como o esperado.

Observe também que o pivot para manter o feebate neutro cai conforme aumentamos a alíquota, pois, os shares dos veículos mais poluentes se reduzirão enquanto que o dos menos poluentes aumentarão, o que fará com que a média ponderada de emissão diminua. Nesse sentido, a mudança sobre as vendas não é tão evidente, já que, embora haja diminuição dos veículos que pagam o feebate existem também o aumento daqueles que recebem o subsídio. Entretanto, pelos mesmos argumentos que fizemos acerca do pivot, que deve se menor para uma alíquota maior, e, então mais modelos serão taxados o que fará com que no total as vendas caiam conforme aumentamos a alíquota, o que de fato é visto na coluna Vendas.

Na coluna Cons. vemos que o excedente do consumidor tende a diminuir e isto acontece pela diminuição das vendas de veículos de maior cilindrada que tem preços maiores. Já na coluna Prod. o excedente do produtor aumenta atingindo o máximo por volta de uma alíquota de $R \$ 20$ por grama $/ \mathrm{km}$ e reduzindo entre $\mathrm{R} \$ 40$ e $\mathrm{R} \$ 60$, pois, como no caso linear os markups para as classes do aninhamento são próximos e as elasticidades dos veículos mais baratos é menor, uma redução nas vendas dos veículos que pagam o feebate acaba sendo compensada pelo aumento nas vendas de veículos com subsídio um pouco mais que proporcionalmente. Este fenômeno acaba sendo superado pela redução das vendas ao reduzirmos o pivot ao aumentarmos a alíquota, o que explica a redução 
subsequente nos ganhos das firmas.

Com relação aos ganhos ambientais (coluna $A m b$.), observe que parte da redução se deve ao encolhimento nas vendas, e então, o efeito do ganho ambiental pelo incentivo a compra de veículos menos poluentes é inferior ao que aparece na Tabela 15, Tabela 27 e Tabela 28, além, é claro, do já mencionado efeito rebote, pois ao se subsidiar a venda de um carro menos poluente o indivíduo que não compraria um carro pode agora fazê-lo deixando de usar transporte público, ou bicicleta ou outros meios menos ou não poluentes. Também no efeito rebote temos os indivíduos que usarão o bônus no gasto com combustível, mas este efeito é menor já que assumimos o gasto total ao longo da vida dos veículos.

Infelizmente, repare que nenhuma combinação 'pivot x alíquota' é capaz de fazer com que a mudança no bem estar total (coluna Total), que inclui os excedentes dos consumidores e produtores mais as receitas dos governos mais o ganho ambiental, seja positivo. Ou seja, os ganhos ambientais serão sempre menores do que a perda social, e isto também é verdadeiro para o caso do custo do carbono para um alto impacto ambiental apresentado na Tabela 28. Isto também foi encontrado por Adamou, Clerides e Zachariadis (2014) e Greene et al. (2005), sendo que os autores afirmam que para pequenas alíquotas o bem estar tende a aumentar, o que não observamos em nossas simulações do mercado nacional.

Mas ao considerar que o consumidor tenha uma alternativa de carro independente de satisfazê-lo completamente e que podemos observar tal fato nas mudanças das vendas ao invés do próprio excedente do consumidor, verifica-se que as quedas nas vendas são percentualmente menores do que o ganho ambiental. Como já mencionado, com uma alíquota em torno de $\mathrm{R} \$ 50$ não haverá mudanças significativas para o produtor, sugerindo que até este valor poderia ser implantado o feebate. Por outro lado o prejuízo que o governo teria é maior do que este ganho ambiental tanto para um impacto médio (Tabela 27), quanto para um alto impacto (Tabela 28), e portanto, mesmo assim, o torna inviável.

O esquema apresentado acima nos leva a uma outra estratégia para o feebate: ao invés de tornar o feebate neutro, podemos fazer com que a receita do governo seja neutra, ou de outra forma, a soma do IVA e do feebate tenha soma zero, o qual apresentamos na segunda parte da Tabela 15 e com mais detalhes na Tabela 29 e na Tabela 30 (páginas 87 e 88). Neste caso o produtor sempre apresenta decréscimo ao aumentar a alíquota e a variação no excedente do consumidor é muito menor do que no caso anterior, o esperado, já que o governo está repassando o prejuízo que teria para os dois últimos ao fazer com que o pivot seja menor, e então, um maior número de modelos passa a ser taxado. Veja que o ganho ambiental é maior do que nos casos anteriores, mas desta vez a maior parte deste ganho provém da redução nas vendas.

Numa outra tentativa de simulação fizemos com que o bem estar social fosse neutro ao implantar o feebate, não apresentamos na Tabela 15 por não ser um resultado 
interessante, mas são apresentados na Tabela 31 e Tabela 32 (página 89). As tabelas não apresentam o mesmo número de simulações, o que foi causado pela não convergência do preço e share nos mercados para grandes alíquotas. Neste caso os ganhos ambientais sempre são negativos como também as receitas do governo, e as variações nas vendas, nos excedentes do consumidor e produtor sempre são positivas, significando que as simulações reduziram o IVA agregado através do feebate ao aumentar o pivot aumentando os modelos que recebem o subsídio e assim, por um lado reduzindo o peso morto causado pelos impostos, e por outro lado, subsidiando parte do carro. Portanto com estas últimas simulações para o caso de preço linear verificamos que um esquema assim é inviável e nunca reduzirá o impacto ambiental e simultaneamente manter, pelo menos, a perda social nula.

\subsection{Preços Logarítmicos}

Os preços com uma transformação logarítmica implicarão, como já vimos, em elasticidades mais parecidas entre os modelos. Com isto o efeito de uma mudança nos preços será percentualmente maior para carros mais barato, além disto teremos markups proporcionais aos preços fazendo com que modelos mais caros tenham impacto maior no excedente do produtor.

Apresentamos na Tabela 17 os resultados resumido das simulações restantes para o feebate, e mostramos na Tabela 34 e na Tabela 35 o resultado completo de uma política para manter o feebate neutro sem que isto signifique manter a receita total do governo neutra. Notoriamente, podemos ver que as vendas aumentam conforme aumentamos a alíquota atingindo um máximo próximo de uma alíquota de $\mathrm{R} \$ 40$ e zerando entre $\mathrm{R} \$ 60$ e $\mathrm{R} \$ 80$. Isto ocorre pois, como a alíquota é simétrica e geralmente os veículos menos poluentes são mais baratos, acabam recebendo um subsídio maior relativamente ao seu preço aumentando-se mais suas vendas do que a redução dos veículos mais caros. E, conforme o pivot diminui para manter o feebate neutro mais modelos passam a ser taxados, e o subsídio diminui para os restantes, reduzindo no geral as vendas. Apresentamos na Tabela 18 e Tabela 40 a variação em cada segmento, e podemos observar que tal como no caso linear o segmento que mais se beneficia é o Popular, no entanto, com um aumento bem mais acentuado já que aqui temos maiores elasticidades para este segmento como vimos nas Tabela 13 e Tabela 14 .

Quanto ao pivot, note que este cai mais conforme aumentamos a alíquota quando comparado ao caso linear, porque lá as elasticidades para os veículos de menor valor eram menores, não alterando significativamente as vendas para esta classe. Aqui, como as elasticidades são maiores, o subsídio dado faz com que as vendas aumentem proporcionalmente mais, necessitando de um pivot menor para manter o feebate neutro. 
Tabela 17 - Alterações pela implementação do feebate - Resumo - Preço logarítmico

\begin{tabular}{|c|c|c|c|c|c|c|c|c|c|c|}
\hline \multirow[b]{2}{*}{ Aliq. } & \multirow[b]{2}{*}{ Pivot } & \multirow[b]{2}{*}{ Vendas } & \multirow[b]{2}{*}{ Feebate } & \multirow[b]{2}{*}{ Gov. } & \multirow[b]{2}{*}{ Consum. } & \multirow[b]{2}{*}{ Prod. } & \multicolumn{2}{|c|}{ Médio } & \multicolumn{2}{|c|}{ Alto } \\
\hline & & & & & & & Amb. & Total & Amb. & Total \\
\hline \multicolumn{11}{|c|}{ Feebate Neutro } \\
\hline 20 & 160,0 & $\begin{array}{c}3,9 \\
(0,5)\end{array}$ & 0,00 & $\begin{array}{l}-61,8 \\
(-0,7)\end{array}$ & $\begin{array}{l}-13,1 \\
(-0,2)\end{array}$ & $\begin{array}{l}-21,2 \\
(-0,4)\end{array}$ & $\begin{array}{l}19,1 \\
(0,9)\end{array}$ & $\begin{array}{l}-77,1 \\
(-0,4)\end{array}$ & $\begin{array}{l}53,0 \\
(0,9)\end{array}$ & $\begin{array}{l}-43,2 \\
(-0,2)\end{array}$ \\
\hline 40 & 157,5 & $\begin{array}{c}5,4 \\
(0,6)\end{array}$ & 0,00 & $\begin{array}{r}-147,7 \\
(-1,7)\end{array}$ & $\begin{array}{c}-61,4 \\
(-1,2)\end{array}$ & $\begin{array}{l}-51,7 \\
(-1,1)\end{array}$ & $\begin{array}{l}47,9 \\
(2,3)\end{array}$ & $\begin{array}{c}-212,9 \\
(-1,1)\end{array}$ & $\begin{array}{l}132,9 \\
(2,3)\end{array}$ & $\begin{array}{c}-127,9 \\
(-0,7)\end{array}$ \\
\hline 60 & 154,8 & $\begin{array}{c}3,7 \\
(0,4)\end{array}$ & 0,00 & $\begin{array}{c}-261,1 \\
(-2,9)\end{array}$ & $\begin{array}{c}-151,4 \\
(-2,8)\end{array}$ & $\begin{array}{l}-91,7 \\
(-1,9)\end{array}$ & $\begin{array}{l}87,4 \\
(4,2)\end{array}$ & $\begin{array}{r}-416,7 \\
(-2,2)\end{array}$ & $\begin{array}{c}242,6 \\
(4,2)\end{array}$ & $\begin{array}{r}-261,6 \\
(-1,4)\end{array}$ \\
\hline 80 & 151,9 & $\begin{array}{c}-1,6 \\
(-0,2)\end{array}$ & 0,00 & $\begin{array}{c}-403,6 \\
(-4,5)\end{array}$ & $\begin{array}{c}-286,3 \\
(-5,4)\end{array}$ & $\begin{array}{c}-141,1 \\
(-3,0)\end{array}$ & $\begin{array}{l}137,8 \\
(6,5)\end{array}$ & $\begin{array}{c}-693,2 \\
(-3,6)\end{array}$ & $\begin{array}{c}382,4 \\
(6,5)\end{array}$ & $\begin{array}{c}-448,6 \\
(-2,4)\end{array}$ \\
\hline \multicolumn{11}{|c|}{ Receita do Governo Neutra } \\
\hline 40 & 151,6 & $\begin{array}{c}-9,9 \\
(-1,2)\end{array}$ & 203,5 & 0,00 & $\begin{array}{c}-213,5 \\
(-4,0)\end{array}$ & $\begin{array}{l}-89,8 \\
(-1,9)\end{array}$ & $\begin{array}{l}82,6 \\
(3,9)\end{array}$ & $\begin{array}{c}-220,8 \\
(-1,2)\end{array}$ & $\begin{array}{c}229,0 \\
(3,9)\end{array}$ & $\begin{array}{l}-74,3 \\
(-0,4)\end{array}$ \\
\hline 60 & 147,9 & $\begin{array}{l}-23,1 \\
(-2,7)\end{array}$ & 356,7 & 0,00 & $\begin{array}{c}-412,0 \\
(-7,7)\end{array}$ & $\begin{array}{r}-158,6 \\
(-3,3)\end{array}$ & $\begin{array}{l}146,5 \\
(6,7)\end{array}$ & $\begin{array}{c}-424,1 \\
(-2,2)\end{array}$ & $\begin{array}{l}406,5 \\
(6,7)\end{array}$ & $\begin{array}{r}-164,1 \\
(-0,9)\end{array}$ \\
\hline 80 & 144,1 & $\begin{array}{l}-42,9 \\
(-5,1)\end{array}$ & 548,1 & 0,00 & $\begin{array}{l}-675,2 \\
(-12,7)\end{array}$ & $\begin{array}{c}-245,3 \\
(-5,2)\end{array}$ & $\begin{array}{l}226,0 \\
(10,1)\end{array}$ & $\begin{array}{c}-694,5 \\
(-3,7)\end{array}$ & $\begin{array}{l}627,0 \\
(10,1)\end{array}$ & $\begin{array}{c}-293,5 \\
(-1,5)\end{array}$ \\
\hline \multicolumn{11}{|c|}{ Bem Estar Neutro } \\
\hline 0,5 & 156,0 & $\begin{array}{c}-0,1 \\
(-0,01)\end{array}$ & 2,6 & $\begin{array}{c}0,6 \\
(0,01)\end{array}$ & $\begin{array}{c}-1,9 \\
(-0,04)\end{array}$ & $\begin{array}{c}-0,9 \\
(-0,02)\end{array}$ & - & - & $\begin{array}{c}2,3 \\
(0,04)\end{array}$ & $\begin{array}{c}0,00 \\
(0)\end{array}$ \\
\hline 1 & 155,8 & $-0,1$ & 5,3 & 1,2 & $-4,0$ & $-1,9$ & - & - & 4,7 & 0,00 \\
\hline & & $(-0,02)$ & & $(0,01)$ & $(-0,1)$ & $(-0,04)$ & - & - & $(0,1)$ & (0) \\
\hline 5 & 154,6 & $-1,0$ & 29,6 & 7,7 & $-23,0$ & $-10,1$ & - & - & 25,5 & 0,00 \\
\hline & & $(-0,1)$ & & $(0,1)$ & $(-0,4)$ & $(-0,2)$ & - & - & $(0,4)$ & (0) \\
\hline 10 & 153,1 & $-2,8$ & 67,9 & 20,3 & $-54,5$ & $-22,4$ & - & - & 56,6 & 0,00 \\
\hline & & $(-0,3)$ & & $(0,2)$ & $(-1,0)$ & $(-0,5)$ & - & - & $(1,0)$ & (0) \\
\hline 20 & 149,7 & $-9,0$ & 172,9 & 61,8 & $-144,6$ & $-54,2$ & - & - & 137,0 & 0,00 \\
\hline 40 & 141,8 & $\begin{array}{l}(-1,1) \\
-34,5\end{array}$ & 523,3 & $\begin{array}{l}(0,7) \\
224,7\end{array}$ & $\begin{array}{r}(-2,7) \\
-456,0\end{array}$ & $\begin{array}{l}(-1,1) \\
-153,7\end{array}$ & $\begin{array}{l}- \\
-\end{array}$ & - & $\begin{array}{l}(2,3) \\
385,0\end{array}$ & $\begin{array}{l}\text { (U) } \\
0,00\end{array}$ \\
\hline & & $(-4,1)$ & & $(2,5)$ & $(-8,5)$ & $(-3,2)$ & - & - & $(6,3)$ & $(0)$ \\
\hline
\end{tabular}

Nota 1: Vendas em milhares de unidades, outras variações em milhões de reais

Nota 2: Percentuais em parêntese

Nota 3: Os '-' mostram que não houve convergência

Fonte: Elaboração própria

É possível ver que tanto no caso de médio impacto quanto no de alto impacto a variação no bem estar social total é sempre negativa, evidenciando que o feebate em nenhuma combinação 'alíquota x pivot' seja socialmente benéfico. Contanto, ao se considerar que há um aumento de vendas para algumas alíquotas e que o excedente do consumidor cai por causa das venda de veículos mais caros, supomos que uma maior parcela do mercado acaba sendo atendida com um veículo mais barato. E levando-se em conta que queremos incentivar veículo menos poluentes e ao mesmo tempo buscar uma solução que beneficie a todos, a faixa da alíquota de $\mathrm{R} \$ 20$, parece interessante neste sentido, a não ser pela redução da receita do governo e excedente do produtor que acabam pagando pelo benefício ambiental.

Ao tentarmos fazer com que o governo tenha variação de receita neutra (segunda parte da Tabela 17, Tabela 36 e Tabela 37), verificamos que em nenhum caso existe uma relação entre alíquota e pivot que torne o imposto socialmente benéfico. E assim como no caso linear, os pivots tendem a ser menores do que com o feebate neutro e pelos mesmos motivos já explicitados. Por este mesmo fato as vendas não terão variação positiva. 
Tabela 18 - Variação percentual nas vendas por segmento - Preço logarítmico

\begin{tabular}{lccccccc}
\hline \multicolumn{7}{c}{ Segmento } \\
Aliq. & Pivot & Médio - & Médio + & MPV & Pequeno & Popular & SUV \\
\hline \hline \multicolumn{7}{l}{ Feebate Neutro } \\
20 & 160,0 & $-3,2$ & $-2,3$ & $-5,3$ & $-1,0$ & 13,4 & $-3,8$ \\
40 & 157,5 & $-6,8$ & $-4,8$ & $-10,8$ & $-2,8$ & 28,4 & $-7,8$ \\
60 & 154,8 & $-10,6$ & $-7,8$ & $-16,2$ & $-5,4$ & 44,8 & $-12,0$ \\
80 & 151,9 & $-14,6$ & $-11,0$ & $-21,8$ & $-8,9$ & 62,2 & $-16,4$ \\
\hline \multicolumn{7}{l}{ Receita do Governo Neutra } \\
40 & 151,6 & $-8,0$ & $-4,9$ & $-11,3$ & $-4,5$ & 24,6 & $-8,1$ \\
60 & 147,9 & $-12,6$ & $-7,9$ & $-17,0$ & $-8,4$ & 37,1 & $-12,4$ \\
80 & 144,1 & $-17,4$ & $-11,2$ & $-22,8$ & $-13,2$ & 48,8 & $-16,9$ \\
\hline Bem & estar Social Neutro - Alto Impacto & & & \\
0,5 & 156,0 & $-0,1$ & $-0,1$ & $-0,1$ & $-0,04$ & 0,3 & $-0,1$ \\
1 & 155,8 & $-0,2$ & $-0,1$ & $-0,3$ & $-0,1$ & 0,6 & $-0,2$ \\
5 & 154,6 & $-1,0$ & $-0,6$ & $-1,4$ & $-0,5$ & 2,8 & $-1,0$ \\
10 & 153,1 & $-2,1$ & $-1,1$ & $-2,9$ & $-1,0$ & 5,5 & $-2,0$ \\
20 & 149,7 & $-4,4$ & $-2,4$ & $-5,9$ & $-2,6$ & 10,6 & $-4,1$ \\
40 & 141,8 & $-10,1$ & $-5,2$ & $-12,2$ & $-7,4$ & 18,5 & $-8,6$ \\
\hline
\end{tabular}

Nota: Variação em porcentagem

Fonte: Elaboração própria

Evidenciando assim que ao manter a receita neutra, ora taxando, ou ora subsidiando, aumentamos o peso morto causado por este novo imposto, e que o ganho ambiental não é significativo para justificá-lo, tanto para um cenário de médio impacto quanto para o de alto impacto.

A seguir na terceira parte da Tabela 17, Tabela 38 e Tabela 39 (página 95) apresentamos a busca para uma mudança no bem estar social neutra. E, nestas simulações, encontramos para um impacto alto relações de alíquota e pivot que apresentam um ganho ambiental e mantém o bem estar social neutro, mas ao custo de se reduzir o excedente do consumidor e firmas. Note que aqui também parte da redução é devida pela redução nas vendas, contudo, ainda assim o ganho ambiental é maior percentualmente. Para o caso de médio impacto (Tabela 38) houve apenas perdas ambientais, o mesmo que o citado no caso linear, e não havendo convergência para praticamente todas as alíquotas.

Apesar de termos encontrado pontos que tornam o impacto social neutro, este foi para um alto impacto ambiental correspondente ao preço de $\mathrm{R} \$ 86$ por tonelada de carbono, sendo que o Interagency Working Group on Social Cost of Greenhouse Gases (2016) considera este custo como pouco provável. Assim, só seria absolutamente justificável o emprego de tal tributo num cenário onde as previsões sobre os impactos ambientais sejam muito pessimistas. 



\section{Conclusão}

Em nosso estudo do feebate encontramos alguns cenários no qual talvez fosse possível implantá-lo. Primeiramente com prejuízo para o governo e firmas mas com uma baixa redução nas vendas caso se aplique uma alíquota entre $\mathrm{R} \$ 40$ e $\mathrm{R} \$ 60$ com o pivot entre $159 \mathrm{~g} / \mathrm{km}$ e $155 \mathrm{~g} / \mathrm{km}$ para tentar manter o feebate neutro. Neste caso a mudança no bem estar social incluído os custos ambientais sempre é nula, mas nesta região poderia haver ganhos ambientais e um aumento nas vendas ou um aumento no excedente das firmas, minimizando assim possíveis impactos negativos.

Não logramos exito quando tentamos manter as receitas do governo neutras e obter de alguma forma algum ganho ambiental-social. O principal motivo que apontamos é o custo de emissão de $\mathrm{CO}_{2}$. Adamou, Clerides e Zachariadis (2014) concluem em seu trabalho que os custos de emissão que compensariam este esquema seriam de 1,5 a 2 vezes maior do que o custo utilizados por eles que foi de $€ 15$ (a preços de 2005). Encontramos valores muito acima destes para o mercado brasileiro em torno de 2 a 4 vezes o valor de médio impacto ambiental (US\$31) o que excede até mesmo a possibilidade de alto impacto (US\$86). Huse e Lucinda (2014) encontram um valor de US\$109/ton para o custo do $\mathrm{CO}_{2}$ no mercado sueco num esquema de desconto na compra, portanto próximo do que encontramos.

Ao tentar manter o bem estar social neutro, apenas o caso de alto impacto ambiental apresentou convergência na solução, mostrando ser possível conciliar a relação ambientesociedade, embora a um alto custo de $\mathrm{CO}_{2}$. Os valores possíveis se situam entre uma alíquota de $\mathrm{R} \$ 0$ a $\mathrm{R} \$ 40$ com o pivot entre $156 \mathrm{~g} / \mathrm{km}$ e $142 \mathrm{~g} / \mathrm{km}$. Neste caso além dos consumidores e das firmas pagarem pelo impacto ambiental, pagam ainda uma receita extra para o governo. Além do exposto, temos que considerar que parte da redução nos custos ambientais foi causada pela redução nas vendas totais. Para uma alíquota de $\mathrm{R} \$ 20$ há um benefício ambiental de 2,3\% para uma redução do excedente do consumidor e produtor de $2,7 \%$ e $1,1 \%$ respectivamente, e um ganho de receita para o governo de $0,7 \%$.

No geral os ganhos ambientais são modestos quando comparados às outras perdas, e isto usando o custo para um alto impacto ambiental. Acreditamos que, talvez, o verdadeiro valor do feebate resida muito mais no poder de estimular um comportamento altruísta do consumidor na escolha de veículos menos poluentes, do que incentivar ou punir via preços. Quanto a isto seria difícil avaliar já que no Brasil não há o uso obrigatório de um selo de eficiência, há apenas um selo opcional do CONPET de excelência, e desta forma, talvez seja uma boa estratégia a adição de um adesivo nos veículos a venda mostrando quanto o consumidor esteja economizando e diminuindo em impactos ambientais concomitantemente 
com a implantação de um feebate, mas, estudos precisam ser realizados nesse sentido.

Além disto desconsideramos o incentivo ao desenvolvimento de novas tecnologias, que pode ter efeito bastante relevante conforme já citado por Greene et al. (2005) mas desde que o desenvolvimento seja direcionado no aumento da eficiência energética e não no aumento de potência. E também não levamos em consideração os custos causados pela dependência do petróleo, os quais não são desprezíveis, chegando a ser o dobro do custo do aquecimento global no caso dos Estados Unidos (Tabela 2), assim, se considerarmos nesta mesma proporção para o Brasil, os custos de médio impacto seriam muito próximos dos obtidos com os de alto impacto, e portanto, no curto prazo o feebate seria uma alternativa viável.

Não podemos esquecer que a maioria dos países tributa veículos de acordo com a cilindrada, como apresentamos na TIBI (Tabela 4), que é uma forma implícita de um feebate, já que como mencionado várias vezes neste trabalho a cilindrada mantem forte correlação com a emissão de gases poluentes. Mas isto é implementado muito mais como uma desoneração a veículos populares, e em especial no caso brasileiro com o uso do álcool para promover combustíveis alternativos para reduzir a dependência do petróleo, do que para incentivar veículos mais verdes. E assim o feebate seria uma forma de promover explicitamente a intenção de reduzir emissões.

Por fim, o presente trabalho explorou um tipo de política pouco estudada na literatura nacional, e embora no atual momento não exista um ganho evidente, talvez, no futuro com a ampliação de modelos disponíveis de carros híbridos e elétricos, o cenário para a aplicação deste tipo de imposto pode mudar, e assim acreditamos que esta dissertação possa servir de base de comparação para próximos estudos. 


\section{Referências}

ADAMOU, A.; CLERIDES, S.; ZACHARIADIS, T. Welfare implications of car feebates: A simulation analysis. Economic Journal, v. 124, n. 578, p. 420-443, 2014. ISSN 14680297. Citado 4 vezes nas páginas 15, 26, 60 e 65 .

ANDERSON, S.; SALLEE, J. Designing Policies to Make Cars Greener: A Review of the Literature. Cambridge, MA, 2016. 1-26 p. Disponível em: <http: //arxiv.org/abs/1406.3533http://www.nber.org/papers/w22242.pdf>. Citado 2 vezes nas páginas 15 e 21.

ANDERSON, S. T. et al. Automobile fuel economy standards: Impacts, efficiency, and alternatives. Review of Environmental Economics and Policy, v. 5, n. 1, p. 89-108, 2011. ISSN 17506816. Disponível em: <https://are.berkeley.edu/\{ $\}$ sallee/apsf-reep.p $>$. Citado na página 25.

BERRY, S. T. Estimating Discrete-Choice Models of Product Differentiation. The RAND Journal of Economics, v. 25, n. 2, p. 242-262, 1994. ISSN 0741-6261. Disponível em: <http://www.jstor.org/stable/2555829>. Citado na página 29.

BERRY, S. T.; LEVINSOHN, J.; PAKES, A. Automobile Prices in Market Equilibrium. Econometrica, v. 63, n. 4, p. 841-890, 1995. ISSN 00129682. Disponível em: <http://www.jstor.org/stable/2171802http://www.jstor.org/stable/pdfplus/2171802. pdf?acceptTC=true $>$. Citado 2 vezes nas páginas 29 e 32.

BOARD, T. R.; COUNCIL, N. R. Effectiveness and Impact of Corporate Average Fuel Economy (CAFE) Standards. Washington, DC: The National Academies Press, 2002. ISBN 978-0-309-07601-2. Disponível em: <https://www.nap.edu/catalog/10172/ effectiveness-and-impact-of-corporate-average-fuel-economy-cafe-standards $>$. Citado na página 23.

COMMON, M. William d. nordhaus and joseph boyer, warming the world: Economic models of global warming. mit press, cambridge mass., 2000. isbn 0262140713.

Environment and Development Economics, v. 7, n. 03, p. 593-601, 2002. Disponível em: <http://EconPapers.repec.org/RePEc:cup:endeec:v:7:y:2002:i:03:p:593-601_24>. Citado na página 18.

DELUCCHI, M. A.; MURPHY, J. J. US military expenditures to protect the use of Persian Gulf oil for motor vehicles. Energy Policy, v. 36, n. 6, p. 2253-2264, 2008. ISSN 03014215. Citado na página 19.

DNIT. Quadro 0101 - No DE ACIDENTES POR GRAVIDADE. 2011. Disponível em: <http://www.dnit.gov.br/rodovias/operacoes-rodoviarias/estatisticas-de-acidentes $>$. Citado na página 19.

FERREIRA, L. M. S. Análises de bem estar da variação do IPI sobre automóveis novos : uma abordagem de apreçamento hedônico em escolha discreta. Dissertação (Mestrado), 2017. Citado na página 40. 
FIUZA, E. P. S. AUTOMOBILE DEMAND AND SUPPLY IN BRAZIL : EFFECTS OF TAX REBATES AND TRADE LIBERALIZATION ON PRICE-MARGINAL COST MARKUPS IN THE 1990s *. 2002. Citado na página 54.

GFEI. Fuel Eonomy State of the World 2016; Time for global action. p. 65p, 2016. Disponível em: < https://www.globalfueleconomy.org/media/203446/ gfei-state-of-the-world-report-2016.pdf $>$. Citado na página 26.

GILLEN, B. J.; SHUM, M.; MOON, H. R. Demand Estimation with High-Dimensional Product Characteristics. In: Bayesian Model Comparison, Advances in Econometrics vol 34. [s.n.], 2014. p. 301-323. Disponível em: <http://www.emeraldinsight.com/doi/abs/10. 1108/S0731-905320140000034020>. Citado na página 33.

GREENE, D. L. et al. Feebates, rebates and gas-guzzler taxes: A study of incentives for increased fuel economy. Energy Policy, v. 33, n. 6, p. 757-775, 2005. ISSN 03014215. Disponível em: <http://www.cta.ornl.gov/cta/Publications/Reports/ FeebateEnergyPolicy $\left\{\backslash \_\right\} F I N A L .>$ Citado 6 vezes nas páginas 15, 16, 25, 27, 60 e 66 .

HASTIE, T.; TIBSHIRANI, R.; FRIEDMAN, J. The Elements of Statistical Learning. [s.n.], 2009. v. 18. 746 p. ISSN 00111287. ISBN 0387952845. Disponível em: <https://web.stanford.edu/ hastie/Papers/ESLII.pdf>. Citado na página 33.

HUSE, C.; LUCINDA, C. The market impact and the cost of environmental policy: Evidence from the swedish green car rebate. The Economic Journal, v. 124, n. 578, p. F393F419, 2014. Disponível em: < https://onlinelibrary.wiley.com/doi/abs/10.1111/ecoj.12060>. Citado na página 65.

Interagency Working Group on Social Cost of Greenhouse Gases. Technical Update of the Social Cost of Carbon for Regulatory Impact Analysis Under Executive Order 12866. Interagency Working Group on Social Cost of Greenhouse Gases, n. August, p. 1-21, 2016. Disponível em: <https://www.epa.gov/sites/production/files/2016-12/documents/sc\{ __ \} $\operatorname{co} 2\left\{\backslash \_\right\} \operatorname{tsd}\left\{\backslash \_\right\}$august $>$. Citado 3 vezes nas páginas 44, 57 e 63.

International Energy Agency. CO2 Emissions from Fuel Combustion: Overview. IEA Statistics, p. 14, 2017. Disponível em: <http://www.iea.org/publications/freepublications/ publication/CO2EmissionsFromFuelCombustion2017Overview.pdf $>$. Citado 2 vezes nas páginas 15 e 41.

IPCC. Climate Change 2014: Mitigation of Climate Change. [s.n.], 2014. 1454 p. ISSN 17583004. ISBN 9781107654815. Disponível em: < http://www.ipcc.ch/report/ar5/wg3/>. Citado 2 vezes nas páginas 19 e 20.

LORINCZ, S. RCL: Stata module for estimation and simulation of random coefficient logit models. 2016. Statistical Software Components, Boston College Department of Economics. Disponível em: < https://ideas.repec.org/c/boc/bocode/s458216.html>. Citado na página 43.

PARRY, I. W. H.; SMALL, K. A. Does Britain or the United States have the right gasoline tax? 2005. 1276-1289 p. Citado na página 22.

PARRY, I. W. H.; WALLS, M.; HARRINGTON, W. Automobile Externalities and Policies. Journal of Economic Literature, v. 45, n. 2, p. 373-399, 2007. ISSN 0022-0515. 
Disponível em: < http://www.jstor.org/stable/pdf/27646797.pdf>. Citado 3 vezes nas páginas 20, 21 e 22.

SCHRANK., D. et al. 2015 Urban Mobility Scorecard. Texas A\&M Transportation Institue, v. 39, n. August, p. 5, 2015. Disponível em: <http://d2dt15nnlpfr0r.cloudfront. net/tti.tamu.edu/documents/mobility-scorecard-2015.pdf>. Citado na página 19.

SMALL, K. A.; ROSEN, H. S. Applied Welfare Economics with Discrete Choice Models. Econometrica, v. 49, p. 105-130, 1981. ISSN 00129682. Disponível em: <http://www.jstor.org/stable/1911129>. Citado na página 45.

VERBOVEN, F. International Price Discrimination in the European Car Market. RAND Journal of Economics, v. 27, n. 2, p. 240-268, 1996. ISSN 0741-6261. Disponível em: $<$ http://ideas.repec.org/a/rje/randje/v27y1996isummerp240-268.html>. Citado 2 vezes nas páginas 29 e 38.

YANG, Z. Practical lessons in vehicle efficiency policy: The 10-year evolution of France's CO2-based bonus-malus (feebate) system. 2018. < https://www.theicct.org/blog/staff/ practical-lessons-vehicle-efficiency-policy-10-year-evolution-frances-co2-based-bonus $>$. Último acesso em: 2018-04-01. Citado na página 26. 



\section{APÊNDICE A - Vendas}

Tabela 19 - Unidades vendidas entre 2008 a 2012 por segmento

\begin{tabular}{lrrrrrr}
\hline Segmento & 2008 & 2009 & 2010 & 2011 & 2012 & TOTAL \\
\hline \hline Carro Grande & 3.363 & 2.623 & 3.177 & 9.758 & 3.949 & 22.870 \\
Carro Luxo & 7.793 & 11.654 & 13.495 & 13.461 & 11.165 & 57.568 \\
Carro Médio+ & 148.150 & 151.166 & 151.710 & 125.833 & 143.035 & 719.894 \\
Carro Médio- & 256.785 & 361.196 & 366.044 & 427.174 & 484.467 & 1.895 .666 \\
Esporte & 1.097 & 1.146 & 1.923 & 7.612 & 7.069 & 18.847 \\
MPV & 83.985 & 95.548 & 96.287 & 109.956 & 105.391 & 491.167 \\
Pequeno & 1.110 .985 & 1.162 .764 & 1.316 .419 & 1.202 .716 & 1.267 .662 & 6.060 .546 \\
Perua Grande & 109 & 128 & 19 & 2 & 71 & 329 \\
Perua Luxo & 58 & 18 & 3 & 1 & 0 & 80 \\
Perua Média & 2.538 & 15 & 1 & 0 & 1 & 2.555 \\
Popular & 286.000 & 322.618 & 299.863 & 344.678 & 332.687 & 1.585 .846 \\
SUV & 131.989 & 150.239 & 182.589 & 208.847 & 229.913 & 903.577 \\
\hline TOTAL & 2.032 .852 & 2.259 .115 & 2.431 .530 & 2.450 .038 & 2.585 .410 & 11.758 .945 \\
\hline
\end{tabular}

Fonte: Elaborção Própria

Tabela 20 - Vendas de 2008 a 2012 por combustível

\begin{tabular}{lrrrrrr}
\hline Combustível & 2008 & 2009 & 2010 & 2011 & 2012 & TOTAL \\
\hline \hline Diesel & 18.036 & 14.849 & 18.945 & 22.084 & 18.235 & 92.149 \\
Gasolina & 188.378 & 191.659 & 241.175 & 315.615 & 234.207 & 1.171 .034 \\
Álcool & 1.826 .438 & 2.052 .607 & 2.171 .410 & 2.112 .339 & 2.332 .968 & 10.495 .762 \\
\hline TOTAL & 2.032 .852 & 2.259 .115 & 2.431 .530 & 2.450 .038 & 2.585 .410 & 11.758 .945 \\
\hline
\end{tabular}

Fonte: Elaborção Própria 
Tabela 21 - Unidades vendidas entre 2008 a 2012 por fabricante

\begin{tabular}{|c|c|c|c|c|c|c|}
\hline Fabricante & 2008 & 2009 & 2010 & 2011 & 2012 & TOTAL \\
\hline FIAT & 470.303 & 505.136 & 487.470 & 485.034 & 543.138 & 2.491 .081 \\
\hline VOLKSWAGEN & 442.303 & 516.688 & 501.763 & 474.340 & 516.610 & 2.451 .704 \\
\hline CHEVROLET & 424.674 & 449.163 & 491.343 & 451.106 & 445.491 & 2.261 .777 \\
\hline FORD & 203.376 & 240.354 & 259.933 & 238.576 & 242.683 & 1.184 .922 \\
\hline RENAULT & 102.574 & 105.048 & 141.714 & 169.169 & 206.352 & 724.857 \\
\hline HONDA & 108.022 & 116.132 & 116.497 & 85.426 & 123.995 & 550.072 \\
\hline HYUNDAI & 28.921 & 56.505 & 84.566 & 96.564 & 91.539 & 358.095 \\
\hline PEUGEOT & 71.852 & 71.483 & 74.870 & 68.770 & 58.756 & 345.731 \\
\hline CITROEN & 61.069 & 62.655 & 75.058 & 78.177 & 65.098 & 342.057 \\
\hline TOYOTA & 53.602 & 55.989 & 57.761 & 56.780 & 63.648 & 287.780 \\
\hline NISSAN & 10.612 & 15.505 & 25.829 & 50.600 & 81.211 & 183.757 \\
\hline KIA & 14.710 & 18.184 & 42.287 & 61.992 & 32.398 & 169.571 \\
\hline MITSUBISHI & 19.433 & 15.363 & 21.269 & 29.968 & 35.188 & 121.221 \\
\hline CHERY & 0 & 469 & 6.554 & 20.155 & 13.046 & 40.224 \\
\hline $\mathrm{JAC}$ & 0 & 0 & 0 & 22.547 & 17.163 & 39.710 \\
\hline BMW & 2.764 & 4.983 & 7.937 & 11.188 & 8.274 & 35.146 \\
\hline LAND ROVER & 3.946 & 2.861 & 4.703 & 7.418 & 7.447 & 26.375 \\
\hline MERCEDES & 3.415 & 5.301 & 6.819 & 4.546 & 5.417 & 25.498 \\
\hline SUZUKI & 258 & 2.881 & 4.353 & 6.889 & 6.649 & 21.030 \\
\hline AUDI & 1.325 & 1.891 & 3.056 & 5.136 & 4.661 & 16.069 \\
\hline VOLVO & 1.018 & 2.130 & 2.042 & 4.894 & 2.799 & 12.883 \\
\hline SSANGYONG & 654 & 653 & 3.263 & 3.796 & 1.756 & 10.122 \\
\hline SUBARU & 904 & 2.081 & 2.482 & 2.206 & 1.269 & 8.942 \\
\hline DODGE & 717 & 1.159 & 2.453 & 2.103 & 1.535 & 7.967 \\
\hline JEEP & 831 & 579 & 550 & 2.321 & 3.138 & 7.419 \\
\hline MINI & 134 & 963 & 1.587 & 2.809 & 1.883 & 7.376 \\
\hline CHRYSLER & 3.097 & 1.430 & 709 & 608 & 650 & 6.494 \\
\hline TROLLER & 1.009 & 1.295 & 1.084 & 1.094 & 886 & 5.368 \\
\hline LIFAN & 0 & 0 & 449 & 2.571 & 1.086 & 4.106 \\
\hline PORSCHE & 769 & 561 & 935 & 1.236 & 563 & 4.064 \\
\hline SMART & 14 & 991 & 1.417 & 1.022 & 606 & 4.050 \\
\hline EFFA & 196 & 255 & 379 & 573 & 191 & 1.594 \\
\hline MAHINDRA & 118 & 230 & 161 & 122 & 83 & 714 \\
\hline JAGUAR & 125 & 112 & 83 & 109 & 52 & 481 \\
\hline FERRARI & 33 & 25 & 46 & 64 & 51 & 219 \\
\hline LEXUS & 49 & 21 & 17 & 19 & 29 & 135 \\
\hline MASERATI & 23 & 22 & 29 & 33 & 26 & 133 \\
\hline LAMBORGHINI & 1 & 15 & 30 & 19 & 19 & 84 \\
\hline ASTON MARTIN & 1 & 2 & 20 & 32 & 11 & 66 \\
\hline BENTLEY & 0 & 0 & 11 & 22 & 10 & 43 \\
\hline ROLLS-ROYCE & 0 & 0 & 1 & 4 & 3 & 8 \\
\hline TOTAL & 2.032 .852 & 2.259 .115 & 2.431 .530 & 2.450 .038 & 2.585 .410 & 11.758 .945 \\
\hline
\end{tabular}

Fonte: Elaborção Própria 
Tabela 22 - Vendas percentuais entre os anos de 2008 a 2012 por fabricante

\begin{tabular}{|c|c|c|c|c|c|c|c|}
\hline Fabricante & 2008 & 2009 & 2010 & 2011 & 2012 & TODOS & Acumulado \\
\hline FIAT & 23,135 & 22,360 & 20,048 & 19,797 & 21,008 & 21,185 & 21,185 \\
\hline VOLKSWAGEN & 21,758 & 22,871 & 20,636 & 19,361 & 19,982 & 20,850 & 42,034 \\
\hline CHEVROLET & 20,891 & 19,882 & 20,207 & 18,412 & 17,231 & 19,235 & 61,269 \\
\hline FORD & 10,004 & 10,639 & 10,690 & 9,738 & 9,387 & 10,077 & 71,346 \\
\hline RENAULT & 5,046 & 4,650 & 5,828 & 6,905 & 7,981 & 6,164 & 77,510 \\
\hline HONDA & 5,314 & 5,141 & 4,791 & 3,487 & 4,796 & 4,678 & 82,188 \\
\hline HYUNDAI & 1,423 & 2,501 & 3,478 & 3,941 & 3,541 & 3,045 & 85,233 \\
\hline PEUGEOT & 3,535 & 3,164 & 3,079 & 2,807 & 2,273 & 2,940 & 88,173 \\
\hline CITROEN & 3,004 & 2,773 & 3,087 & 3,191 & 2,518 & 2,909 & 91,082 \\
\hline TOYOTA & 2,637 & 2,478 & 2,376 & 2,318 & 2,462 & 2,447 & 93,529 \\
\hline NISSAN & 0,522 & 0,686 & 1,062 & 2,065 & 3,141 & 1,563 & 95,092 \\
\hline KIA & 0,724 & 0,805 & 1,739 & 2,530 & 1,253 & 1,442 & 96,534 \\
\hline MITSUBISHI & 0,956 & 0,680 & 0,875 & 1,223 & 1,361 & 1,031 & 97,565 \\
\hline CHERY & 0,000 & 0,021 & 0,270 & 0,823 & 0,505 & 0,342 & 97,907 \\
\hline $\mathrm{JAC}$ & 0,000 & 0,000 & 0,000 & 0,920 & 0,664 & 0,338 & 98,245 \\
\hline BMW & 0,136 & 0,221 & 0,326 & 0,457 & 0,320 & 0,299 & 98,544 \\
\hline LAND ROVER & 0,194 & 0,127 & 0,193 & 0,303 & 0,288 & 0,224 & 98,768 \\
\hline MERCEDES & 0,168 & 0,235 & 0,280 & 0,186 & 0,210 & 0,217 & 98,985 \\
\hline SUZUKI & 0,013 & 0,128 & 0,179 & 0,281 & 0,257 & 0,179 & 99,164 \\
\hline AUDI & 0,065 & 0,084 & 0,126 & 0,210 & 0,180 & 0,137 & 99,300 \\
\hline VOLVO & 0,050 & 0,094 & 0,084 & 0,200 & 0,108 & 0,110 & 99,410 \\
\hline SSANGYONG & 0,032 & 0,029 & 0,134 & 0,155 & 0,068 & 0,086 & 99,496 \\
\hline SUBARU & 0,044 & 0,092 & 0,102 & 0,090 & 0,049 & 0,076 & 99,572 \\
\hline DODGE & 0,035 & 0,051 & 0,101 & 0,086 & 0,059 & 0,068 & 99,640 \\
\hline JEEP & 0,041 & 0,026 & 0,023 & 0,095 & 0,121 & 0,063 & 99,703 \\
\hline MINI & 0,007 & 0,043 & 0,065 & 0,115 & 0,073 & 0,063 & 99,766 \\
\hline CHRYSLER & 0,152 & 0,063 & 0,029 & 0,025 & 0,025 & 0,055 & 99,821 \\
\hline TROLLER & 0,050 & 0,057 & 0,045 & 0,045 & 0,034 & 0,046 & 99,867 \\
\hline LIFAN & 0,000 & 0,000 & 0,018 & 0,105 & 0,042 & 0,035 & 99,901 \\
\hline PORSCHE & 0,038 & 0,025 & 0,038 & 0,050 & 0,022 & 0,035 & 99,936 \\
\hline SMART & 0,001 & 0,044 & 0,058 & 0,042 & 0,023 & 0,034 & 99,970 \\
\hline EFFA & 0,010 & 0,011 & 0,016 & 0,023 & 0,007 & 0,014 & 99,984 \\
\hline MAHINDRA & 0,006 & 0,010 & 0,007 & 0,005 & 0,003 & 0,006 & 99,990 \\
\hline JAGUAR & 0,006 & 0,005 & 0,003 & 0,004 & 0,002 & 0,004 & 99,994 \\
\hline FERRARI & 0,002 & 0,001 & 0,002 & 0,003 & 0,002 & 0,002 & 99,996 \\
\hline LEXUS & 0,002 & 0,001 & 0,001 & 0,001 & 0,001 & 0,001 & 99,997 \\
\hline MASERATI & 0,001 & 0,001 & 0,001 & 0,001 & 0,001 & 0,001 & 99,998 \\
\hline LAMBORGHINI & 0,000 & 0,001 & 0,001 & 0,001 & 0,001 & 0,001 & 99,999 \\
\hline ASTON MARTIN & 0,000 & 0,000 & 0,001 & 0,001 & 0,000 & 0,001 & 100,000 \\
\hline BENTLEY & 0,000 & 0,000 & 0,000 & 0,001 & 0,000 & 0,000 & 100,000 \\
\hline ROLLS-ROYCE & 0,000 & 0,000 & 0,000 & 0,000 & 0,000 & 0,000 & 100,000 \\
\hline TOTAL & 100 & 100 & 100 & 100 & 100 & 100 & \\
\hline
\end{tabular}

Dados em porcentagem. Fonte: Elaborção Própria 



\section{APÊNDICE B - Matriz de Elasticidades Cruzadas}

Aqui apresentamos a matriz de elasticidade cruzada para a cidade de São Paulo no ano de 2012 para alguns dos modelos mais vendidos. 


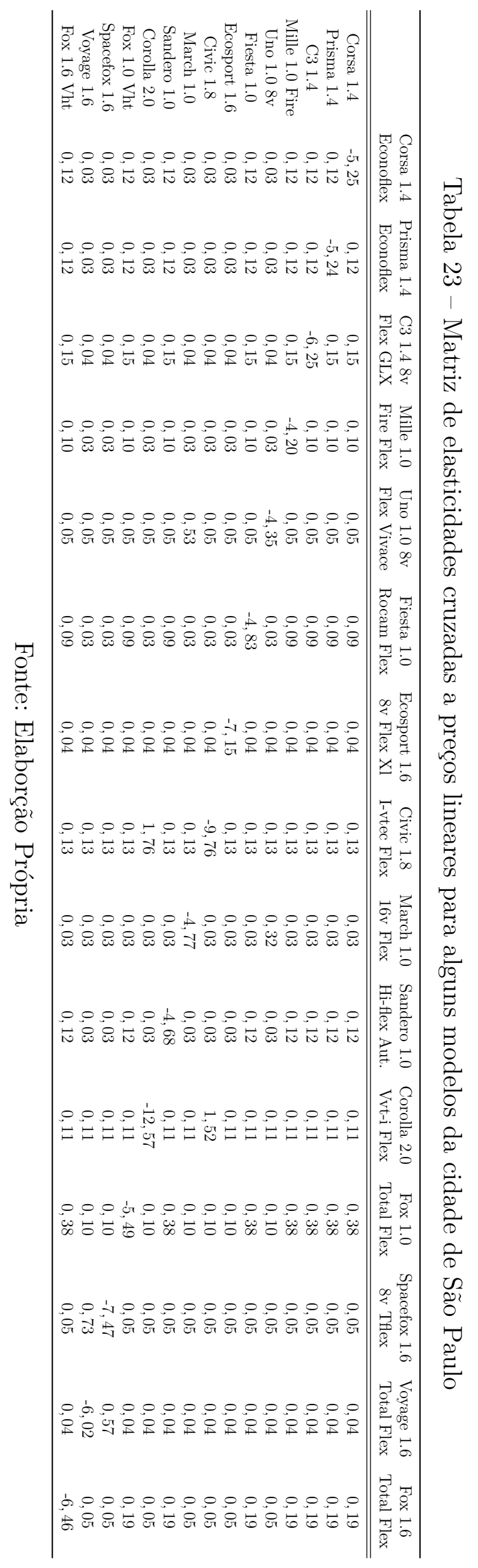




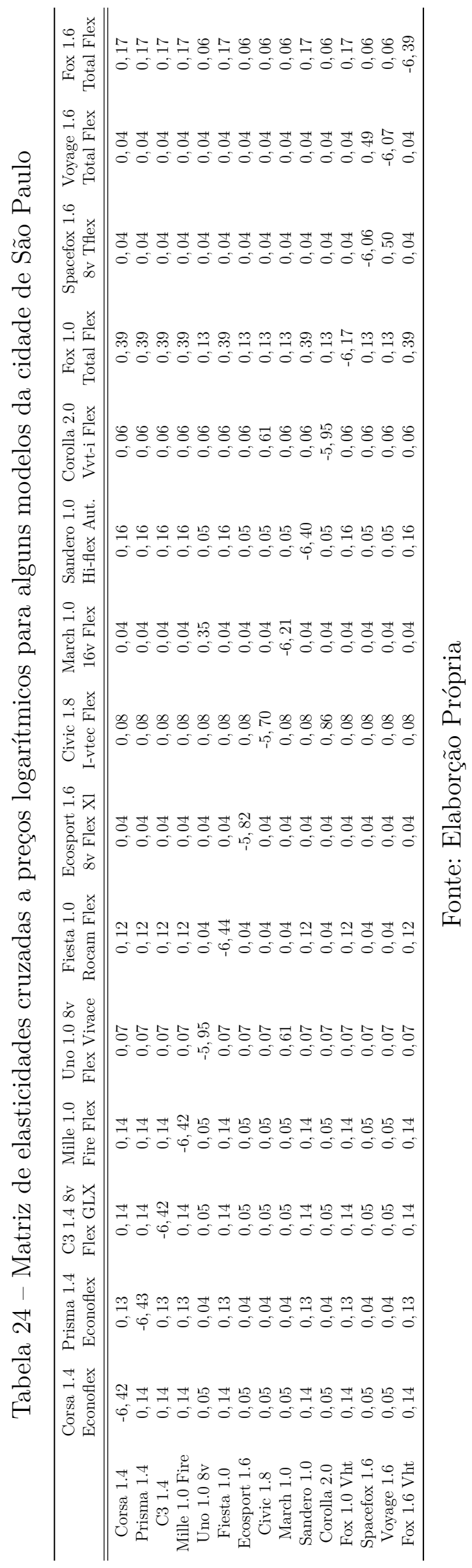





\section{APÊNDICE C - Primeiro Estágio}

Apresentamos as regressões do preço linear e logarítmico contra os instrumentos. As variáveis que apresentam $B L P \_1$ e $B L P \_2$, são os instrumentos construídos, correspondendo às duas últimas fórmulas da Equação 2.8, e $B L P \_s \_1$ e $B L P \_s \_2$ às fórmulas da Equação 2.9. 
Tabela 25 - Primeiro Estágio

\begin{tabular}{|c|c|c|}
\hline & Preço & $\ln ($ Preço $)$ \\
\hline torque & $170^{* * *}$ & $.00339^{* * *}$ \\
\hline espaco_interno_ln & $28932^{* * *}$ & $.701^{* * *}$ \\
\hline dist_eixos & $-23.17^{* * *}$ & $-.000766^{* * *}$ \\
\hline litros & $-3981^{* * *}$ & $-.0402^{* * *}$ \\
\hline consumo & $782^{* * *}$ & $.00998^{* * *}$ \\
\hline $\mathrm{CO}_{2}$ & $7.32^{* * *}$ & $.000329^{* * *}$ \\
\hline carga_ln & $-4925^{* * *}$ & $-.198^{* * *}$ \\
\hline$p i b \_c a p \_l n$ & $121^{* * *}$ & $.00209^{* * *}$ \\
\hline arcondicionado & $4351^{* * *}$ & $.100^{* * *}$ \\
\hline direcao & $6054^{* * *}$ & $.155^{* * *}$ \\
\hline transmissao & $7270^{* * *}$ & $.0798^{* * *}$ \\
\hline airbag & $3086^{* * *}$ & $.0770^{* * *}$ \\
\hline$A B S$ & $3416^{* * *}$ & $.0255^{* * *}$ \\
\hline portas & $-1032^{* * *}$ & $-.00286^{* * *}$ \\
\hline importado & $2162^{* * *}$ & $.0459^{* * *}$ \\
\hline 2008 & $11553^{* * *}$ & $.281^{* * *}$ \\
\hline 2009 & $7625^{* * *}$ & $.188^{* * *}$ \\
\hline 2010 & $5634^{* * *}$ & $.132^{* * *}$ \\
\hline 2011 & $3425^{* * *}$ & $.0802^{* * *}$ \\
\hline volume_externo_ln & $22572^{* * *}$ & $.468^{* * *}$ \\
\hline peso_bruto_ln & $19583^{* * *}$ & $.420^{* * *}$ \\
\hline$B L P \_1$ torque & $-11.3^{* * *}$ & $-.000275^{* * *}$ \\
\hline BLP_2_torque & $-6.20^{* * *}$ & $-.0000835^{* * *}$ \\
\hline BLP_s_1_torque & $40.3^{* * *}$ & $.000821^{* * *}$ \\
\hline BLP_s_2_torque & $5.67^{* * *}$ & $.000145^{* * *}$ \\
\hline BLP_1_dist_eixos & $6.24^{* * *}$ & $.000116^{* * *}$ \\
\hline BLP_2_dist_eixos & $-.592^{* * *}$ & $-.0000173^{* * *}$ \\
\hline$B L P \_s \_1 \_$dist_eixos & $-8.41^{* * *}$ & $-.000174^{* * *}$ \\
\hline BLP_s_2_dist_eixos & $1.30^{* * *}$ & $.0000574^{* * *}$ \\
\hline BLP_2_const & $-23044^{* * *}$ & $-.511^{* * *}$ \\
\hline BLP_s_2_const & $53086^{* * *}$ & $1.68^{* * *}$ \\
\hline BLP_1_aceleracao & $-342^{* * *}$ & $-.00767^{* * *}$ \\
\hline BLP_2_aceleracao & $-54.6^{* * *}$ & $-.00110^{* * *}$ \\
\hline BLP_s_1_aceleracao & $572^{* * *}$ & $.0125^{* * *}$ \\
\hline BLP_s_2_aceleracao & $76.1^{* * *}$ & $.00321^{* * *}$ \\
\hline BLP_1_volume_externo_ln & $-221^{* * *}$ & $-.00363^{* * *}$ \\
\hline$B L P \_2 \_v o l u m e \_$externo_ln & $1095^{* * *}$ & $.0249^{* * *}$ \\
\hline BLP_s_1_volume_externo_ln & $187^{* * *}$ & $.00472^{* * *}$ \\
\hline BLP_s_2_volume_externo_ln & $-2465^{* * *}$ & $-.0816^{* * *}$ \\
\hline BLP_1_consumo & $-79.2^{* * *}$ & $-.000458^{* * *}$ \\
\hline BLP_2_consumo & $33.8^{* * *}$ & $.000489^{* * *}$ \\
\hline BLP_s_1_consumo & $196^{* * *}$ & $.00227^{* * *}$ \\
\hline BLP_s_2_consumo & $-58.4^{* * *}$ & $-.00105^{* * *}$ \\
\hline$B L P \_1 \_\mathrm{CO}_{2}$ & $-24.8^{* * *}$ & $-.000414^{* * *}$ \\
\hline $\mathrm{BLP}{ }_{2} \mathrm{CO}_{2}$ & $3.50^{* * *}$ & $.0000109^{* * *}$ \\
\hline$B L P \_s \_1 \_C O_{2}$ & $17.1^{* * *}$ & $.000279^{* * *}$ \\
\hline$B L P \_s \_2 \_C O_{2}$ & $-5.70^{* * *}$ & $.0000129^{* * *}$ \\
\hline Constante & $-1006841^{* * *}$ & $-11.6^{* * *}$ \\
\hline $\mathrm{R}^{2}$ & 0,91 & 0,93 \\
\hline Estatistica F $(47,113339)$ & $24280^{* * *}$ & $34176^{* * *}$ \\
\hline
\end{tabular}

Nota: ${ }^{*} \mathrm{p}<0,1 ;{ }^{* *} \mathrm{p}<0,05 ;{ }^{* * *} \mathrm{p}<0,01$

Fonte: Elaboração própria 


\section{APÊNDICE D - Regressão - custo marginal}

Tabela 26 - Regressão do Custo Marginal

\begin{tabular}{|c|c|c|}
\hline & \multicolumn{2}{|c|}{$\log (\mathrm{mc})$} \\
\hline & preço & $\log ($ preço $)$ \\
\hline $\log ($ carga $)$ & $\begin{array}{c}-0,33^{* * *} \\
(0,004)\end{array}$ & $\begin{array}{c}-0,27^{* * *} \\
(0,003)\end{array}$ \\
\hline $\log$ (litros) & $\begin{array}{c}-0,16^{* * *} \\
(0,01)\end{array}$ & $\begin{array}{c}-0,14^{* * *} \\
(0,01)\end{array}$ \\
\hline $\log ($ volume externo $)$ & $\begin{array}{c}0,43^{* * *} \\
(0,01)\end{array}$ & $\begin{array}{c}0,38^{* * *} \\
(0,01)\end{array}$ \\
\hline $\log ($ torque $)$ & $\begin{array}{c}0,55^{* * *} \\
(0,01)\end{array}$ & $\begin{array}{c}0,45^{* * *} \\
(0,01)\end{array}$ \\
\hline $\log ($ Peso Bruto $)$ & $\begin{array}{c}0,71^{* * *} \\
(0,01)\end{array}$ & $\begin{array}{c}0,63^{* * *} \\
(0,01)\end{array}$ \\
\hline $\log \left(C \mathrm{O}_{2}\right)$ & $\begin{array}{c}-0,03^{* * *} \\
(0,003)\end{array}$ & $\begin{array}{c}-0,03^{* * *} \\
(0,002)\end{array}$ \\
\hline $\log ($ Consumo $)$ & $\begin{array}{l}0,07^{* * *} \\
(0,003)\end{array}$ & $\begin{array}{l}0,08^{* * *} \\
(0,002)\end{array}$ \\
\hline ABS & $\begin{array}{l}0,01^{* * *} \\
(0,002)\end{array}$ & $\begin{array}{l}0,02^{* * *} \\
(0,001)\end{array}$ \\
\hline Transmissao & $\begin{array}{l}0,14^{* * *} \\
(0,002)\end{array}$ & $\begin{array}{l}0,13^{* * *} \\
(0,002)\end{array}$ \\
\hline Direcao & $\begin{array}{l}0,16^{* * *} \\
(0,001)\end{array}$ & $\begin{array}{l}0,13^{* * *} \\
(0,001)\end{array}$ \\
\hline Arcondicionado & $\begin{array}{l}0,14^{* * *} \\
(0,001)\end{array}$ & $\begin{array}{l}0,12^{* * *} \\
(0,001)\end{array}$ \\
\hline Airbag & $\begin{array}{l}0,10^{* * *} \\
(0,001)\end{array}$ & $\begin{array}{l}0,09^{* * *} \\
(0,001)\end{array}$ \\
\hline Quatro Portas & $\begin{array}{l}0,02^{* * *} \\
(0,001)\end{array}$ & $\begin{array}{l}0,01^{* * *} \\
(0,001)\end{array}$ \\
\hline Importado & $\begin{array}{l}0,06^{* * *} \\
(0,001)\end{array}$ & $\begin{array}{l}0,05^{* * *} \\
(0,001)\end{array}$ \\
\hline 2008 & $\begin{array}{l}0,30^{* * *} \\
(0,001)\end{array}$ & $\begin{array}{l}0,25^{* * *} \\
(0,001)\end{array}$ \\
\hline 2009 & $\begin{array}{l}0,24^{* * *} \\
(0,001)\end{array}$ & $\begin{array}{l}0,20^{* * *} \\
(0,001)\end{array}$ \\
\hline 2010 & $\begin{array}{l}0,15^{* * *} \\
(0,001)\end{array}$ & $\begin{array}{l}0,12^{* * *} \\
(0,001)\end{array}$ \\
\hline 2011 & $\begin{array}{l}0,09^{* * *} \\
(0,001)\end{array}$ & $\begin{array}{l}0,07^{* * *} \\
(0,001)\end{array}$ \\
\hline Constante & $\begin{array}{c}-5,85^{* * *} \\
(0,11)\end{array}$ & $\begin{array}{c}-4,03^{* * *} \\
(0,09)\end{array}$ \\
\hline Observations & 113,361 & 113,361 \\
\hline $\mathrm{R}^{2}$ & 0,91 & 0,91 \\
\hline Adjusted $\mathrm{R}^{2}$ & 0,91 & 0,91 \\
\hline Residual Std. Error $(\mathrm{df}=113342)$ & 0,11 & 0,09 \\
\hline F Statistic $(\mathrm{df}=18 ; 113.342)$ & $66,024,52^{* * *}$ & $64,008,63^{* * *}$ \\
\hline
\end{tabular}

Fonte: Elaboração própria 



\section{APÊNDICE E - Algoritmos}

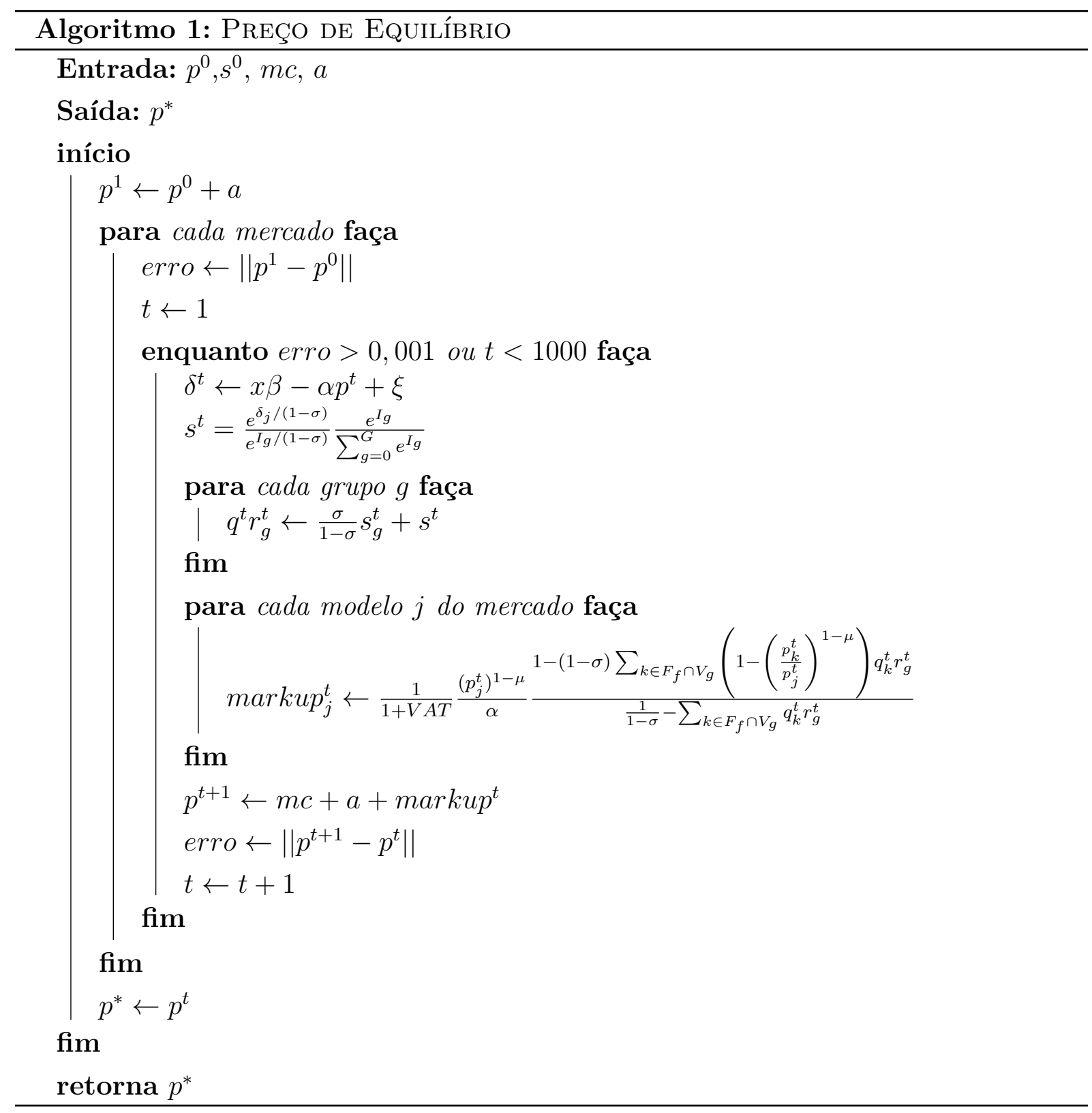




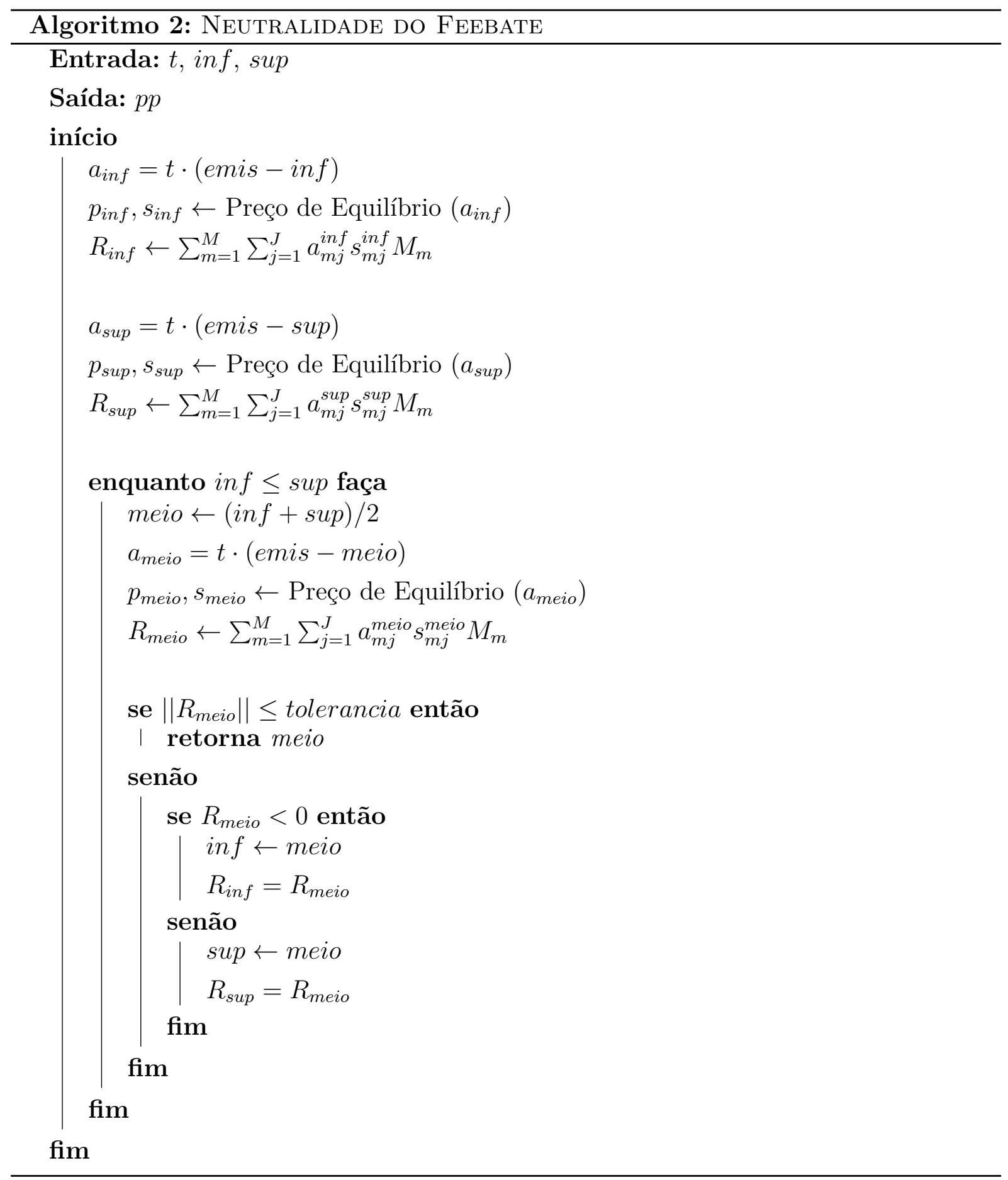




\section{APÊNDICE F - Simulações}

\section{Preços Lineares}

\section{Feebate Neutro}

Tabela 27 - Alterações pela implementação do feebate - Feebate neutro - Preço linear

\begin{tabular}{|c|c|c|c|c|c|c|c|c|}
\hline Aliq. & Pivot & Vendas & Feebate & Gov. & Consum. & Prod. & Amb. & Total \\
\hline 0,5 & 162,1 & $\begin{array}{c}0,00 \\
(0,00)\end{array}$ & $-0,00$ & $\begin{array}{c}-2,1 \\
(-0,02)\end{array}$ & $\begin{array}{c}-0,2 \\
(-0,00)\end{array}$ & $\begin{array}{c}0,2 \\
(0,00)\end{array}$ & $\begin{array}{c}0,5 \\
(0,02)\end{array}$ & $\begin{array}{c}-1,6 \\
(-0,01)\end{array}$ \\
\hline 1 & 162,1 & $\begin{array}{c}0,01 \\
(0,00)\end{array}$ & $-0,00$ & $\begin{array}{c}-4,2 \\
(-0,05)\end{array}$ & $\begin{array}{c}-0,4 \\
(-0,01)\end{array}$ & $\begin{array}{c}0,4 \\
(0,01)\end{array}$ & $\begin{array}{c}1,0 \\
(0,05)\end{array}$ & $\begin{array}{c}-3,3 \\
(-0,02)\end{array}$ \\
\hline 5 & 161,8 & $\begin{array}{c}-0,01 \\
(-0,00)\end{array}$ & 0,00 & $\begin{array}{l}-21,5 \\
(-0,2)\end{array}$ & $\begin{array}{c}-2,5 \\
(-0,05)\end{array}$ & $\begin{array}{c}1,7 \\
(0,04)\end{array}$ & $\begin{array}{c}5,2 \\
(0,2)\end{array}$ & $\begin{array}{l}-17,2 \\
(-0,1)\end{array}$ \\
\hline 10 & 161,4 & $\begin{array}{c}-0,1 \\
(-0,01)\end{array}$ & 0,00 & $\begin{array}{l}-43,9 \\
(-0,5)\end{array}$ & $\begin{array}{c}-6,4 \\
(-0,1)\end{array}$ & $\begin{array}{c}3,0 \\
(0,1)\end{array}$ & $\begin{array}{l}10,6 \\
(0,5)\end{array}$ & $\begin{array}{l}-36,6 \\
(-0,2)\end{array}$ \\
\hline 20 & 160,6 & $\begin{array}{c}-0,6 \\
(-0,1)\end{array}$ & 0,00 & $\begin{array}{l}-90,9 \\
(-1,0)\end{array}$ & $\begin{array}{l}-18,6 \\
(-0,3)\end{array}$ & $\begin{array}{c}4,5 \\
(0,1)\end{array}$ & $\begin{array}{l}22,5 \\
(1,1)\end{array}$ & $\begin{array}{l}-82,5 \\
(-0,4)\end{array}$ \\
\hline 40 & 158,9 & $\begin{array}{c}-2,9 \\
(-0,4)\end{array}$ & 0,00 & $\begin{array}{c}-194,9 \\
(-2,2)\end{array}$ & $\begin{array}{l}-61,3 \\
(-1,1)\end{array}$ & $\begin{array}{c}2,8 \\
(0,1)\end{array}$ & $\begin{array}{l}49,9 \\
(2,3)\end{array}$ & $\begin{array}{c}-203,5 \\
(-1,1)\end{array}$ \\
\hline 60 & 157,2 & $\begin{array}{c}-7,1 \\
(-0,8)\end{array}$ & 0,00 & $\begin{array}{c}-313,3 \\
(-3,5)\end{array}$ & $\begin{array}{c}-129,8 \\
(-2,4)\end{array}$ & $\begin{array}{c}-5,5 \\
(-0,1)\end{array}$ & $\begin{array}{l}82,6 \\
(3,9)\end{array}$ & $\begin{array}{c}-366,1 \\
(-1,9)\end{array}$ \\
\hline 80 & 155,4 & $\begin{array}{l}-13,2 \\
(-1,6)\end{array}$ & 0,00 & $\begin{array}{c}-447,0 \\
(-5,0)\end{array}$ & $\begin{array}{c}-225,4 \\
(-4,1)\end{array}$ & $\begin{array}{l}-20,6 \\
(-0,5)\end{array}$ & $\begin{array}{c}120,6 \\
(5,6)\end{array}$ & $\begin{array}{c}-572,4 \\
(-3,0)\end{array}$ \\
\hline 100 & 153,5 & $\begin{array}{l}-21,3 \\
(-2,5)\end{array}$ & 0,00 & $\begin{array}{c}-596,9 \\
(-6,7)\end{array}$ & $\begin{array}{c}-348,8 \\
(-6,4)\end{array}$ & $\begin{array}{l}-42,8 \\
(-0,9)\end{array}$ & $\begin{array}{c}164,0 \\
(7,6)\end{array}$ & $\begin{array}{c}-824,4 \\
(-4,4)\end{array}$ \\
\hline 120 & 151,6 & $\begin{array}{l}-31,7 \\
(-3,8)\end{array}$ & $-0,00$ & $\begin{array}{c}-763,4 \\
(-8,5)\end{array}$ & $\begin{array}{c}-499,9 \\
(-9,1)\end{array}$ & $\begin{array}{l}-72,2 \\
(-1,6)\end{array}$ & $\begin{array}{c}212,8 \\
(9,7)\end{array}$ & $\begin{array}{c}-1.122,8 \\
(-5,9)\end{array}$ \\
\hline 140 & 149,6 & $\begin{array}{l}-44,2 \\
(-5,3)\end{array}$ & $-0,00$ & $\begin{array}{l}-947,1 \\
(-10,6)\end{array}$ & $\begin{array}{l}-677,8 \\
(-12,4)\end{array}$ & $\begin{array}{c}-109,3 \\
(-2,4)\end{array}$ & $\begin{array}{c}266,8 \\
(11,9)\end{array}$ & $\begin{array}{c}-1.467,4 \\
(-7,7)\end{array}$ \\
\hline 160 & 147,6 & $\begin{array}{l}-59,1 \\
(-7,0)\end{array}$ & 0,00 & $\begin{array}{c}-1.147,7 \\
(-12,9)\end{array}$ & $\begin{array}{l}-880,7 \\
(-16,1)\end{array}$ & $\begin{array}{c}-154,3 \\
(-3,4)\end{array}$ & $\begin{array}{c}325,7 \\
(14,3)\end{array}$ & $\begin{array}{c}-1.857,0 \\
(-9,8)\end{array}$ \\
\hline
\end{tabular}

Nota 1: Vendas em milhares de unidades, outras variações em milhões de reais

Nota 2: Percentuais em parêntese

Fonte: Elaboração própria 
Tabela 28 - Alterações pela implementação do feebate - Feebate neutro - Preço linear Alto Impacto Ambiental

\begin{tabular}{|c|c|c|c|c|c|c|c|c|}
\hline Aliq. & Pivot & Vendas & Feebate & Gov. & Consum. & Prod. & Amb. & Total \\
\hline 0,5 & 162,1 & $\begin{array}{c}0,00 \\
(0,00)\end{array}$ & $-0,00$ & $\begin{array}{c}-2,1 \\
(-0,02)\end{array}$ & $\begin{array}{c}-0,2 \\
(-0,00)\end{array}$ & $\begin{array}{c}0,2 \\
(0,00)\end{array}$ & $\begin{array}{c}1,4 \\
(0,02)\end{array}$ & $\begin{array}{c}-0,7 \\
(-0,00)\end{array}$ \\
\hline 1 & 162,1 & $\begin{array}{c}0,01 \\
(0,00)\end{array}$ & $-0,00$ & $\begin{array}{c}-4,2 \\
(-0,05)\end{array}$ & $\begin{array}{c}-0,4 \\
(-0,01)\end{array}$ & $\begin{array}{c}0,4 \\
(0,01)\end{array}$ & $\begin{array}{c}2,8 \\
(0,05)\end{array}$ & $\begin{array}{c}-1,5 \\
(-0,01)\end{array}$ \\
\hline 5 & 161,8 & $\begin{array}{c}-0,01 \\
(-0,00)\end{array}$ & 0,00 & $\begin{array}{l}-21,5 \\
(-0,2)\end{array}$ & $\begin{array}{c}-2,5 \\
(-0,05)\end{array}$ & $\begin{array}{c}1,7 \\
(0,04)\end{array}$ & $\begin{array}{l}14,3 \\
(0,2)\end{array}$ & $\begin{array}{c}-8,0 \\
(-0,04)\end{array}$ \\
\hline 10 & 161,4 & $\begin{array}{c}-0,1 \\
(-0,01)\end{array}$ & 0,00 & $\begin{array}{l}-43,9 \\
(-0,5)\end{array}$ & $\begin{array}{l}-6,4 \\
(-0,1)\end{array}$ & $\begin{array}{c}3,0 \\
(0,1)\end{array}$ & $\begin{array}{l}29,5 \\
(0,5)\end{array}$ & $\begin{array}{l}-17,8 \\
(-0,1)\end{array}$ \\
\hline 20 & 160,6 & $\begin{array}{l}-0,6 \\
(-0,1)\end{array}$ & 0,00 & $\begin{array}{l}-90,9 \\
(-1,0)\end{array}$ & $\begin{array}{l}-18,6 \\
(-0,3)\end{array}$ & $\begin{array}{c}4,5 \\
(0,1)\end{array}$ & $\begin{array}{l}62,3 \\
(1,1)\end{array}$ & $\begin{array}{l}-42,6 \\
(-0,2)\end{array}$ \\
\hline 40 & 158,9 & $\begin{array}{l}-2,9 \\
(-0,4)\end{array}$ & 0,00 & $\begin{array}{c}-194,9 \\
(-2,2)\end{array}$ & $\begin{array}{l}-61,3 \\
(-1,1)\end{array}$ & $\begin{array}{c}2,8 \\
(0,1)\end{array}$ & $\begin{array}{c}138,4 \\
(2,3)\end{array}$ & $\begin{array}{c}-115,0 \\
(-0,6)\end{array}$ \\
\hline 60 & 157,2 & $\begin{array}{c}-7,1 \\
(-0,8)\end{array}$ & 0,00 & $\begin{array}{l}-313,3 \\
(-3,5)\end{array}$ & $\begin{array}{l}-129,8 \\
(-2,4)\end{array}$ & $\begin{array}{l}-5,5 \\
(-0,1)\end{array}$ & $\begin{array}{c}229,0 \\
(3,9)\end{array}$ & $\begin{array}{c}-219,6 \\
(-1,2)\end{array}$ \\
\hline 80 & 155,4 & $\begin{array}{l}-13,2 \\
(-1,6)\end{array}$ & 0,00 & $\begin{array}{c}-447,0 \\
(-5,0)\end{array}$ & $\begin{array}{c}-225,4 \\
(-4,1)\end{array}$ & $\begin{array}{l}-20,6 \\
(-0,5)\end{array}$ & $\begin{array}{c}334,5 \\
(5,6)\end{array}$ & $\begin{array}{c}-358,5 \\
(-1,9)\end{array}$ \\
\hline 100 & 153,5 & $\begin{array}{l}-21,3 \\
(-2,5)\end{array}$ & 0,00 & $\begin{array}{c}-596,9 \\
(-6,7)\end{array}$ & $\begin{array}{c}-348,8 \\
(-6,4)\end{array}$ & $\begin{array}{l}-42,8 \\
(-0,9)\end{array}$ & $\begin{array}{l}455,0 \\
(7,6)\end{array}$ & $\begin{array}{c}-533,4 \\
(-2,8)\end{array}$ \\
\hline 120 & 151,6 & $\begin{array}{l}-31,7 \\
(-3,8)\end{array}$ & $-0,00$ & $\begin{array}{c}-763,4 \\
(-8,5)\end{array}$ & $\begin{array}{c}-499,9 \\
(-9,1)\end{array}$ & $\begin{array}{l}-72,2 \\
(-1,6)\end{array}$ & $\begin{array}{c}590,4 \\
(9,7)\end{array}$ & $\begin{array}{c}-745,2 \\
(-3,9)\end{array}$ \\
\hline 140 & 149,6 & $\begin{array}{l}-44,2 \\
(-5,3)\end{array}$ & $-0,00$ & $\begin{array}{l}-947,1 \\
(-10,6)\end{array}$ & $\begin{array}{l}-677,8 \\
(-12,4)\end{array}$ & $\begin{array}{c}-109,3 \\
(-2,4)\end{array}$ & $\begin{array}{l}740,2 \\
(11,9)\end{array}$ & $\begin{array}{c}-994,0 \\
(-5,2)\end{array}$ \\
\hline 160 & 147,6 & $\begin{array}{l}-59,1 \\
(-7,0)\end{array}$ & 0,00 & $\begin{array}{c}-1.147,7 \\
(-12,9)\end{array}$ & $\begin{array}{l}-880,7 \\
(-16,1)\end{array}$ & $\begin{array}{c}-154,3 \\
(-3,4)\end{array}$ & $\begin{array}{l}903,6 \\
(14,3)\end{array}$ & $\begin{array}{c}-1.279,1 \\
(-6,8)\end{array}$ \\
\hline
\end{tabular}

Nota 1: Vendas em milhares de unidades, outras variações em milhões de reais

Nota 2: Percentuais em parêntese

Fonte: Elaboração própria 


\section{Receita do Governo Neutra}

Tabela 29 - Alterações pela implementação do feebate - Receita do governo neutra - Preço linear

\begin{tabular}{|c|c|c|c|c|c|c|c|c|}
\hline Aliq. & Pivot & Vendas & Feebate & Gov. & Consum. & Prod. & Amb. & Total \\
\hline 0,5 & 154,9 & $\begin{array}{c}-0,2 \\
(-0,02)\end{array}$ & 3,0 & $\begin{array}{c}-0,00 \\
(-0,00)\end{array}$ & $\begin{array}{c}-2,6 \\
(-0,05)\end{array}$ & $\begin{array}{c}-0,7 \\
(-0,02)\end{array}$ & $\begin{array}{c}0,9 \\
(0,04)\end{array}$ & $\begin{array}{c}-2,4 \\
(-0,01)\end{array}$ \\
\hline 1 & 154,8 & $\begin{array}{c}-0,3 \\
(-0,04)\end{array}$ & 6,1 & $\begin{array}{c}0,00 \\
(0,00)\end{array}$ & $\begin{array}{c}-5,2 \\
(-0,1)\end{array}$ & $\begin{array}{c}-1,5 \\
(-0,03)\end{array}$ & $\begin{array}{c}1,8 \\
(0,1)\end{array}$ & $\begin{array}{c}-4,9 \\
(-0,03)\end{array}$ \\
\hline 5 & 154,4 & $\begin{array}{l}-1,7 \\
(-0,2)\end{array}$ & 30,9 & $\begin{array}{c}0,00 \\
(0,00)\end{array}$ & $\begin{array}{l}-27,0 \\
(-0,5)\end{array}$ & $\begin{array}{l}-7,6 \\
(-0,2)\end{array}$ & $\begin{array}{c}9,3 \\
(0,4)\end{array}$ & $\begin{array}{l}-25,3 \\
(-0,1)\end{array}$ \\
\hline 10 & 153,9 & $\begin{array}{l}-3,5 \\
(-0,4)\end{array}$ & 62,9 & 0,00 & $\begin{array}{l}-56,3 \\
(-1,0)\end{array}$ & $\begin{array}{l}-16,0 \\
(-0,4)\end{array}$ & $\begin{array}{l}19,1 \\
(0,9)\end{array}$ & $\begin{array}{l}-53,2 \\
(-0,3)\end{array}$ \\
\hline 20 & 152,8 & $\begin{array}{l}-7,7 \\
(-0,9)\end{array}$ & 130,4 & $\begin{array}{c}0,00 \\
(0,00)\end{array}$ & $\begin{array}{c}-122,0 \\
(-2,2)\end{array}$ & $\begin{array}{l}-35,1 \\
(-0,8)\end{array}$ & $\begin{array}{l}40,0 \\
(1,9)\end{array}$ & $\begin{array}{r}-117,0 \\
(-0,6)\end{array}$ \\
\hline 40 & 150,4 & $\begin{array}{l}-18,4 \\
(-2,2)\end{array}$ & 280,6 & $\begin{array}{c}0,00 \\
(0,00)\end{array}$ & $\begin{array}{c}-283,4 \\
(-5,2)\end{array}$ & $\begin{array}{l}-83,7 \\
(-1,8)\end{array}$ & $\begin{array}{l}87,8 \\
(4,1)\end{array}$ & $\begin{array}{l}-279,3 \\
(-1,5)\end{array}$ \\
\hline 60 & 147,8 & $\begin{array}{l}-32,4 \\
(-3,8)\end{array}$ & 453,7 & $\begin{array}{c}0,00 \\
(0,00)\end{array}$ & $\begin{array}{c}-488,1 \\
(-8,9)\end{array}$ & $\begin{array}{c}-147,9 \\
(-3,3)\end{array}$ & $\begin{array}{c}144,1 \\
(6,5)\end{array}$ & $\begin{array}{c}-492,0 \\
(-2,6)\end{array}$ \\
\hline 80 & 145,0 & $\begin{array}{l}-50,3 \\
(-6,0)\end{array}$ & 653,8 & $\begin{array}{c}-0,00 \\
(-0)\end{array}$ & $\begin{array}{l}-740,2 \\
(-13,5)\end{array}$ & $\begin{array}{c}-230,6 \\
(-5,1)\end{array}$ & $\begin{array}{c}210,0 \\
(9,3)\end{array}$ & $\begin{array}{c}-760,8 \\
(-4,0)\end{array}$ \\
\hline 100 & 142,0 & $\begin{array}{l}-73,0 \\
(-8,7)\end{array}$ & 886,4 & $\begin{array}{c}0,00 \\
(0,00)\end{array}$ & $\begin{array}{c}-1.043,8 \\
(-19,1)\end{array}$ & $\begin{array}{c}-335,9 \\
(-7,4)\end{array}$ & $\begin{array}{c}286,8 \\
(12,4)\end{array}$ & $\begin{array}{c}-1.092,9 \\
(-5,8)\end{array}$ \\
\hline 120 & 138,5 & $\begin{array}{l}-101,3 \\
(-12,0)\end{array}$ & $1.159,1$ & $\begin{array}{c}-0,00 \\
(-0,00)\end{array}$ & $\begin{array}{c}-1.404,2 \\
(-25,7)\end{array}$ & $\begin{array}{l}-469,9 \\
(-10,4)\end{array}$ & $\begin{array}{c}376,4 \\
(15,6)\end{array}$ & $\begin{array}{c}-1.497,7 \\
(-7,9)\end{array}$ \\
\hline 140 & 134,5 & $\begin{array}{l}-137,1 \\
(-16,3)\end{array}$ & $1.485,0$ & $\begin{array}{c}-0,00 \\
(-0,00)\end{array}$ & $\begin{array}{c}-1.830,4 \\
(-33,4)\end{array}$ & $\begin{array}{l}-643,2 \\
(-14,2)\end{array}$ & $\begin{array}{l}482,2 \\
(19,1)\end{array}$ & $\begin{array}{c}-1.991,4 \\
(-10,5)\end{array}$ \\
\hline 160 & 129,6 & $\begin{array}{l}-183,9 \\
(-21,8)\end{array}$ & $1.892,1$ & $\begin{array}{c}-0,00 \\
(-0,00)\end{array}$ & $\begin{array}{c}-2.343,7 \\
(-42,8)\end{array}$ & $\begin{array}{l}-877,9 \\
(-19,3)\end{array}$ & $\begin{array}{l}611,7 \\
(22,6)\end{array}$ & $\begin{array}{c}-2.609,9 \\
(-13,8)\end{array}$ \\
\hline
\end{tabular}

Nota 1: Vendas em milhares de unidades, outras variações em milhões de reais

Nota 2: Percentuais em parêntese

Fonte: Elaboração própria 
Tabela 30 - Alterações pela implementação do feebate - Receita do governo neutra - Preço linear - Alto Impacto Ambiental

\begin{tabular}{|c|c|c|c|c|c|c|c|c|}
\hline Aliq. & Pivot & Vendas & Feebate & Gov. & Consum. & Prod. & Amb. & Total \\
\hline 0,5 & 154,9 & $\begin{array}{c}-0,2 \\
(-0,02)\end{array}$ & 3,0 & $\begin{array}{c}-0,00 \\
(-0,00)\end{array}$ & $\begin{array}{c}-2,6 \\
(-0,05)\end{array}$ & $\begin{array}{c}-0,7 \\
(-0,02)\end{array}$ & $\begin{array}{c}2,5 \\
(0,04)\end{array}$ & $\begin{array}{c}-0,8 \\
(-0,00)\end{array}$ \\
\hline 1 & 154,8 & $\begin{array}{c}-0,3 \\
(-0,04)\end{array}$ & 6,1 & $\begin{array}{c}0,00 \\
(0,00)\end{array}$ & $\begin{array}{c}-5,2 \\
(-0,1)\end{array}$ & $\begin{array}{c}-1,5 \\
(-0,03)\end{array}$ & $\begin{array}{c}5,1 \\
(0,1)\end{array}$ & $\begin{array}{c}-1,6 \\
(-0,01)\end{array}$ \\
\hline 5 & 154,4 & $\begin{array}{l}-1,7 \\
(-0,2)\end{array}$ & 30,9 & $\begin{array}{c}0,00 \\
(0,00)\end{array}$ & $\begin{array}{l}-27,0 \\
(-0,5)\end{array}$ & $\begin{array}{l}-7,6 \\
(-0,2)\end{array}$ & $\begin{array}{l}25,9 \\
(0,4)\end{array}$ & $\begin{array}{c}-8,7 \\
(-0,05)\end{array}$ \\
\hline 10 & 153,9 & $\begin{array}{c}-3,5 \\
(-0,4)\end{array}$ & 62,9 & 0,00 & $\begin{array}{l}-56,3 \\
(-1,0)\end{array}$ & $\begin{array}{l}-16,0 \\
(-0,4)\end{array}$ & $\begin{array}{l}53,0 \\
(0,9)\end{array}$ & $\begin{array}{l}-19,3 \\
(-0,1)\end{array}$ \\
\hline 20 & 152,8 & $\begin{array}{c}-7,7 \\
(-0,9)\end{array}$ & 130,4 & $\begin{array}{c}0,00 \\
(0,00)\end{array}$ & $\begin{array}{l}-122,0 \\
(-2,2)\end{array}$ & $\begin{array}{l}-35,1 \\
(-0,8)\end{array}$ & $\begin{array}{l}111,1 \\
(1,9)\end{array}$ & $\begin{array}{l}-46,0 \\
(-0,2)\end{array}$ \\
\hline 40 & 150,4 & $\begin{array}{l}-18,4 \\
(-2,2)\end{array}$ & 280,6 & $\begin{array}{c}0,00 \\
(0,00)\end{array}$ & $\begin{array}{c}-283,4 \\
(-5,2)\end{array}$ & $\begin{array}{l}-83,7 \\
(-1,8)\end{array}$ & $\begin{array}{c}243,5 \\
(4,1)\end{array}$ & $\begin{array}{c}-123,5 \\
(-0,7)\end{array}$ \\
\hline 60 & 147,8 & $\begin{array}{l}-32,4 \\
(-3,8)\end{array}$ & 453,7 & $\begin{array}{c}0,00 \\
(0,00)\end{array}$ & $\begin{array}{c}-488,1 \\
(-8,9)\end{array}$ & $\begin{array}{c}-147,9 \\
(-3,3)\end{array}$ & $\begin{array}{l}399,7 \\
(6,5)\end{array}$ & $\begin{array}{l}-236,3 \\
(-1,2)\end{array}$ \\
\hline 80 & 145,0 & $\begin{array}{l}-50,3 \\
(-6,0)\end{array}$ & 653,8 & $\begin{array}{c}-0,00 \\
(-0)\end{array}$ & $\begin{array}{l}-740,2 \\
(-13,5)\end{array}$ & $\begin{array}{c}-230,6 \\
(-5,1)\end{array}$ & $\begin{array}{l}582,5 \\
(9,3)\end{array}$ & $\begin{array}{c}-388,3 \\
(-2,0)\end{array}$ \\
\hline 100 & 142,0 & $\begin{array}{l}-73,0 \\
(-8,7)\end{array}$ & 886,4 & $\begin{array}{c}0,00 \\
(0,00)\end{array}$ & $\begin{array}{c}-1.043,8 \\
(-19,1)\end{array}$ & $\begin{array}{c}-335,9 \\
(-7,4)\end{array}$ & $\begin{array}{l}795,6 \\
(12,4)\end{array}$ & $\begin{array}{c}-584,1 \\
(-3,1)\end{array}$ \\
\hline 120 & 138,5 & $\begin{array}{l}-101,3 \\
(-12,0)\end{array}$ & $1.159,1$ & $\begin{array}{c}-0,00 \\
(-0,00)\end{array}$ & $\begin{array}{c}-1.404,2 \\
(-25,7)\end{array}$ & $\begin{array}{l}-469,9 \\
(-10,4)\end{array}$ & $\begin{array}{c}1.044,2 \\
(15,6)\end{array}$ & $\begin{array}{l}-829,9 \\
(-4,4)\end{array}$ \\
\hline 140 & 134,5 & $\begin{array}{l}-137,1 \\
(-16,3)\end{array}$ & $1.485,0$ & $\begin{array}{c}-0,00 \\
(-0,00)\end{array}$ & $\begin{array}{c}-1.830,4 \\
(-33,4)\end{array}$ & $\begin{array}{l}-643,2 \\
(-14,2)\end{array}$ & $\begin{array}{c}1.337,7 \\
(19,1)\end{array}$ & $\begin{array}{c}-1.135,9 \\
(-6,0)\end{array}$ \\
\hline 160 & 129,6 & $\begin{array}{l}-183,9 \\
(-21,8)\end{array}$ & $1.892,1$ & $\begin{array}{c}-0,00 \\
(-0,00)\end{array}$ & $\begin{array}{c}-2.343,7 \\
(-42,8)\end{array}$ & $\begin{array}{l}-877,9 \\
(-19,3)\end{array}$ & $\begin{array}{c}1.697,0 \\
(22,6)\end{array}$ & $\begin{array}{c}-1.524,5 \\
(-8,0)\end{array}$ \\
\hline
\end{tabular}

Nota 1: Vendas em milhares de unidades, outras variações em milhões de reais

Nota 2: Percentuais em parêntese

Fonte: Elaboração própria 


\section{Bem Estar Social Neutro}

Tabela 31 - Alterações pela implementação do feebate - Bem estar social neutro - Preço linear

\begin{tabular}{|c|c|c|c|c|c|c|c|c|}
\hline Aliq. & Pivot & Vendas & Feebate & Gov. & Consum. & Prod. & Amb. & Total \\
\hline 0,5 & 176,8 & $\begin{array}{c}0,3 \\
(0,04)\end{array}$ & $\begin{array}{l}-6,2 \\
(-0,1)\end{array}$ & $\begin{array}{l}-6,4 \\
(0,1)\end{array}$ & $\begin{array}{c}4,7 \\
(0,05)\end{array}$ & $\begin{array}{c}2,0 \\
(-0,02)\end{array}$ & $\begin{array}{l}-0,3 \\
(-0)\end{array}$ & $-0,00$ \\
\hline 1 & 176,9 & $\begin{array}{c}0,7 \\
(0,1)\end{array}$ & $-12,5$ & $\begin{array}{l}-13,0 \\
(-0,1)\end{array}$ & $\begin{array}{c}9,5 \\
(0,2)\end{array}$ & $\begin{array}{c}4,1 \\
(0,1)\end{array}$ & $\begin{array}{c}-0,7 \\
(-0,03)\end{array}$ & $\begin{array}{c}0,00 \\
(0)\end{array}$ \\
\hline 5 & 177,6 & $\begin{array}{c}3,6 \\
(0,4)\end{array}$ & $-66,7$ & $\begin{array}{l}-68,2 \\
(-0,8)\end{array}$ & $\begin{array}{l}50,3 \\
(0,9)\end{array}$ & $\begin{array}{l}21,7 \\
(0,5)\end{array}$ & $\begin{array}{c}-3,8 \\
(-0,2)\end{array}$ & $\begin{array}{c}0,00 \\
(0,00)\end{array}$ \\
\hline 10 & 178,4 & $\begin{array}{c}7,6 \\
(0,9)\end{array}$ & $-144,8$ & $\begin{array}{c}-145,8 \\
(-1,6)\end{array}$ & $\begin{array}{l}108,2 \\
(2,0)\end{array}$ & $\begin{array}{l}46,3 \\
(1,0)\end{array}$ & $\begin{array}{c}-8,7 \\
(-0,4)\end{array}$ & $\begin{array}{c}0,00 \\
(0)\end{array}$ \\
\hline 20 & 180,4 & $\begin{array}{l}17,4 \\
(2,1)\end{array}$ & $-341,1$ & $\begin{array}{r}-333,7 \\
(-3,7)\end{array}$ & $\begin{array}{l}250,5 \\
(4,6)\end{array}$ & $\begin{array}{c}105,5 \\
(2,3)\end{array}$ & $\begin{array}{l}-22,3 \\
(-1,1)\end{array}$ & $\begin{array}{c}0,00 \\
(0)\end{array}$ \\
\hline 40 & 185,9 & $\begin{array}{l}46,3 \\
(5,5)\end{array}$ & $-959,7$ & $\begin{array}{l}-898,1 \\
(-10,1)\end{array}$ & $\begin{array}{l}689,5 \\
(12,6)\end{array}$ & $\begin{array}{c}279,7 \\
(6,2)\end{array}$ & $\begin{array}{l}-71,1 \\
(-3,5)\end{array}$ & $\begin{array}{c}0,00 \\
(0,00)\end{array}$ \\
\hline 60 & 196,9 & $\begin{array}{l}101,9 \\
(12,1)\end{array}$ & $-2.249,8$ & $\begin{array}{c}-2.036,7 \\
(-22,8)\end{array}$ & $\begin{array}{c}1.607,6 \\
(29,4)\end{array}$ & $\begin{array}{c}611,6 \\
(13,5)\end{array}$ & $\begin{array}{c}-182,6 \\
(-9,7)\end{array}$ & $\begin{array}{c}-0,00 \\
(-0,00)\end{array}$ \\
\hline
\end{tabular}

Nota 1: Vendas em milhares de unidades, outras variações em milhões de reais

Nota 2: Percentuais em parêntese

Fonte: Elaboração própria

Tabela 32 - Alterações pela implementação do feebate - Bem estar social neutro - Preço linear - Alto Impacto Ambiental

\begin{tabular}{ccccccccc}
\hline Aliq. & Pivot & Vendas & Feebate & Gov. & Consum. & Prod. & Amb. & Total \\
\hline \hline 0,5 & 244,6 & 1,9 & $-34,8$ & $-26,4$ & 27,4 & 10,6 & $-11,6$ & 0,00 \\
& & $(0,2)$ & & $(-0,3)$ & $(0,5)$ & $(0,2)$ & $(-0,2)$ & $(0)$ \\
\hline
\end{tabular}

Nota 1: Vendas em milhares de unidades, outras variações em milhões de reais

Nota 2: Percentuais em parêntese

Fonte: Elaboração própria 


\section{Variação das vendas por segmento}

Tabela 33 - Variação percentual nas vendas por segmento - Preço linear

\begin{tabular}{|c|c|c|c|c|c|c|c|}
\hline \multirow[b]{2}{*}{ Aliq. } & \multirow[b]{2}{*}{ Pivot } & \multicolumn{6}{|c|}{ Segmento } \\
\hline & & Médio - & Médio + & MPV & Pequeno & Popular & SUV \\
\hline \multicolumn{8}{|c|}{ Feebate Neutro } \\
\hline 0,5 & 162,1 & $-0,1$ & $-0,1$ & $-0,1$ & $-0,01$ & 0,2 & $-0,1$ \\
\hline 1 & 162,1 & $-0,1$ & $-0,1$ & $-0,3$ & $-0,02$ & 0,4 & $-0,2$ \\
\hline 5 & 161,8 & $-0,6$ & $-0,6$ & $-1,4$ & $-0,1$ & 1,8 & $-1,2$ \\
\hline 10 & 161,4 & $-1,2$ & $-1,3$ & $-2,8$ & $-0,2$ & 3,6 & $-2,4$ \\
\hline 20 & 160,6 & $-2,4$ & $-2,7$ & $-5,5$ & $-0,5$ & 7,4 & $-4,8$ \\
\hline 40 & 158,9 & $-4,9$ & $-5,7$ & $-11,0$ & $-1,3$ & 15,0 & $-9,6$ \\
\hline 60 & 157,2 & $-7,5$ & $-9,1$ & $-16,4$ & $-2,5$ & 22,7 & $-14,3$ \\
\hline 80 & 155,4 & $-10,0$ & $-12,8$ & $-21,7$ & $-4,1$ & 30,6 & $-19,1$ \\
\hline 100 & 153,5 & $-12,7$ & $-16,8$ & $-26,9$ & $-6,1$ & 38,4 & $-23,8$ \\
\hline 120 & 151,6 & $-15,3$ & $-21,0$ & $-32,0$ & $-8,5$ & 46,1 & $-28,6$ \\
\hline 140 & 149,6 & $-18,0$ & $-25,5$ & $-37,1$ & $-11,2$ & 53,6 & $-33,4$ \\
\hline 160 & 147,6 & $-20,6$ & $-30,1$ & $-41,9$ & $-14,4$ & 60,8 & $-38,1$ \\
\hline \multicolumn{8}{|c|}{ Receita do Governo Neutra } \\
\hline 0,5 & 154,9 & $-0,1$ & $-0,1$ & $-0,2$ & $-0,03$ & 0,2 & $-0,1$ \\
\hline 1 & 154,8 & $-0,2$ & $-0,2$ & $-0,3$ & $-0,1$ & 0,3 & $-0,3$ \\
\hline 5 & 154,4 & $-0,8$ & $-0,8$ & $-1,6$ & $-0,3$ & 1,6 & $-1,4$ \\
\hline 10 & 153,9 & $-1,6$ & $-1,7$ & $-3,2$ & $-0,6$ & 3,2 & $-2,8$ \\
\hline 20 & 152,8 & $-3,3$ & $-3,5$ & $-6,3$ & $-1,3$ & 6,4 & $-5,6$ \\
\hline 40 & 150,4 & $-6,7$ & $-7,4$ & $-12,6$ & $-3,1$ & 12,8 & $-11,2$ \\
\hline 60 & 147,8 & $-10,3$ & $-11,8$ & $-18,9$ & $-5,5$ & 18,9 & $-16,9$ \\
\hline 80 & 145,0 & $-14,2$ & $-16,6$ & $-25,1$ & $-8,4$ & 24,6 & $-22,7$ \\
\hline 100 & 142,0 & $-18,3$ & $-21,8$ & $-31,5$ & $-12,0$ & 29,6 & $-28,6$ \\
\hline 120 & 138,5 & $-22,7$ & $-27,6$ & $-37,8$ & $-16,3$ & 33,5 & $-34,8$ \\
\hline 140 & 134,5 & $-27,7$ & $-33,9$ & $-44,3$ & $-21,5$ & 35,7 & $-41,2$ \\
\hline 160 & 129,6 & $-33,6$ & $-41,0$ & $-51,2$ & $-28,0$ & 35,2 & $-48,1$ \\
\hline \multicolumn{8}{|c|}{ Bem estar Social Neutro - Médio Impacto } \\
\hline 0,5 & 176,8 & $-0,02$ & $-0,02$ & $-0,1$ & 0,03 & 0,2 & $-0,1$ \\
\hline 1 & 176,9 & $-0,04$ & $-0,05$ & $-0,2$ & 0,1 & 0,4 & $-0,2$ \\
\hline 5 & 177,6 & $-0,2$ & $-0,2$ & $-1,0$ & 0,3 & 2,3 & $-0,8$ \\
\hline 10 & 178,4 & $-0,3$ & $-0,4$ & $-1,9$ & 0,7 & 4,6 & $-1,5$ \\
\hline 20 & 180,4 & $-0,3$ & $-0,7$ & $-3,5$ & 1,6 & 9,7 & $-2,8$ \\
\hline 40 & 185,9 & 0,8 & $-0,4$ & $-5,8$ & 4,4 & 21,9 & $-4,3$ \\
\hline 60 & 196,9 & 4,9 & 2,3 & $-5,6$ & 10,1 & 39,1 & $-3,1$ \\
\hline \multicolumn{8}{|c|}{ Bem estar Social Neutro - Alto Impacto } \\
\hline 0,5 & 244,6 & 0,2 & 0,2 & 0,1 & 0,2 & 0,4 & 0,1 \\
\hline
\end{tabular}

Nota: Variação em porcentagem

Fonte: Elaboração própria 


\section{Preços Logarítmicos}

\section{Feebate Neutro}

Tabela 34 - Alterações pela implementação do feebate - Feebate neutro - Preço logarítmico

\begin{tabular}{|c|c|c|c|c|c|c|c|c|}
\hline Aliq. & Pivot & Vendas & Feebate & Gov. & Consum. & Prod. & Amb. & Total \\
\hline 0,5 & 162,1 & $\begin{array}{c}0,1 \\
(0,01)\end{array}$ & $-0,00$ & $\begin{array}{c}-1,3 \\
(-0,01)\end{array}$ & $\begin{array}{c}0,04 \\
(0,00)\end{array}$ & $\begin{array}{c}-0,4 \\
(-0,01)\end{array}$ & $\begin{array}{c}0,4 \\
(0,02)\end{array}$ & $\begin{array}{c}-1,3 \\
(-0,01)\end{array}$ \\
\hline 1 & 162,1 & $\begin{array}{c}0,2 \\
(0,03)\end{array}$ & $-0,00$ & $\begin{array}{c}-2,6 \\
(-0,03)\end{array}$ & $\begin{array}{c}0,1 \\
(0,00)\end{array}$ & $\begin{array}{c}-0,8 \\
(-0,02)\end{array}$ & $\begin{array}{c}0,7 \\
(0,04)\end{array}$ & $\begin{array}{c}-2,6 \\
(-0,01)\end{array}$ \\
\hline 5 & 161,6 & $\begin{array}{c}1,2 \\
(0,1)\end{array}$ & 0,00 & $\begin{array}{l}-13,4 \\
(-0,2)\end{array}$ & $\begin{array}{c}-0,4 \\
(-0,01)\end{array}$ & $\begin{array}{l}-4,5 \\
(-0,1)\end{array}$ & $\begin{array}{c}3,9 \\
(0,2)\end{array}$ & $\begin{array}{l}-14,3 \\
(-0,1)\end{array}$ \\
\hline 10 & 161,1 & $\begin{array}{c}2,2 \\
(0,3)\end{array}$ & 0,00 & $\begin{array}{l}-28,2 \\
(-0,3)\end{array}$ & $\begin{array}{c}-2,6 \\
(-0,05)\end{array}$ & $\begin{array}{l}-9,5 \\
(-0,2)\end{array}$ & $\begin{array}{c}8,4 \\
(0,4)\end{array}$ & $\begin{array}{l}-31,9 \\
(-0,2)\end{array}$ \\
\hline 20 & 160,0 & $\begin{array}{c}3,9 \\
(0,5)\end{array}$ & 0,00 & $\begin{array}{l}-61,8 \\
(-0,7)\end{array}$ & $\begin{array}{l}-13,1 \\
(-0,2)\end{array}$ & $\begin{array}{l}-21,2 \\
(-0,4)\end{array}$ & $\begin{array}{l}19,1 \\
(0,9)\end{array}$ & $\begin{array}{l}-77,1 \\
(-0,4)\end{array}$ \\
\hline 40 & 157,5 & $\begin{array}{c}5,4 \\
(0,6)\end{array}$ & 0,00 & $\begin{array}{r}-147,7 \\
(-1,7)\end{array}$ & $\begin{array}{l}-61,4 \\
(-1,2)\end{array}$ & $\begin{array}{l}-51,7 \\
(-1,1)\end{array}$ & $\begin{array}{l}47,9 \\
(2,3)\end{array}$ & $\begin{array}{c}-212,9 \\
(-1,1)\end{array}$ \\
\hline 60 & 154,8 & $\begin{array}{c}3,7 \\
(0,4)\end{array}$ & 0,00 & $\begin{array}{c}-261,1 \\
(-2,9)\end{array}$ & $\begin{array}{l}-151,4 \\
(-2,8)\end{array}$ & $\begin{array}{l}-91,7 \\
(-1,9)\end{array}$ & $\begin{array}{l}87,4 \\
(4,2)\end{array}$ & $\begin{array}{l}-416,7 \\
(-2,2)\end{array}$ \\
\hline 80 & 151,9 & $\begin{array}{l}-1,6 \\
(-0,2)\end{array}$ & 0,00 & $\begin{array}{c}-403,6 \\
(-4,5)\end{array}$ & $\begin{array}{c}-286,3 \\
(-5,4)\end{array}$ & $\begin{array}{c}-141,1 \\
(-3,0)\end{array}$ & $\begin{array}{l}137,8 \\
(6,5)\end{array}$ & $\begin{array}{c}-693,2 \\
(-3,6)\end{array}$ \\
\hline 100 & 148,9 & $\begin{array}{l}-10,7 \\
(-1,3)\end{array}$ & 0,00 & $\begin{array}{c}-574,6 \\
(-6,4)\end{array}$ & $\begin{array}{c}-465,1 \\
(-8,7)\end{array}$ & $\begin{array}{c}-199,4 \\
(-4,2)\end{array}$ & $\begin{array}{l}198,1 \\
(9,2)\end{array}$ & $\begin{array}{c}-1.041,0 \\
(-5,5)\end{array}$ \\
\hline 120 & 145,8 & $\begin{array}{l}-23,5 \\
(-2,8)\end{array}$ & 0,00 & $\begin{array}{c}-771,2 \\
(-8,6)\end{array}$ & $\begin{array}{l}-681,7 \\
(-12,8)\end{array}$ & $\begin{array}{c}-266,0 \\
(-5,6)\end{array}$ & $\begin{array}{l}266,4 \\
(12,2)\end{array}$ & $\begin{array}{c}-1.452,6 \\
(-7,6)\end{array}$ \\
\hline
\end{tabular}

Nota 1: Vendas em milhares de unidades, outras variações em milhões de reais

Nota 2: Percentuais em parêntese

Fonte: Elaboração própria 
Tabela 35 - Alterações pela implementação do feebate - Feebate neutro - Preço logarítmico - Alto Impacto Ambiental

\begin{tabular}{|c|c|c|c|c|c|c|c|c|}
\hline Aliq. & Pivot & Vendas & Feebate & Gov. & Consum. & Prod. & Amb. & Total \\
\hline 0,5 & 162,1 & $\begin{array}{c}0,1 \\
(0,01)\end{array}$ & $-0,00$ & $\begin{array}{c}-1,3 \\
(-0,01)\end{array}$ & $\begin{array}{c}0,04 \\
(0,00)\end{array}$ & $\begin{array}{c}-0,4 \\
(-0,01)\end{array}$ & $\begin{array}{c}1,0 \\
(0,02)\end{array}$ & $\begin{array}{c}-0,6 \\
(-0,00)\end{array}$ \\
\hline 1 & 162,1 & $\begin{array}{c}0,2 \\
(0,03)\end{array}$ & $-0,00$ & $\begin{array}{c}-2,6 \\
(-0,03)\end{array}$ & $\begin{array}{c}0,1 \\
(0,00)\end{array}$ & $\begin{array}{c}-0,8 \\
(-0,02)\end{array}$ & $\begin{array}{c}2,1 \\
(0,04)\end{array}$ & $\begin{array}{c}-1,3 \\
(-0,01)\end{array}$ \\
\hline 5 & 161,6 & $\begin{array}{l}1,2 \\
(0,1)\end{array}$ & 0,00 & $\begin{array}{l}-13,4 \\
(-0,2)\end{array}$ & $\begin{array}{c}-0,4 \\
(-0,01)\end{array}$ & $\begin{array}{l}-4,5 \\
(-0,1)\end{array}$ & $\begin{array}{l}10,9 \\
(0,2)\end{array}$ & $\begin{array}{c}-7,4 \\
(-0,04)\end{array}$ \\
\hline 10 & 161,1 & $\begin{array}{c}2,2 \\
(0,3)\end{array}$ & 0,00 & $\begin{array}{l}-28,2 \\
(-0,3)\end{array}$ & $\begin{array}{c}-2,6 \\
(-0,05)\end{array}$ & $\begin{array}{l}-9,5 \\
(-0,2)\end{array}$ & $\begin{array}{l}23,4 \\
(0,4)\end{array}$ & $\begin{array}{l}-16,9 \\
(-0,1)\end{array}$ \\
\hline 20 & 160,0 & $\begin{array}{c}3,9 \\
(0,5)\end{array}$ & 0,00 & $\begin{array}{l}-61,8 \\
(-0,7)\end{array}$ & $\begin{array}{l}-13,1 \\
(-0,2)\end{array}$ & $\begin{array}{l}-21,2 \\
(-0,4)\end{array}$ & $\begin{array}{l}53,0 \\
(0,9)\end{array}$ & $\begin{array}{l}-43,2 \\
(-0,2)\end{array}$ \\
\hline 40 & 157,5 & $\begin{array}{c}5,4 \\
(0,6)\end{array}$ & 0,00 & $\begin{array}{c}-147,7 \\
(-1,7)\end{array}$ & $\begin{array}{l}-61,4 \\
(-1,2)\end{array}$ & $\begin{array}{l}-51,7 \\
(-1,1)\end{array}$ & $\begin{array}{l}132,9 \\
(2,3)\end{array}$ & $\begin{array}{c}-127,9 \\
(-0,7)\end{array}$ \\
\hline 60 & 154,8 & $\begin{array}{c}3,7 \\
(0,4)\end{array}$ & 0,00 & $\begin{array}{c}-261,1 \\
(-2,9)\end{array}$ & $\begin{array}{c}-151,4 \\
(-2,8)\end{array}$ & $\begin{array}{l}-91,7 \\
(-1,9)\end{array}$ & $\begin{array}{c}242,6 \\
(4,2)\end{array}$ & $\begin{array}{c}-261,6 \\
(-1,4)\end{array}$ \\
\hline 80 & 151,9 & $\begin{array}{l}-1,6 \\
(-0,2)\end{array}$ & 0,00 & $\begin{array}{c}-403,6 \\
(-4,5)\end{array}$ & $\begin{array}{c}-286,3 \\
(-5,4)\end{array}$ & $\begin{array}{c}-141,1 \\
(-3,0)\end{array}$ & $\begin{array}{c}382,4 \\
(6,5)\end{array}$ & $\begin{array}{c}-448,6 \\
(-2,4)\end{array}$ \\
\hline 100 & 148,9 & $\begin{array}{l}-10,7 \\
(-1,3)\end{array}$ & 0,00 & $\begin{array}{c}-574,6 \\
(-6,4)\end{array}$ & $\begin{array}{c}-465,1 \\
(-8,7)\end{array}$ & $\begin{array}{c}-199,4 \\
(-4,2)\end{array}$ & $\begin{array}{c}549,6 \\
(9,2)\end{array}$ & $\begin{array}{c}-689,5 \\
(-3,6)\end{array}$ \\
\hline 120 & 145,8 & $\begin{array}{l}-23,5 \\
(-2,8)\end{array}$ & 0,00 & $\begin{array}{c}-771,2 \\
(-8,6)\end{array}$ & $\begin{array}{l}-681,7 \\
(-12,8)\end{array}$ & $\begin{array}{c}-266,0 \\
(-5,6)\end{array}$ & $\begin{array}{c}739,0 \\
(12,2)\end{array}$ & $\begin{array}{c}-980,0 \\
(-5,2)\end{array}$ \\
\hline
\end{tabular}

Nota 1: Vendas em milhares de unidades, outras variações em milhões de reais

Nota 2: Percentuais em parêntese

Fonte: Elaboração própria 


\section{Receita do Governo Neutra}

Tabela 36 - Alterações pela implementação do feebate - Receita do governo neutra - Preço logarítmico

\begin{tabular}{|c|c|c|c|c|c|c|c|c|}
\hline Aliq. & Pivot & Vendas & Feebate & Gov. & Consum. & Prod. & Amb. & Total \\
\hline 0,5 & 157,8 & $\begin{array}{c}-0,01 \\
(-0,00)\end{array}$ & 1,8 & $\begin{array}{c}-0,00 \\
(-0)\end{array}$ & $\begin{array}{c}-1,3 \\
(-0,03)\end{array}$ & $\begin{array}{c}-0,8 \\
(-0,02)\end{array}$ & $\begin{array}{c}0,7 \\
(0,03)\end{array}$ & $\begin{array}{c}-1,4 \\
(-0,01)\end{array}$ \\
\hline 1 & 157,8 & $\begin{array}{c}-0,02 \\
(-0,00)\end{array}$ & 3,6 & $\begin{array}{c}-0,00 \\
(-0,00)\end{array}$ & $\begin{array}{l}-2,7 \\
(-0,1)\end{array}$ & $\begin{array}{c}-1,5 \\
(-0,03)\end{array}$ & $\begin{array}{c}1,4 \\
(0,1)\end{array}$ & $\begin{array}{c}-2,9 \\
(-0,02)\end{array}$ \\
\hline 5 & 157,2 & $\begin{array}{c}-0,2 \\
(-0,03)\end{array}$ & 18,8 & $\begin{array}{c}0,00 \\
(0,00)\end{array}$ & $\begin{array}{l}-14,8 \\
(-0,3)\end{array}$ & $\begin{array}{c}-8,1 \\
(-0,2)\end{array}$ & $\begin{array}{c}7,3 \\
(0,3)\end{array}$ & $\begin{array}{l}-15,6 \\
(-0,1)\end{array}$ \\
\hline 10 & 156,4 & $\begin{array}{c}-0,7 \\
(-0,1)\end{array}$ & 39,4 & 0,00 & $\begin{array}{l}-32,7 \\
(-0,6)\end{array}$ & $\begin{array}{l}-17,0 \\
(-0,4)\end{array}$ & $\begin{array}{l}15,4 \\
(0,7)\end{array}$ & $\begin{array}{l}-34,3 \\
(-0,2)\end{array}$ \\
\hline 20 & 154,9 & $\begin{array}{l}-2,5 \\
(-0,3)\end{array}$ & 86,0 & $\begin{array}{c}0,00 \\
(0,00)\end{array}$ & $\begin{array}{l}-78,4 \\
(-1,5)\end{array}$ & $\begin{array}{l}-37,5 \\
(-0,8)\end{array}$ & $\begin{array}{l}34,1 \\
(1,6)\end{array}$ & $\begin{array}{l}-81,8 \\
(-0,4)\end{array}$ \\
\hline 40 & 151,6 & $\begin{array}{c}-9,9 \\
(-1,2)\end{array}$ & 203,5 & 0,00 & $\begin{array}{c}-213,5 \\
(-4,0)\end{array}$ & $\begin{array}{l}-89,8 \\
(-1,9)\end{array}$ & $\begin{array}{l}82,6 \\
(3,9)\end{array}$ & $\begin{array}{c}-220,8 \\
(-1,2)\end{array}$ \\
\hline 60 & 147,9 & $\begin{array}{l}-23,1 \\
(-2,7)\end{array}$ & 356,7 & $\begin{array}{c}0,00 \\
(0,00)\end{array}$ & $\begin{array}{c}-412,0 \\
(-7,7)\end{array}$ & $\begin{array}{c}-158,6 \\
(-3,3)\end{array}$ & $\begin{array}{l}146,5 \\
(6,7)\end{array}$ & $\begin{array}{l}-424,1 \\
(-2,2)\end{array}$ \\
\hline 80 & 144,1 & $\begin{array}{l}-42,9 \\
(-5,1)\end{array}$ & 548,1 & 0,00 & $\begin{array}{l}-675,2 \\
(-12,7)\end{array}$ & $\begin{array}{c}-245,3 \\
(-5,2)\end{array}$ & $\begin{array}{l}226,0 \\
(10,1)\end{array}$ & $\begin{array}{c}-694,5 \\
(-3,7)\end{array}$ \\
\hline 100 & 140,0 & $\begin{array}{l}-69,6 \\
(-8,3)\end{array}$ & 778,4 & $\begin{array}{c}0,00 \\
(0,00)\end{array}$ & $\begin{array}{l}-998,1 \\
(-18,7)\end{array}$ & $\begin{array}{c}-351,4 \\
(-7,4)\end{array}$ & $\begin{array}{l}319,8 \\
(13,9)\end{array}$ & $\begin{array}{c}-1.029,7 \\
(-5,4)\end{array}$ \\
\hline 120 & 135,8 & $\begin{array}{l}-103,3 \\
(-12,3)\end{array}$ & $1.047,4$ & $\begin{array}{c}0,00 \\
(0,00)\end{array}$ & $\begin{array}{c}-1.371,0 \\
(-25,7)\end{array}$ & $\begin{array}{l}-478,8 \\
(-10,1)\end{array}$ & $\begin{array}{l}426,0 \\
(17,7)\end{array}$ & $\begin{array}{c}-1.423,9 \\
(-7,5)\end{array}$ \\
\hline
\end{tabular}

Nota 1: Vendas em milhares de unidades, outras variações em milhões de reais

Nota 2: Percentuais em parêntese

Fonte: Elaboração própria 
Tabela 37 - Alterações pela implementação do feebate - Receita do governo neutra - Preço Logarítmico - Alto Impacto Ambiental

\begin{tabular}{|c|c|c|c|c|c|c|c|c|}
\hline Aliq. & Pivot & Vendas & Feebate & Gov. & Consum. & Prod. & Amb. & Total \\
\hline 0,5 & 157,8 & $\begin{array}{c}-0,01 \\
(-0,00)\end{array}$ & 1,8 & $\begin{array}{c}-0,00 \\
(-0)\end{array}$ & $\begin{array}{c}-1,3 \\
(-0,03)\end{array}$ & $\begin{array}{c}-0,8 \\
(-0,02)\end{array}$ & $\begin{array}{c}1,9 \\
(0,03)\end{array}$ & $\begin{array}{c}-0,2 \\
(-0,00)\end{array}$ \\
\hline 1 & 157,8 & $\begin{array}{c}-0,02 \\
(-0,00)\end{array}$ & 3,6 & $\begin{array}{c}-0,00 \\
(-0,00)\end{array}$ & $\begin{array}{l}-2,7 \\
(-0,1)\end{array}$ & $\begin{array}{c}-1,5 \\
(-0,03)\end{array}$ & $\begin{array}{c}3,9 \\
(0,1)\end{array}$ & $\begin{array}{c}-0,4 \\
(-0,00)\end{array}$ \\
\hline 5 & 157,2 & $\begin{array}{c}-0,2 \\
(-0,03)\end{array}$ & 18,8 & $\begin{array}{c}0,00 \\
(0,00)\end{array}$ & $\begin{array}{l}-14,8 \\
(-0,3)\end{array}$ & $\begin{array}{l}-8,1 \\
(-0,2)\end{array}$ & $\begin{array}{l}20,2 \\
(0,3)\end{array}$ & $\begin{array}{c}-2,7 \\
(-0,01)\end{array}$ \\
\hline 10 & 156,4 & $\begin{array}{c}-0,7 \\
(-0,1)\end{array}$ & 39,4 & 0,00 & $\begin{array}{l}-32,7 \\
(-0,6)\end{array}$ & $\begin{array}{l}-17,0 \\
(-0,4)\end{array}$ & $\begin{array}{l}42,6 \\
(0,7)\end{array}$ & $\begin{array}{c}-7,0 \\
(-0,04)\end{array}$ \\
\hline 20 & 154,9 & $\begin{array}{l}-2,5 \\
(-0,3)\end{array}$ & 86,0 & $\begin{array}{c}0,00 \\
(0,00)\end{array}$ & $\begin{array}{l}-78,4 \\
(-1,5)\end{array}$ & $\begin{array}{l}-37,5 \\
(-0,8)\end{array}$ & $\begin{array}{l}94,6 \\
(1,6)\end{array}$ & $\begin{array}{l}-21,3 \\
(-0,1)\end{array}$ \\
\hline 40 & 151,6 & $\begin{array}{c}-9,9 \\
(-1,2)\end{array}$ & 203,5 & 0,00 & $\begin{array}{c}-213,5 \\
(-4,0)\end{array}$ & $\begin{array}{l}-89,8 \\
(-1,9)\end{array}$ & $\begin{array}{c}229,0 \\
(3,9)\end{array}$ & $\begin{array}{l}-74,3 \\
(-0,4)\end{array}$ \\
\hline 60 & 147,9 & $\begin{array}{l}-23,1 \\
(-2,7)\end{array}$ & 356,7 & $\begin{array}{c}0,00 \\
(0,00)\end{array}$ & $\begin{array}{c}-412,0 \\
(-7,7)\end{array}$ & $\begin{array}{c}-158,6 \\
(-3,3)\end{array}$ & $\begin{array}{l}406,5 \\
(6,7)\end{array}$ & $\begin{array}{c}-164,1 \\
(-0,9)\end{array}$ \\
\hline 80 & 144,1 & $\begin{array}{l}-42,9 \\
(-5,1)\end{array}$ & 548,1 & 0,00 & $\begin{array}{l}-675,2 \\
(-12,7)\end{array}$ & $\begin{array}{c}-245,3 \\
(-5,2)\end{array}$ & $\begin{array}{l}627,0 \\
(10,1)\end{array}$ & $\begin{array}{c}-293,5 \\
(-1,5)\end{array}$ \\
\hline 100 & 140,0 & $\begin{array}{l}-69,6 \\
(-8,3)\end{array}$ & 778,4 & $\begin{array}{c}0,00 \\
(0,00)\end{array}$ & $\begin{array}{l}-998,1 \\
(-18,7)\end{array}$ & $\begin{array}{c}-351,4 \\
(-7,4)\end{array}$ & $\begin{array}{l}887,1 \\
(13,9)\end{array}$ & $\begin{array}{c}-462,4 \\
(-2,4)\end{array}$ \\
\hline 120 & 135,8 & $\begin{array}{l}-103,3 \\
(-12,3)\end{array}$ & $1.047,4$ & $\begin{array}{c}0,00 \\
(0,00)\end{array}$ & $\begin{array}{c}-1.371,0 \\
(-25,7)\end{array}$ & $\begin{array}{l}-478,8 \\
(-10,1)\end{array}$ & $\begin{array}{c}1.181,7 \\
(17,7)\end{array}$ & $\begin{array}{c}-668,1 \\
(-3,5)\end{array}$ \\
\hline
\end{tabular}

Nota 1: Vendas em milhares de unidades, outras variações em milhões de reais

Nota 2: Percentuais em parêntese

Fonte: Elaboração própria 


\section{Bem Estar Social Neutro}

Tabela 38 - Alterações pela implementação do feebate - Bem estar social neutro - Preço logarítmico

\begin{tabular}{ccccccccc}
\hline Aliq. & Pivot & Vendas & Feebate & Gov. & Consum. & Prod. & Amb. & Total \\
\hline \hline 0,5 & 208,4 & 1,6 & $-19,5$ & $-15,2$ & 15,0 & 3,3 & $-3,1$ & 0,00 \\
& & $(0,2)$ & & $(-0,2)$ & $(0,3)$ & $(0,1)$ & $(-0,1)$ & $(0)$ \\
& & & & & & & & \\
1 & 210,2 & 3,3 & $-40,7$ & $-31,6$ & 31,2 & 6,9 & $-6,5$ & 0,00 \\
& & $(0,4)$ & & $(-0,4)$ & $(0,6)$ & $(0,1)$ & $(-0,3)$ & $(0)$ \\
\hline
\end{tabular}

Nota 1: Vendas em milhares de reais, outras variações em milhões de reais

Nota 2: Percentuais em parêntese

Fonte: Elaboração própria

Tabela 39 - Alterações pela implementação do feebate - Bem estar social neutro - Preço Logarítmico - Alto Impacto Ambiental

\begin{tabular}{|c|c|c|c|c|c|c|c|c|}
\hline Aliq. & Pivot & Vendas & Feebate & Gov. & Consum. & Prod. & Amb. & Total \\
\hline 0,5 & 156,0 & $\begin{array}{c}-0,1 \\
(-0,01)\end{array}$ & 2,6 & $\begin{array}{c}0,6 \\
(0,01)\end{array}$ & $\begin{array}{c}-1,9 \\
(-0,04)\end{array}$ & $\begin{array}{c}-0,9 \\
(-0,02)\end{array}$ & $\begin{array}{c}2,3 \\
(0,04)\end{array}$ & $\begin{array}{c}0,00 \\
(0)\end{array}$ \\
\hline 1 & 155,8 & $\begin{array}{c}-0,1 \\
(-0,02)\end{array}$ & 5,3 & $\begin{array}{c}1,2 \\
(0,01)\end{array}$ & $\begin{array}{l}-4,0 \\
(-0,1)\end{array}$ & $\begin{array}{c}-1,9 \\
(-0,04)\end{array}$ & $\begin{array}{c}4,7 \\
(0,1)\end{array}$ & $\begin{array}{c}0,00 \\
(0)\end{array}$ \\
\hline 5 & 154,6 & $\begin{array}{l}-1,0 \\
(-0,1)\end{array}$ & 29,6 & $\begin{array}{c}7,7 \\
(0,1)\end{array}$ & $\begin{array}{l}-23,0 \\
(-0,4)\end{array}$ & $\begin{array}{l}-10,1 \\
(-0,2)\end{array}$ & $\begin{array}{l}25,5 \\
(0,4)\end{array}$ & $\begin{array}{c}0,00 \\
(0)\end{array}$ \\
\hline 10 & 153,1 & $\begin{array}{l}-2,8 \\
(-0,3)\end{array}$ & 67,9 & $\begin{array}{l}20,3 \\
(0,2)\end{array}$ & $\begin{array}{l}-54,5 \\
(-1,0)\end{array}$ & $\begin{array}{l}-22,4 \\
(-0,5)\end{array}$ & $\begin{array}{l}56,6 \\
(1,0)\end{array}$ & $\begin{array}{c}0,00 \\
(0)\end{array}$ \\
\hline 20 & 149,7 & $\begin{array}{l}-9,0 \\
(-1,1)\end{array}$ & 172,9 & $\begin{array}{l}61,8 \\
(0,7)\end{array}$ & $\begin{array}{c}-144,6 \\
(-2,7)\end{array}$ & $\begin{array}{l}-54,2 \\
(-1,1)\end{array}$ & $\begin{array}{l}137,0 \\
(2,3)\end{array}$ & $\begin{array}{c}0,00 \\
(0)\end{array}$ \\
\hline 40 & 141,8 & $\begin{array}{l}-34,5 \\
(-4,1)\end{array}$ & 523,3 & $\begin{array}{l}224,7 \\
(2,5)\end{array}$ & $\begin{array}{c}-456,0 \\
(-8,5)\end{array}$ & $\begin{array}{c}-153,7 \\
(-3,2)\end{array}$ & $\begin{array}{c}385,0 \\
(6,3)\end{array}$ & $\begin{array}{c}0,00 \\
(0)\end{array}$ \\
\hline 60 & 129,6 & $\begin{array}{c}-90,9 \\
(-10,8)\end{array}$ & $1.198,1$ & $\begin{array}{l}567,1 \\
(6,3)\end{array}$ & $\begin{array}{c}-1.050,6 \\
(-19,7)\end{array}$ & $\begin{array}{c}-342,3 \\
(-7,2)\end{array}$ & $\begin{array}{l}825,8 \\
(12,5)\end{array}$ & $\begin{array}{c}0,00 \\
(0)\end{array}$ \\
\hline
\end{tabular}

Nota 1: Vendas em milhares de unidades, outras variações em milhões de reais

Nota 2: Percentuais em parêntese

Fonte: Elaboração própria 


\section{Variação das vendas por segmento}

Tabela 40 - Variação percentual nas vendas por segmento - Preço logarítmico

\begin{tabular}{|c|c|c|c|c|c|c|c|}
\hline \multirow[b]{2}{*}{ Aliq. } & \multirow[b]{2}{*}{ Pivot } & \multicolumn{6}{|c|}{ Segmento } \\
\hline & & Médio - & Médio + & MPV & Pequeno & Popular & SUV \\
\hline \multicolumn{8}{|c|}{ Feebate Neutro } \\
\hline 0,5 & 162,1 & $-0,1$ & $-0,1$ & $-0,1$ & $-0,02$ & 0,3 & $-0,1$ \\
\hline 1 & 162,1 & $-0,2$ & $-0,1$ & $-0,3$ & $-0,03$ & 0,6 & $-0,2$ \\
\hline 5 & 161,6 & $-0,8$ & $-0,5$ & $-1,3$ & $-0,2$ & 3,2 & $-0,9$ \\
\hline 10 & 161,1 & $-1,6$ & $-1,1$ & $-2,7$ & $-0,4$ & 6,5 & $-1,9$ \\
\hline 20 & 160,0 & $-3,2$ & $-2,3$ & $-5,3$ & $-1,0$ & 13,4 & $-3,8$ \\
\hline 40 & 157,5 & $-6,8$ & $-4,8$ & $-10,8$ & $-2,8$ & 28,4 & $-7,8$ \\
\hline 60 & 154,8 & $-10,6$ & $-7,8$ & $-16,2$ & $-5,4$ & 44,8 & $-12,0$ \\
\hline 80 & 151,9 & $-14,6$ & $-11,0$ & $-21,8$ & $-8,9$ & 62,2 & $-16,4$ \\
\hline 100 & 148,9 & $-18,7$ & $-14,5$ & $-27,2$ & $-13,3$ & 79,9 & $-20,9$ \\
\hline 120 & 145,8 & $-22,9$ & $-18,2$ & $-32,6$ & $-18,2$ & 97,2 & $-25,5$ \\
\hline \multicolumn{8}{|c|}{ Receita do Governo Neutra } \\
\hline 0,5 & 157,8 & $-0,1$ & $-0,1$ & $-0,1$ & $-0,03$ & 0,3 & $-0,1$ \\
\hline 1 & 157,8 & $-0,2$ & $-0,1$ & $-0,3$ & $-0,1$ & 0,6 & $-0,2$ \\
\hline 5 & 157,2 & $-0,9$ & $-0,5$ & $-1,4$ & $-0,4$ & 2,9 & $-1,0$ \\
\hline 10 & 156,4 & $-1,9$ & $-1,1$ & $-2,8$ & $-0,8$ & 5,9 & $-1,9$ \\
\hline 20 & 154,9 & $-3,8$ & $-2,3$ & $-5,6$ & $-1,8$ & 12,0 & $-3,9$ \\
\hline 40 & 151,6 & $-8,0$ & $-4,9$ & $-11,3$ & $-4,5$ & 24,6 & $-8,1$ \\
\hline 60 & 147,9 & $-12,6$ & $-7,9$ & $-17,0$ & $-8,4$ & 37,1 & $-12,4$ \\
\hline 80 & 144,1 & $-17,4$ & $-11,2$ & $-22,8$ & $-13,2$ & 48,8 & $-16,9$ \\
\hline 100 & 140,0 & $-22,4$ & $-14,7$ & $-28,5$ & $-18,8$ & 58,5 & $-21,6$ \\
\hline 120 & 135,8 & $-27,5$ & $-18,5$ & $-34,1$ & $-25,2$ & 65,4 & $-26,4$ \\
\hline \multicolumn{8}{|c|}{ Bem estar Social Neutro - Médio Impacto } \\
\hline 0,5 & 208,4 & 0,1 & $-0,04$ & $-0,1$ & 0,2 & 0,6 & $-0,1$ \\
\hline 1 & 210,2 & 0,1 & $-0,1$ & $-0,1$ & 0,3 & 1,2 & $-0,1$ \\
\hline \multicolumn{8}{|c|}{ Bem estar Social Neutro - Alto Impacto } \\
\hline 0,5 & 156,0 & $-0,1$ & $-0,1$ & $-0,1$ & $-0,04$ & 0,3 & $-0,1$ \\
\hline 1 & 155,8 & $-0,2$ & $-0,1$ & $-0,3$ & $-0,1$ & 0,6 & $-0,2$ \\
\hline 5 & 154,6 & $-1,0$ & $-0,6$ & $-1,4$ & $-0,5$ & 2,8 & $-1,0$ \\
\hline 10 & 153,1 & $-2,1$ & $-1,1$ & $-2,9$ & $-1,0$ & 5,5 & $-2,0$ \\
\hline 20 & 149,7 & $-4,4$ & $-2,4$ & $-5,9$ & $-2,6$ & 10,6 & $-4,1$ \\
\hline 40 & 141,8 & $-10,1$ & $-5,2$ & $-12,2$ & $-7,4$ & 18,5 & $-8,6$ \\
\hline 60 & 129,6 & $-17,9$ & $-8,8$ & $-19,4$ & $-15,9$ & 18,7 & $-13,9$ \\
\hline
\end{tabular}

Nota: Variação em porcentagem

Fonte: Elaboração própria 